This PDF is a selection from an out-of-print volume from the National Bureau of Economic Research

Volume Title: Regional Cycles of Manufacturing Employment in the United States, 1914-1953

Volume Author/Editor: George H. Borts

Volume Publisher: NBER

Volume ISBN: 0-87014-387-5

Volume URL: http://www.nber.org/books/bort60-1

Publication Date: 1960

Chapter Title: Regional Cycles of Manufacturing Employment in the United States, 1914-1953

Chapter Author: George H. Borts

Chapter URL: http://www.nber.org/chapters/c2448

Chapter pages in book: (p. 1 - 61) 


\title{
REGIONAL CYCLES OF MANUFACTURING EMPLOYMENT IN THE UNITED STATES, 1914-1953*
}

\author{
George H. Borts \\ National Bureau of Economic Research and Brown University
}

1. INTRODUCTION

$\mathrm{T}$ IHE study of regional business cycles in the United States has only recently been opened to the attention of economists. ${ }^{1}$ It has waited upon the preparation of data adequate for describing economic fluctuations within geographic sectors of the country. When data for only a few regions were available, investigators were forced to neglect any systematic differences in regional behavior that might exist and to assume that a few observations could be used to describe economic behavior in the United States as a whole. ${ }^{2}$

There is, of course, wide interest in the regional impact of business fluctuations. Both the businessman and the public administrator must be concerned with how economic change affects specific localities. The state employment security division officers who administer unemployment compensation funds are an example. The solvency of these funds depends upon the severity with which business cycle contractions affect the various states. Some of the conditions which determine the severity of regional cycles have been ascertained by this study and may be useful in predicting what might be expected in the various states at times of sharp economic change.

We have also attempted to abstract from the history of regional business cycles some clues as to how prosperity and depression spread from one region to another and some of the reasons why there are marked regional differences in economic behavior. The record that follows will show that some states show a much sharper response to business cycle changes than that experienced by the nation as a whole, while other states are relatively immune. In this respect our data may provide an additional laboratory for the economic statistician seeking new relationships among the many variables that determine economic change. ${ }^{3}$

The results of this study suggest a relation between economic growth and

* This paper has been approved for publication as a report of the National Bureau of Economic Resesrch by the Director of Research and the Bosrd of Directors of the National Buresu, in accordance with the resolution of the board governing National Bureau reports (see the Annual Report of the National Bureau of Economic Research). It is to be reprinted as No. 73 in the National Bureau's series of Occasional Papers.

1 Among recent studies are the following: Frank A. Hanna, "Cyclical and Secular Changes in State Per Capita Incomes, 1929-50," Review of Economics and Statistics, 1954; and "Analysis of Interstate Income Differentisls: Theory and Practice ${ }^{n}$ in Regional Income, Studies in Income and Wealth, 21, Princeton University Press for Nationsl Bureau of Economic Research, 1057. Paul B. Simpson, Regional Aspects of Business Cycles and Special Studies of the Pacific Northwest, University of Oregon, mimeo., 1953. Rutledge Vining, "The Region as an Economic Entity and Certain Variations to be Observed in the Study of Systems of Regions," American Economic Revion, Papers and Proceedings, May 1949; "Location of Industry and Regional Patterns of Business-Cycle Behavior, ${ }^{n}$ Econometrica, Jan. 1946; "The Region as a Concept in Business-Cycle Analysis," Econometrica, July 1946; "Regional Variation in Cyclical Fluctuation Viewed as a Frequency Distribution, "Econometrica, July 1945; and Philip Neff and Annette Weifenbach, Business Cycles in Selected Industrial Areas. University of California Press, 1949.

2 Cf. the following: William A. Berridge, Cycles of Unemployment in the United States, 1908-1928, HoughtonMiflin, 1923, Chaps. II, III, IV; Harry Jerome, Mioration and Business Cycles, National Bureau of Economic Research, 1926, Chap. III.

2 Data on regional income changes are used in this fashion, for example, in the paper by Geoffrey H. Moore, Thomas R. Atkinson and Philip A. Klein, "Changes in the Quality of Consumer Instalment Credit" in Consumer Instalment Credit: Conference on Regulations Part II, Vol. I, Board of Governors of the Federal Reserve System, 1957, pp. 99 ff. 
cyclical stability. This question has fascinated many investigators and is the subject of a large literature in economic theory. To what extent do the conditions that make for growth also imply instability? Under what circumstances may rapid growth and freedom from severe cyclical fluctuations go together? These questions have caught the attention of many economists. Schumpeter, Hicks, Kaldor, and Smithies are a few of those who have attempted to specify the conditions under which there would be an interaction between the business cycle and economic growth. ${ }^{4}$ The regional data examined in this study enable us to make some observations on these important questions, since the several areas experienced different growth rates and different degrees of cyclical rise and decline in employment. Indeed, this study represents one of the few attempts that have been made to test the relations which these authors have suggested.

Summary of Findings. Six principal conclusions are reached in this study:

(1) There are long-lasting differences among states in the severity of the cyclical fluctuations experienced.

(2) These differences are in part the result of differences in the types of manufacturing industry found in each state.

(3) The differences have tended to diminish over the past four decades, partly because of greater industrial diversification within states, and partly because the later cycles have been milder than the earlier.

(4) In cycles with strong contractions there is a well-marked pattern of transmission of cyclical impulses among and within states. States with important industries of high variability also experience more severe cycles in other industries. Thus the differences in severity of state cycles are wider than would be expected on the basis of industrial composition alone. The cycle spreads among the states through the impact of changes in national demand upon each state's industry-mix. The cycle spreads within each state through the impact of the contraction in the state's key industries on the demand for the products of its other industries.

(5) Rapid growth and cyclical instability do not necessarily go together, as many have suggested, since a number of rapidly growing states have experienced relatively mild cyclical fluctuations, and some slowly growing ones have suffered wide fluctuations. However, the combination of (a) high growth rates and wide fluctuations and (b) low growth rates and mild cycles are found more frequently than their opposites.

(6) States that experience retardation in growth, relative to other states, tend to show cyclical swings in manufacturing employment larger than those of the other states. This is true even when allowance is made for the effect of differences in industry-mix on the size of the cyclical swings in different states. It suggests that a change in the trend of growth alters the cyclical behavior of state industries relative to their national counterparts. When the state loses its growth position, its industrial components show stronger cyclical amplitudes. Thus our state data suggest that economic growth may be related to cyclical stability.

- Cf. J. A. Schumpeter, Theory of Economic Development, Harvard University Press, 1934; J. R. Hicks, A Contribution to the Theory of the Trade Cycle, Oxford, Clarendon Press, 1949; N. Kaldor, "The Relation of Economic Growth and Cyclical Fluctuations," Economic Journal, March 1954; A. Smithies, "Economic Fluctuations and Growth," Econometrica, Jan. 1957. 
Plan of the Presentation. The findings underlying these conclusions are presented in the three sections that follow. There is a detailed examination of the trends briefly touched upon above and tests of a number of hypotheses put forward to explain them.

Section 2 deals with the available data on cyclical fluctuations in manufacturing employment and with measures of cyclical severity and long-term growth. These include cyclical amplitudes, cyclical declines and expansions, the influence of industrial composition upon cyclical variability, and others.

These measures are used for examining, in Section 3, the remarkable stability from cycle to cycle in the relative severity of cyclical fluctuations among states. The section begins with a brief summary of the findings on the degree of stability of regional behavior over the entire period 1914 to 1953. In addition, some possible explanations of the phenomena revealed by the analysis are discussed.

Among the possible explanations of regional cyclical patterns, two are dealt with in detail in Section 4: the regional transmission of cyclical impulses; and the relation of the regional cycle to long-term growth patterns. The statistical implications of various hypotheses are discussed, and interpretations of the statistical findings are suggested.

Appendix A deals with the homogeneity of rank correlations, Appendix B contains the basic tables, and Appendix $\mathrm{C}$ contains a discussion of data sources and statistical constructs.

\section{SOURCES OF DATA AND STATISTICAL METHODS}

This investigation of regional cycles is limited to variations in manufacturing employment in thirty-three states..$^{5}$ A substantial amount of hitherto unanalyzed data is available. Authors who have earlier studied regional cycles have used such measures of activity as personal income payments, bank debits and clearings, department store sales, and electric power production. Little attention has been given to regional variations in manufacturing employment.

The sources of data and statistical constructs are discussed in Appendix C. Cycles in manufacturing employment were identified with the following periods of business contraction and expansion: 1919-1921-1923, 1929-1933-1937, 19481949-1953. These dates roughly define peaks and troughs of business activity. The only major cyclical changes in this period not dealt with are the 1937-1938 decline and the expansion generated by the second World War. They are excluded by a lack of data for the year 1938 and for a year at the peak of wartime production.

In addition to three cycles defined above, a fourth was recognized, overlapping with the first, with expansion from 1914 to 1919 and contraction from 1919 to 1921 .

The cycle running peak-to-peak from 1948 to 1953 was also analyzed in greater detail because of the appearance of a peak in some sectors in 1951.

- Fifteen states were excluded from the study because of the difficulty of obtaining detailed information on their industrial composition in the earlier years. The states excluded are: Arkansas, Arizona, New Mexico, Oklahoma, Colorado. Idahr, Kansas, Montana. Nebraska, North Dakota. South Dakota, Utah, Wyoming, Nevada, and Delaware. In 1954 the se states accounted for 8 per cent of national personal income payments and 4 per cent of national manufacturing payrolls. 
These movements were analyzed by computing changes between the 1948 peak, the 1949 trough, and the 1951 peak. The changes are treated as a separate cyclical measure.

Cyclical Severity. Cyclical severity is measured by the average annual amplitude. This is defined as:

$$
1 / 2 \frac{\frac{\text { Peak minus Initial Trough }}{\text { Number of years of rise }}+\frac{\text { Peak minus Terminal Trough }}{\text { Number of years of decline }}}{\text { Cycle Base }}
$$

The amplitude is expressed in cycle base units. The cycle base is an average of all observations over the cycle. An important feature of this measure of severity is that the peak-trough movements are independent of linear trend. As an example, suppose we impose on a trendless cycle a positive linear trend of $K$ units per year. Then the initial rise will be larger by $K$ times the number of years of rise, the decline smaller by $K$ times the number of years of decline. The initial rise per year will be larger by plus $K$, the decline per year smaller by minus $K$. Adding the rise per year to the decline per year will cancel this linear trend. ${ }^{6}$

This measure of amplitude was modified for the 1929-1937 cycle, because the data do not identify the same trough year for each state. Some states reached a low point in 1931, others in 1933 (census data for 1932 are not available). Almost all had far sharper drops from 1929 to 1931 than from 1931 to 1933. Use of 1933 as a trough tends to hide the actual severity of the drop (in terms of a rate of change) and the extended period of the low level. Accordingly, two alternate measures of amplitude were devised for this cycle. The first averages the maximum drop per year and the maximum rise per year in any of the four two-year intervals under observation. The second simply averages the average change per year in all of the four two-year intervals. The first measure should identify those states for which the drop was sharp and severe, or for which the low point was maintained over a long time. The second measure should identify those states for which variation was marked during the whole period under observation. Discussion of the usefulness of these measures will be found in later sections.

The Influence of Industrial Composition on Cyclical Severity. Many of the hypotheses advanced in this study were tested by estimating the influence of industrial composition upon the cyclical variability of a state. The problems of measuring the influence of industry-mix on cyclical variability are presented here; and in the next section the usefulness of such a measure will be discussed in detail.

Correcting for the effects of industrial composition requires a statistical standardization technique - the particular technique chosen to depend upon the problem at hand and the available data. The standardization procedure must provide a test of the following null hypothesis: The cyclical behavior of

- For the average annual amplitude to be independent of the trend:

1. the trend must be linear;

2. the trend must not alter the durations of the expansion phase and the contraction phase. 
each industry group in a particular region is independent of its location. The implication of the hypothesis is that the region and the nation would have the same cyclical behavior if they had the same industrial composition. Of a large number of possible standardization measures, two merit discussion:

(1) The cycle the state would have if each state industry were accorded the importance it has in the national industrial structure. This series would consist of the sum of indexes of employment in each state industry, weighted according to the national importance of each industry.

(2) The cycle the nation would have if each national industry were given the weight it has in a particular state. This series would consist of the sum of indexes of employment in each national industry, weighted according to the industrial structure of a single state and varying from state to state.

While either series might be suitable for our purpose, lack of data on the cyclical behavior of individual state industries prevents the construction of the first measure. ${ }^{7}$ The second measure was computed and used wherever estimating the influence of industry-mix was necessary. Comparison of this hypothetical series with the actual employment index for the United States shows the influence of the state's industrial composition upon its cyclical amplitude; for the two series contain the same national industrial employment indexes, combined with different weights. Comparison of the hypothetical series with the actual index for a given state shows the net effect of differences in behavior between individual state and national industries; for the two series employ the same weights to combine different employment indexes for each industry.

In preparing the standardized employment index, twenty national industries were identified, corresponding roughly to the 2-digit industrial classification used in the Census of Manufactures for 194\%. Data for earlier years were regrouped to conform to this classification scheme according to definitions of each industry in the 1947 Census. These were taken from the Census volumes for those years and from Fabricant's Employment in Manufacturing, 1899-1939. ${ }^{8}$ In many instances, Fabricant's data were used because they contained adjustments which made the census subclassifications more comparable from year to year.

The industries used to prepare the standardized employment indices are ${ }^{9}$ tabulated at the top of the next page.

It will be noticed that, in one case, the industry is composed of two 3-digit members of a larger 2-digit group. Jewelry and silverware (391) and Costume jewelry and notions (396) were separated from miscellaneous Manufactures (39), because these 3-digit groups were important in a number of states. The diversity of elements entering the Miscellaneous (39) category makes it impossible to use this industry group as part of a standardization procedure. Appendix

'This lack of data exists for a number of reasons. No firms in a particular national industry may be located in a state. Where an industry is small in a state (consisting of less than three firms) census disclosure rules will prevent publication of the state employment in that industry. Bureau of Labor Statistics data for 1948-1953 do not show state employment by industry for all states. The reason is that the employment security divisions of some states do not prepare these data for publication. This was learned from correspondence with divisions of those states. 1942 .

8 S. Fabricant, Employment in Manufacturing, 1899-1989, National Bureau of Economic Research, New York,

- The state weights used to prepare standardized employment indices are shown in Appendix Tables 194, 196 , and 198. 


\begin{tabular}{cl|cl}
\hline \hline $\begin{array}{c}\text { Census } \\
\text { Number }\end{array}$ & \multicolumn{1}{c|}{ Durable Goods } & $\begin{array}{c}\text { Census } \\
\text { Number }\end{array}$ & \multicolumn{1}{c}{ Non-Durable Goods } \\
\cline { 3 - 3 } 24 & Lumber products & 20 & Food \& kindred products \\
25 & Furniture \& fixtures & 21 & Tobacco manufactures \\
32 & Stone, clay \& glass products & 22 & Textile mill products \\
33 & Primary metal industries & 23 & Apparel \& related products \\
34 & Fabricated metal products & 26 & Paper \& allied products \\
35 & Machinery (except electrical) & 27 & Printing \& publishing \\
36 & Electrical machinery & 28 & Chemicals \& allied products \\
37 & Transportation equipment & 29 & Petroleum \& coal products \\
38 & Instruments & 30 & Rubber products \\
& & 31 & Leather products \\
& & $(391,396)$ & Jewelry and silverware, and cos- \\
& & \multicolumn{3}{c}{ tume jewelry } \\
\hline
\end{tabular}

Table 196 shows the employment in the twenty major industry groups for the relevant dates.

The Measurement of Long-Term Growth. In testing a number of hypotheses it was necessary to measure the long-term trend factors affecting the manufacturing sector of a state's economy. Although a number of techniques have been developed to extract the trend factor from a time series, many of these methods do not provide sufficient degrees of freedom when applied to the available data. ${ }^{10}$ In addition, some of them may alter the observable cyclical patterns in an undesirable manner. All of this has been discussed elsewhere in the literature and does not require elaboration. We chose a simple measure of trend suggested by our knowledge of economic events. Further, the growth patterns expressed by this trend measure are fairly stable over long periods of time. The trend measure adopted is simply the ratio of employment at one cyclical peak to employment at an earlier peak. By using peaks, we are measuring changes between similar phases of the business cycle, so that cyclical influences are largely eliminated. ${ }^{11}$ The trend measure is independent of cyclical phenomena in the sense that a given value of trend as measured is consistent with any value of cyclical amplitude whatever.

In a single instance, an alternative trend measure was used because of lack of data on cycle peaks before 1909. A trough-to-trough ratio was used to measure state growth trends between 1904 and 1914. This measure should be independent of cyclical change for the same reason that the peak-to-peak measure is independent, although troughs in employment to some extent reflect differences in the severity of cyclical contractions. Applications of this measure are discussed in Section 4 below.

As an alternative to peak-to-peak movements we also calculated the ratio of cycle bases as a measure of trend. This leads to similar results. The ranking of states by ratio cycles bases is practically identical with the ranking by peak-to-

10 I have in mind fitting trend functions by the use of least squares, polynomials or moving totals.

11 It may be true that an expansion fails to exhaust resources left unemployed by the previous contraction. Nevertheless, relative peak-to-peak movements will refect the relative strength of secular forces in different regions. 
peak movements. ${ }^{12}$ In addition, peak-to-peak movements have the advantage of providing trend measures over shorter intervals than are provided by the ratio of cycles bases.

\section{THE STABILITY OF STATE FLUCTUATIONS AND GROWTH TRENDS}

The most variable and least variable states are shown in Table 157. The states are ordered in rank from most variable (1) to least variable (33). Where states are tied in rank, they are assigned the same rank number, equal to the average of the ranks that would have been assigned had the states not been tied. The variability measure is an average of the cyclical decline and the cyclical expansion in manufacturing employment. The statistical measure of variability was defined in Section 2.

There are also striking regularities in the rate of cyclical decline and rate of cyclical expansions of the states. In Table 158a, the states are ordered by the magnitude of rate of cyclical declines, and in Table 158b the states are ordered by the magnitude of rates of cyclical expansions. In Table 158a, the states are ranked from the strongest decline (1) to the weakest decline (33); in Table 158b, they are ranked from the strongest expansion (1) to the weakest expansion (33).

\section{TABLE 157. THIRTY-THREE STATES RANKED BY AVERAGE CYCLICAL VARIABILITY IN MANUFACTURING EMPLOYMENT, FOUR CYCLES, 1914 TO $1953^{\mathrm{s}}$}

\begin{tabular}{|c|c|c|}
\hline Most Variable & Moderately Variable & Least Variable \\
\hline $\begin{aligned} \text { 1. } & \text { Michigan } \\
\text { 2. } & \text { Ohio } \\
\text { 3. } & \text { Mississippi } \\
\text { 4. } & \text { Oregon } \\
\text { 5. } & \text { Indiana } \\
\text { 6. } & \text { Connecticut } \\
\text { 7.5 } & \text { Washington } \\
\text { 7.5 } & \text { Wisconsin } \\
\text { 9. } & \text { California } \\
\text { 10. } & \text { West Virginia } \\
\text { 11. } & \text { Pennsylvania }\end{aligned}$ & $\begin{array}{l}\text { 12. Tennessee } \\
\text { 13. Alabama } \\
\text { 14. New Jersey } \\
\text { 15. Vermont } \\
\text { 16. Florida } \\
\text { 17. Maryland } \\
\text { 18. Illinois } \\
\text { 19. Rhode Island } \\
\text { 20. Minnesota } \\
\text { 21. Kentucky } \\
\text { 22. Georgia }\end{array}$ & $\begin{array}{ll}\text { 23. } & \text { Virginia } \\
\text { 24. } & \text { Louisiana } \\
\text { 25. } & \text { Texas } \\
26.5 & \text { Iowa } \\
26.5 & \text { New Hampshire } \\
\text { 28. } & \text { Missouri } \\
\text { 29. } & \text { Maine } \\
\text { 30. } & \text { North Carolina } \\
\text { 31. } & \text { New York } \\
\text { 32. } & \text { Massachusetts } \\
\text { 33. } & \text { South Carolina }\end{array}$ \\
\hline
\end{tabular}

- The individual cycles and actual cyclical amplitudes are shown in Appendix Table 199, and are discussed later in this section.

Of the eleven most variable states, three are located in the Far West along the Pacific coast, four in the East-North Central section, and one each in New England, Middle Atlantic, South Atlantic, and East-South Central sections. Of the eleven least variable states, three are located in the South Atlantic section, three in New England, two each in the West-North Central and West-South Central sections, and one in the Middle Atlantic section.

. In terms of industrial composition, the most variable states are characterized

12 Let $x_{3}$ be the ratio of cycle bases in the 1914-1921 and 1929-1937 cycles. Let $y$ be the ratio of state employment 1929/1919. The rank correlation between $x_{1}$ and $y_{1}$ is +.93 . Let $x_{2}$ be the ratio of cycle bases in the 19291937 and $1948-1953$ cycles. Let $y_{2}$ be the ratio of state employment $1947 / 1937$. The rank correlation between $x_{2}$ and $y_{2}$ is +.88 . 
TABLE 158a. THIIRTY-THREE STATES RANKED BY AVERAGE RATE OF CYCLICAL DECLINE IN MANUFACTURING EMPLOYMENT, FOUR DECLINE PERIODS, 1914 TO 1953.

\begin{tabular}{|c|c|c|}
\hline Strong Decline & Moderate Decline & Weak Decline \\
\hline $\begin{array}{l}\text { 1. Mississippi } \\
\text { 2. Oregon } \\
\text { 3. Ohio } \\
\text { 4. Michigsn } \\
\text { 5. Vermont } \\
\text { 6. Wisconsin } \\
\text { 7. Connecticut } \\
\text { 8. Washington } \\
\text { 9. Indiana } \\
\text { 10. Alabama } \\
\text { 11. West Virginia }\end{array}$ & $\begin{array}{l}\text { 12. Rhode Island } \\
\text { 13. Tennessee } \\
\text { 14. Pennsylvania } \\
\text { 15. New Jersey } \\
\text { 16. Illinois } \\
\text { 17. Louisiana } \\
\text { 18. Florida } \\
\text { 19. New Hampshire } \\
\text { 20. Virginia } \\
\text { 21.5 Minnesota } \\
\text { 21.5 Iowa }\end{array}$ & $\begin{array}{ll}\text { 23.5 } & \text { Maryland } \\
\text { 23.5 } & \text { Kentucky } \\
\text { 25. } & \text { Texas } \\
\text { 26. } & \text { Georgia } \\
\text { 27. } & \text { New York } \\
\text { 28. } & \text { Massachusetts } \\
\text { 29.5 } & \text { California } \\
\text { 29.5 } & \text { Maine } \\
\text { 31. } & \text { North Carolina } \\
\text { 32. } & \text { Missouri } \\
\text { 33. } & \text { South Carolina }\end{array}$ \\
\hline
\end{tabular}

- Data on the individual periods of cyclical decline are shown in appendix Table 200, and are discussed later in this rection.

by a high proportion of durable-goods manufacture, specifically transportation equipment (e.g., automobiles), primary and fabricated metal products, machinery, and lumber. The least variable states are characterized by nondurable manüfactures: textiles, shoes, apparel, tobacco and food products.

There is a notable degree of similarity between the groups with sharpest rate of decline and sharpest rate of expansion (Tables 158a and 158b). The positive correlation between state expansion rates and state decline rates was observed in all but one of the cycles studied (see below). Despite the striking stability in decline and expansion rates, a number of states appear to change position from one table to the other. Some states that have sharp decline rates have relatively. weaker expansion rates (Vermont, West Virginia, Rhode.Island), and some

TABLE 158b. THIRTY-THREE STATES RANKED BY AVERAGE RATE OF CYCLICAL EXPANSION IN MANUFACTURING EMPLOYMENT, SIX EXPANSION PERIODS, 1914 TO 1953:

\begin{tabular}{|c|c|c|}
\hline Strong Expansion & Moderate Expansion & Weak Expansion \\
\hline $\begin{array}{l}\text { 1. Michigan } \\
\text { 2. Indiana } \\
\text { 3. Oregon } \\
\text { 4. California } \\
\text { 5. Ohio } \\
\text { 6. Mississippi } \\
\text { 7. Washington } \\
\text { 8. Tennessee } \\
\text { 9. Illinois } \\
\text { 10.5 Wisconsin } \\
\text { 10.5 Texas }\end{array}$ & $\begin{array}{l}\text { 12. Connecticut } \\
\text { 13.5 Alabama } \\
\text { 13.5 Maryland } \\
\text { 15. New Jersey } \\
\text { 16. Missouri } \\
\text { 17. Kentucky } \\
\text { 18. Florida } \\
\text { 19. Vermont } \\
\text { 20. Pennsylvania } \\
\text { 21. Minnesota } \\
\text { 22.5 Georgia } \\
\text { 22.5 Iows }\end{array}$ & $\begin{array}{l}\text { 24. Virginia } \\
\text { 25. Louisiana } \\
\text { 26. West Virginia } \\
\text { 27. South Carolina } \\
\text { 28. North Carolina } \\
\text { 29. New York } \\
\text { 30. Rhode Island } \\
\text { 31. Maine } \\
\text { 32. Massachusetts } \\
\text { 33. New Hampshire }\end{array}$ \\
\hline
\end{tabular}

- Dits on individual periods of eyclical expansion are shown in appendix Table 200, and are discussed later in this otioin. 
with weak decline rates have relatively stronger expansion rates (Missouri, California, Texas, Kentucky, Maryland). This movement is not strong enough to offset the observed correlation between expansion and decline rates, but it suggests the need for an examination of the forces making for these changes.

One of the most important influences is the long-run growth trend prevailing in each state. These trends were examined in non-overlapping portions of the 1909 to 1953 period and found to be highly stable (Section 2). Table 159 shows the thirty-three states ranked by average growth trend over this period.

TABLE 159. THIRTY THREE -STATES RANKED BY AVERAGE GROWTH RATE IN MANUFACTURING EMPLOYMENT FROM 1909 TO 1953

\begin{tabular}{l|l|l}
\hline \hline Strong Growth & Mild Growth & Weak Growth or Decline \\
\hline 1. California & 12.5 Ohio & 23.s Misaissippi \\
2. Texas & 12.5 South Carolina & 23.5 Connecticut \\
3. Indiana & 14.5 Missouri & 25. Louisiana \\
4. Tennessee & 14.5 Illinois & 26. Pennsylvania \\
5. Michigan & 16. Virginia & 27. Florida \\
6. North Carolina & 17. Maryland & 28. New York \\
7. Alabama & 18.5 Wisconsin & 29. Maine \\
8. Georgia & 18.5 Minnesota & 30. Rhode Island \\
9. Oregon & 20. West Virginia & 31. Vermont \\
10. Kentucky & 21. New Jersey & 32. Massachusetts \\
11. Iowa & 22. Washington & 33. New Hampshire \\
\hline
\end{tabular}

Of the eleven states with strongest growth, two are on the Pacific coast, two in the East-North Central section, four in the East and West-South Central sections, two in the South Atlantic and one in the West-North Central section. The smallest growth has occurred among six states in New England, two in the Middle Atlantic section, and three states in the Southern group.

Table 160 shows the six states with most growth and the six states with least growth in each of the time intervals. It conveys the stability of growth patterns through the number of occasions a state appears in the same growth group.

It is difficult to characterize either the growing or the declining group by industrial composition, although there is some tendency for the growing group to have industries with high cyclical variability. Industrial composition is a better predictor of cyclical variability than of long-term growth. That is, much of the regional growth has been accompanied by sharp geographic differences in trends within a given industry.

The growth trends appear to be an important influence on the relation between decline rates and expansion rates. It was noted previously that three states (Vermont, West Virginia and Rhode Island) had sharp decline rates relative to expansion rates. It can be seen from Table 159 that these states had either mild or weak growth. Five states (Missouri, California, Texas, Kentucky, Maryland) experienced weak decline rates relative to expansion rates. These are states with either mild or strong growth. That this relation applies generally to all thirty-three states is seen in Table 161, where the rank order of decline rates, expansion rates, and average cyclical variability are shown for the strongly 
TABLE 160. SIX STATES WITH MOST GROWTH, SIX STATES WITH LEAST GROWTH IN MANUFACTURING EMPLOYMENT, SIX TIME INTERVALS; 1909-1953"

\begin{tabular}{|c|c|c|c|c|c|c|c|c|c|c|c|c|}
\hline & \multicolumn{2}{|c|}{1909 to 1919} & \multicolumn{2}{|c|}{1919 to 1923} & \multicolumn{2}{|c|}{1923 to 1929} & \multicolumn{2}{|c|}{1929 to 1937} & \multicolumn{2}{|c|}{1937 to 1947} & \multicolumn{2}{|c|}{1948 to 1953} \\
\hline \multicolumn{13}{|c|}{ Most Growth } \\
\hline $\begin{array}{l}1 \\
2 \\
3 \\
4 \\
5 \\
6\end{array}$ & $\begin{array}{l}\text { Calif. } \\
\text { Ore. } \\
\text { Mich. } \\
\text { Wash. } \\
\text { Ohio } \\
\text { N. J. }\end{array}$ & $\begin{array}{l}212.40 \\
205.49 \\
205.12 \\
194.70 \\
162.21 \\
155.51\end{array}$ & $\begin{array}{l}\text { S. C. } \\
\text { Ge. } \\
\text { Tenn. } \\
\text { N. C. } \\
\text { Ky. } \\
\text { Ore. }\end{array}$ & $\begin{array}{r}122.82 \\
112.31 \\
112.11 \\
110.74 \\
109.81 \\
108.71\end{array}$ & $\begin{array}{l}\text { Texas } \\
\text { Tenn. } \\
\text { N. C. } \\
\text { Calif. } \\
\text { Ga. } \\
\text { S. C. }\end{array}$ & $\begin{array}{l}140.19 \\
126.46 \\
122.02 \\
121.28 \\
118.50 \\
113.32\end{array}$ & $\begin{array}{l}\text { Mich. } \\
\text { N. C. } \\
\text { Va. } \\
\text { S. C. } \\
\text { Md. } \\
\text { Tenn. }\end{array}$ & $\begin{array}{l}127.37 \\
126.08 \\
123.56 \\
121.49 \\
118.61 \\
113.99\end{array}$ & $\begin{array}{l}\text { Texas } \\
\text { Calif. } \\
\text { Iowa } \\
\text { Ky. } \\
\text { Ala. } \\
\text { Minn. }\end{array}$ & $\begin{array}{l}184.89 \\
168.21 \\
160.19 \\
157.97 \\
153.15 \\
152.48\end{array}$ & $\begin{array}{l}\text { Calif. } \\
\text { Texas } \\
\text { Fla. } \\
\text { Ind. } \\
\text { Mo. } \\
\text { Mich. }\end{array}$ & $\begin{array}{l}144.93 \\
128.68 \\
128.35 \\
121.80 \\
117.89 \\
115.73\end{array}$ \\
\hline \multicolumn{13}{|c|}{ Least Growth } \\
\hline $\begin{array}{l}28 \\
29 \\
30 \\
31 \\
32 \\
33\end{array}$ & $\begin{array}{l}\text { Va. } \\
\text { Maine } \\
\text { S. C. } \\
\text { N. H. } \\
\text { Ky. } \\
\text { Vt. }\end{array}$ & $\begin{array}{r}112.60 \\
110.10 \\
107.51 \\
106.17 \\
99.51 \\
97.51\end{array}$ & $\begin{array}{l}\text { N. H. } \\
\text { Minn. } \\
\text { Conn. } \\
\text { N. J. } \\
\text { Fla. } \\
\text { Wash. }\end{array}$ & \begin{tabular}{|l|l|}
90.49 \\
90.03 \\
89.54 \\
87.97 \\
85.73 \\
83.34
\end{tabular} & $\begin{array}{l}\text { Penn. } \\
\text { La. } \\
\text { Vt. } \\
\text { N. H. } \\
\text { Maine } \\
\text { Mass. }\end{array}$ & \begin{tabular}{l|}
93.91 \\
93.03 \\
89.59 \\
88.03 \\
84.90 \\
83.83
\end{tabular} & $\begin{array}{l}\text { Wis. } \\
\text { Mass. } \\
\text { Vt. } \\
\text { N. H. } \\
\text { R. I. } \\
\text { Fla. }\end{array}$ & $\begin{array}{l}92.18 \\
90.49 \\
89.35 \\
86.66 \\
86.22 \\
85.07\end{array}$ & $\begin{array}{l}\text { Conn. } \\
\text { Maine } \\
\text { Vt. } \\
\text { R. I. } \\
\text { Mass. } \\
\text { N. H. }\end{array}$ & $\begin{array}{l}118.66 \\
118.07 \\
117.25 \\
116.05 \\
115.89 \\
114.72\end{array}$ & $\begin{array}{l}\text { Ala. } \\
\text { Maine } \\
\text { Mass. } \\
\text { N. H. } \\
\text { W. Va. } \\
\text { R. I. }\end{array}$ & $\begin{array}{r}102.89 \\
102.18 \\
101.94 \\
99.40 \\
97.29 \\
96.37\end{array}$ \\
\hline
\end{tabular}

a Trend measures are computed by expressing state manufacturing employment at the later date as a percentage of the value at the prior date.

growing and weakly growing groups. It is evident that, on the average, the strongly growing states have weak decline rates relative to expansion rates, while the weakly growing states have strong decline rates relative to expansion rates.

It is also evident that the sharpest difference between strongly and weakly growing states lies in the strength of the expansion rates-the strongly growing states having far stronger expansion rates. The strength of the decline rate does not differ much between the two groups-although on the average, the strongly growing states have weaker decline rates. However, examination of individual cycles in this time period does show up exceptions; as the narrowness of the difference would lead one to expect.

On the average, the strongly growing states also experienced greater cyclical variability. To a large extent this is due to industrial composition, as Section 4 will reveal.

The association between growth and cyclical variability is not close. Table 162 shows that a number of states have experienced rapid growth rates and low cyclical variability (notably North Carolina, Iowa, and Texas) and some states have shown low growth rates with high cyclical variability (Pennsylvania, Mississippi, Connecticut, for example). It appears that the factors that give rise to growth in a region do not manifestly promote instability, or vice versa. This issue will be examined in Section 4, where the influence of industrial composition on cyclical variability will be taken into account.

As indicated in the foregoing summary, the relative severity of cyclical fluctuations and growth trends among states is highly stable from one time period to the next. Below we examine these phenomena and consider some possible explanations.

Growth Trends. The peak-to-peak trend measures indicate marked stability 
TABLE 161. RANK OF CYCLICAL DECLINE RATE, CYCLICAL EX-

PANSION RATE AND AVERAGE CYCLICAL VARIABILITY FOR ELEVEN STRONGLY GROWING AND ELEVEN WEAKLY GROWING STATES 1914-1953

\begin{tabular}{|c|c|c|c|}
\hline \multirow[b]{2}{*}{ Strong Growth } & \multicolumn{3}{|c|}{ Rank Order } \\
\hline & $\begin{array}{l}\text { Decline Rate } \\
\text { (low numbered } \\
\text { rank = strong } \\
\text { decline) }\end{array}$ & $\begin{array}{c}\text { Expansion Rate } \\
\text { (low numbered } \\
\text { rank = strong } \\
\text { expansion) }\end{array}$ & $\begin{array}{l}\text { Average Cyclical } \\
\text { Variability } \\
\text { (low numbered } \\
\text { rank=strong } \\
\text { variability) }\end{array}$ \\
\hline 1. California & 29.5 & 4 & 9 \\
\hline 2. Texas & 25 & 10.5 & 25 \\
\hline 3. Indiana & 9 & 2 & 5 \\
\hline 4. Tennessee & 13 & 8 & 12 \\
\hline 5. Michigan & 4 & 1 & 1 \\
\hline 6. North Carolina & 31 & 28 & 30 \\
\hline 7. Alabama & 10 & 13.5 & 13 \\
\hline 8. Georgia & 26 & 22.5 & 22 \\
\hline 9. Oregon & 2 & 3 & 4 \\
\hline 10. Kentucky & 23.5 & 17 & 21 \\
\hline \multirow{2}{*}{$\begin{array}{l}\text { 11. Iowa } \\
\text { Average Rank }\end{array}$} & 21.5 & 22.5 & 26.5 \\
\hline & 17.7 & 12.0 & 15.3 \\
\hline Weak Growth & \multicolumn{3}{|c|}{ Rank Order } \\
\hline 23.5 Mississippi & 1 & 6 & 3 \\
\hline 23.5 Connecticut & 7 & 12 & 6 \\
\hline 25. Louisiana & 17 & 25 & 24 \\
\hline 26. Pennsylvania & 14 & 20 & 11 \\
\hline 27. Florida & 18 & 18 & 16 \\
\hline 28. New York & 27 & 29 & 31 \\
\hline 29. Maine & 29.5 & 31 & 29 \\
\hline 30. Rhode Island & 12 & 30 & 19 \\
\hline 31. Vermont & 5 & 19 & 15 \\
\hline 32. Massachusetts & 28 & 32 & 32 \\
\hline 33. New Hampshire & 19 & 33 & 26.5 \\
\hline Average Rank & 16.1 & 23.2 & 19.3 \\
\hline
\end{tabular}

of relative regional growth patterns. Those states with relatively high growth rates in one period are likely to have relatively high growth rates in the other periods. We have computed this trend measure for the thirty-three states for each of six non-overlapping time intervals between 1909 and 1953. The state with the highest growth rate in a particular time interval is assigned rank number one; the state with the lowest growth rate in that interval rank number thirty-three. Thus there are six ranks for each state, each rank showing its relative growth position in a particular time interval.

The stability of the entire set of rankings can be tested by using a statistic 
TABLE 162. RATES OF GROWTH AND CYCLICAL VARIABILITY, 1914-1953

\begin{tabular}{|c|c|c|c|}
\hline \multirow{2}{*}{$\begin{array}{c}\text { Growth } \\
\text { Rate }\end{array}$} & \multicolumn{3}{|c|}{ Cyclical Variability } \\
\hline & Low & Medium & High \\
\hline Strong & $\begin{array}{l}\text { North Carolina }(\mathrm{L}, \mathrm{L}) \\
\text { Iowa }(\mathrm{M}, \mathrm{M}) \\
\text { Texas }(\mathrm{L}, \mathrm{H})\end{array}$ & $\begin{array}{l}\text { Kentucky }(\mathrm{L}, \mathrm{M}) \\
\text { Tennessee }(\mathrm{M}, \mathrm{H}) \\
\text { Alabams }(\mathrm{H}, \mathrm{M}) \\
\text { Georgia }(\mathrm{L}, \mathrm{M})\end{array}$ & $\begin{array}{l}\text { Indiana }(H, H) \\
\text { Michigan }(\mathbf{H}, \mathbf{H}) \\
\text { Oregon }(\mathbf{H}, \mathbf{H}) \\
\text { California }(\mathrm{L}, \mathrm{H})\end{array}$ \\
\hline Medium & $\begin{array}{l}\text { Virginia (M, L) } \\
\text { South Carolina (L, L) } \\
\text { Missouri (L, M) } \\
\qquad\end{array}$ & $\begin{array}{l}\text { New Jersey }(\mathrm{M}, \mathrm{M}) \\
\text { Minnesota }(\mathrm{M}, \mathrm{M}) \\
\text { Maryland }(\mathrm{L}, \mathrm{M}) \\
\text { Illinois }(\mathrm{M}, \mathrm{H})\end{array}$ & $\begin{array}{l}\text { Ohio }(\mathrm{H}, \mathrm{H}) \\
\text { Wisconsin }(\mathrm{H}, \mathrm{H}) \\
\text { Washington }(\mathrm{H}, \mathrm{H}) \\
\text { West Virginia (H, L) }\end{array}$ \\
\hline Weak & $\begin{array}{l}\text { Maine (L, L) } \\
\text { New Hampshire (M, L) } \\
\text { Massachusetts (L, L) } \\
\text { New York (L, L) } \\
\text { Louisiana (M, L) }\end{array}$ & $\begin{array}{l}\text { Rhode Island }(M, L) \\
\text { Florida }(M, M) \\
\text { Vermont }(H, M)\end{array}$ & $\begin{array}{l}\text { Pennsylvania (M, M) } \\
\text { Mississippi (H, H) } \\
\text { Connecticut (H, M) } \\
\quad\end{array}$ \\
\hline
\end{tabular}

Note: The entries in parentheses show respectively the ranking of the states by average rate of cyelical decline and cyclical expansion (bigh, medium, low). Note that $L$ refers to a weak decline or expansion, while $H$ refers to a trong decline or exponsion.

devised by M.G. Kendall. The null hypothesis is that the distribution of rankings is independent among the time intervals. This test will be used extensively in this section, and it is described in the footnote: The test indicates that the 33 states have significantly stable growth ranks over the six time intervals. Kendall's test leads to an analysis of variance on the 33 mean state growth ranks. The mean ranks account for 49 per cent of the total variance of the sample; and yield an $F$ ratio of 4.72, which is significant at the 1 per cent level. Appendix Table 198 shows the computed state trends and their rankings over the six time intervals. ${ }^{13}$

The stability of the state growth ranks is also shown by the following correlation coefficients between pairs of rankings:

18 M. G. Kendull, The Advanced Theory of Slatistics, C. Griflin \& Co.; London, 1947, p. 419.

In Kendall'" test, the following variste has an $F$ distribution:

$$
F=\frac{(m-1) W}{1-W} \quad \text { where } W=\frac{12 S}{m^{2}\left(n^{8}-n\right)}, \quad S=\sum_{j=1}^{n}\left[G_{j}-\frac{m(n \cdot+1)}{2}\right]^{2}
$$

$m$ in the number of time intervals of $n$ ránked states. $G_{j}$ is the sum of the $m$ ranks of the $j$-th state. $B$ is the sum of the equared differences between the state mean ranks and the population mean rank.

The numerator of $F$ is distributed with

the denominator with

$$
v_{1}=(n-1)-\frac{2}{m} \text { degrees of freedom; }
$$

$$
v_{2}=(m-1) v_{1} \text { degrees of freedom. }
$$

Aaide from the correction factor $-(2 / m)$ in $v_{1}$. Kendall's procedure is to treat each column of $n$ ranks as having $(n-1)$ degrees of freedom. The sample of $m n$ objects then has $m(n-1)$ degrees of freedom, because the objects are renka. In the ordinary anolysis of variance, a sample of $m n$ objects would have $(m n-1)$ degrees of freedom.

14 This measure will be referred to as the "average maximum cyclical change, 1929-1937." 
CORRELATIONS BETWEEN STATE.GROWTH RANKINGS

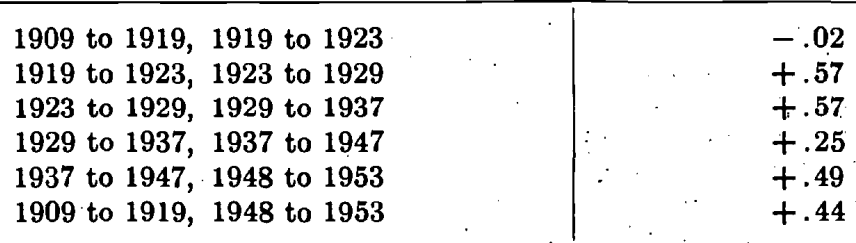

These are computed for successive pairs of time intervals and for the initial and final intervals. With the exception of the first pair of intervals (1909-1919,1919. to 1923), all the correlations are positive. In addition, the growth ranks. in the first pair of intervals are positively correlated with the ranks in other intervals. For example, the ranks for 1909-1919 have a positive correlation of +.44 with the ranks for 1948 to 1953 ; and the ranks for 1919-1923 have a positive correlation of +.57 with the ranks for 1923-1929.

The correlation and variance analyses indicate that state changes in growth rank from one time interval to another are quite limited, for if there were sharp changes the correlations among the rankings would be zero or negative. When such changes in growth ranking occur, they indicate that a state has retarded or accelerated its growth relative to the other states. The acceleration and retardation patterns are examined in Section 4 . They play a large role in the relation between growth and cyclical stability of states.

Cyclical Fluctuations. The full cyclical amplitude, the cyclical decline rate, and the cyclical expansion rate are consistently greater for some states than for others. In addition, with one notable exception to be discussed below, the expansion rates and decline rates are positively correlated. This section is devoted to an examination of these phenomena.

Appendix Table 199 shows six measures of average annual amplitude during four cycles. The number following the amplitude measure is the rank of the state in order of severity during that cycle, the largest amplitude receiving rank (1). The measures are:

1. Average annual amplitude during the 1914-1919-1921 cycle

2. Average annual amplitude during the 1919-1921-1923 cycle

3. Average of the maximum rise and maximum decline for any two-year period during the 1929-1937 cycle $^{\text {is }}$

4. Average of all changes during the four 2-year periods of the 1929-1937 cycle

5. Average annual amplitude during the 1948-1949-1953 cycle

6. Average annual amplitude during the 1948-1949-1951 cycle

All of these measures and the cycles were identified in Section 2. The mean cyclical amplitude, the variance of cyclical amplitudes, and the coefficient of variation (ratio of the standard deviation to the mean) for each cyclical measure are shown in Appendix Table 199. The amplitude orderings of the thirtythree states are highly stable from cycle to cycle. That is, significant state dif- 
ferences appear in the relative severity of successive cycles. The stability is demonstrated through two types of statistical tests:

1. Rank correlations for the 12 non-overlapping pairs of cycles are all positive, and 8 are significant at the 5 per cent level. ${ }^{15}$ These rank correlations are shown in the tabulation below.

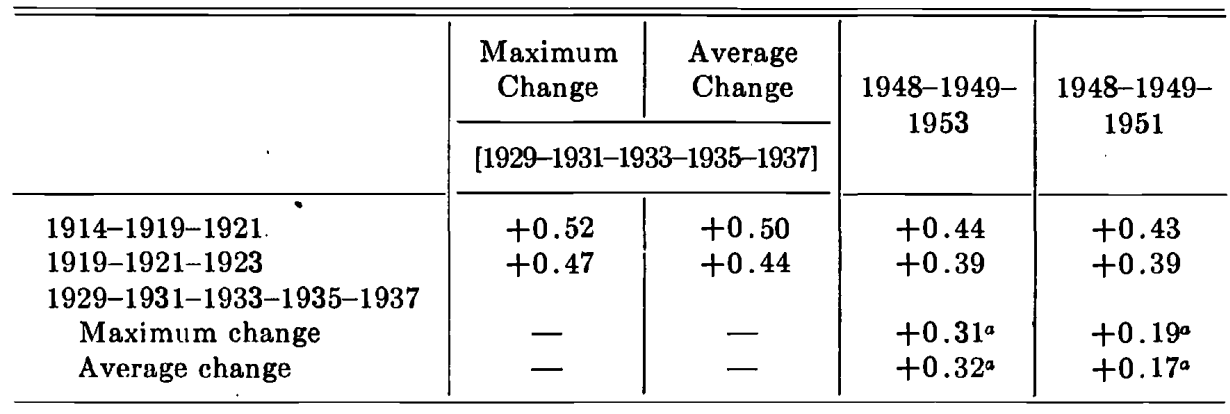

a Not significant.

In Charts 166, 167, and 168, scatter diagrams of the amplitudes of cycles for thirty-three states in pairs of time-intervals give a visual impression of the degree of correlation: Chart 167, for the 1914-1921 and the 1948-1953 cycles; Chart 167 for the 1919-1923 and the 1948-1953 cycles; Chart 168, for the 19291937 cycle (maximum change) and the 1948-1953 cycle. The charts show the extent to which cyclical amplitudes in the most recent cycle resemble those in each of the earlier cycles. They also show the marked reduction of interstate differences in amplitude that has occurred with the passage of time.

2. An analysis of variance on the ranks indicates that the mean state ranks account for 58 per cent of the total variance. ${ }^{16}$ This yields an $F$ ratio of 6.99 , which is highly significant at the 1 per cent level. The same test was conducted on four cyclical measures which exclude the overlap between the last two pairs of cyclical measures. The measures and the cycles compared are:

1. Average annual amplitude 1914-1919-1921

2. Average annual amplitude 1919-1921-1923

3. Average maximum change 1929-1937

4. Average annual amplitude 1948-1953

For these four cycles, the state-amplitude ranks account for 64 per cent of the total variance, ${ }^{17}$ leading to an $F$ ratio of 5.22 , still highly significant at the 1 per cent level.

On the basis of the above evidence, we may conclude that there are long lasting differences among states in the relative amplitudes of cycles of manufacturing employment. Nevertheless, some secular decline in these differences seems to have occurred. The declines over time of the range, standard deviation, and coefficient of variation are seen in Table 165. In 1948-1953, the state

w With 33 observations, the 5 per cent significance level for the Spearman coefficient of rank correlation is +0.335 .

10 With 33 ranks, the variance of the sample of $6 \times 33$ objects 90.67 ; the between-state variance is 317.23 ; the within-state variance is $\mathbf{4 5 . 3 6}$.

17 The overall variance is 90.67 , the between state variance 230.34 , the within state variance 44.11 . 
TABLE 165. INTERSTATE VARIABILITY IN CYCLICAL AMPLITUDES; 1914-1953

(as per cent of cycle base)

\begin{tabular}{l|r|r|r|r|r|r}
\hline \hline Cycle & Mean & Highest & Lowest & Range & $\begin{array}{c}\text { Standard } \\
\text { Deviation }\end{array}$ & $\begin{array}{c}\text { Coefficient } \\
\text { of } \\
\text { Variation }\end{array}$ \\
\hline \multicolumn{6}{c}{ Full Cycle Amplitude per Year } \\
\hline $1914-1921$ & 9.38 & 22.83 & 1.67 & 21.16 & 4.11 & 0.44 \\
$1919-1923$ & 12.09 & 21.65 & 6.11 & 15.54 & 3.85 & 0.32 \\
$1929-1937$ change: & 12.93 & 21.68 & 7.21 & 14.47 & 3.41 & 0.26 \\
Maximum & 9.33 & 14.08 & 5.32 & 8.76 & 2.23 & 0.24 \\
Average & 5.69 & 9.05 & 3.62 & 5.43 & 1.19 & 0.21 \\
$1948-1953$ & 7.06 & 10.80 & 4.65 & 6.15 & 1.64 & 0.23 \\
$1948-1951$ &
\end{tabular}

Decline Rates per Year

\begin{tabular}{|c|c|c|c|c|c|c|}
\hline $1919-1921$ & 13.59 & 31.14 & 1.57 & 29.57 & $5.38^{\circ}$ & 0.40 \\
\hline $1929-1931$ & 15.30 & 30.36 & 6.98 & 23.38 & 4.87 & 0.32 \\
\hline $1931-1933$ & 2.47 & 8.72 & +7.50 & 16.22 & 3.55 & 1.99 \\
\hline $1948-1949$ & 5.73 & 10.76 & 1.52 & 9.24 & 2.10 & 0.35 \\
\hline
\end{tabular}

Expansion Rates per Year

\begin{tabular}{l|r|r|r|r|r|r}
\hline $1914-1919$ & 5.17 & 14.53 & 0.16 & 14.37 & 3.42 & 0.66 \\
$1921-1923$ & 11.62 & 23.58 & 4.78 & 18.80 & 4.53 & 0.39 \\
$1933-1935$ & 9.14 & 19.40 & 2.65 & 16.75 & 3.04 & 0.33 \\
$1935-1937$ & 9.41 & 14.79 & 0.58 & 14.21 & 3.44 & 0.37 \\
$1949-1953$ & 5.30 & 10.98 & 2.81 & 8.17 & 1.70 & 0.32 \\
$1949-1951$ & 8.04 & 14.36 & 4.74 & 9.62 & 2.20 & 0.27 \\
\hline
\end{tabular}

with the largest amplitude experienced a rise and fall per year about two and one-half times that of the state with the smallest amplitude; in 1929-1937, the largest amplitude was about three times the smallest; in 1919-1923, about three and one-half times; and in 1914-1921 about fourteen times. The reduction in interstate differences was due primarily to the disappearance of extremely large amplitudes, a process suggesting an important way in which business cycles have become less severe in the United States. The reduction appears in the interstate differences of declines as well as expansions.

The decline of these differences is related in part to the decline of the amplitude of the postwar cycle compared with the prewar-in the sense that sharper differences appear among the components of an economy in severe contractions. ${ }^{18}$ But further explanation is required, since the variance of the expansion rates also declines. Another factor appears to be that states have become more diversified industrially, so that differences due to heavy specialization on highly cyclical industries have been reduced (see below, under Influence of IndustryMix).

18 Bert G. Hickman, "Post-war Cyclical Experience and Economic Stability," American Economic Review, May, 1958, pp. 117-35. 


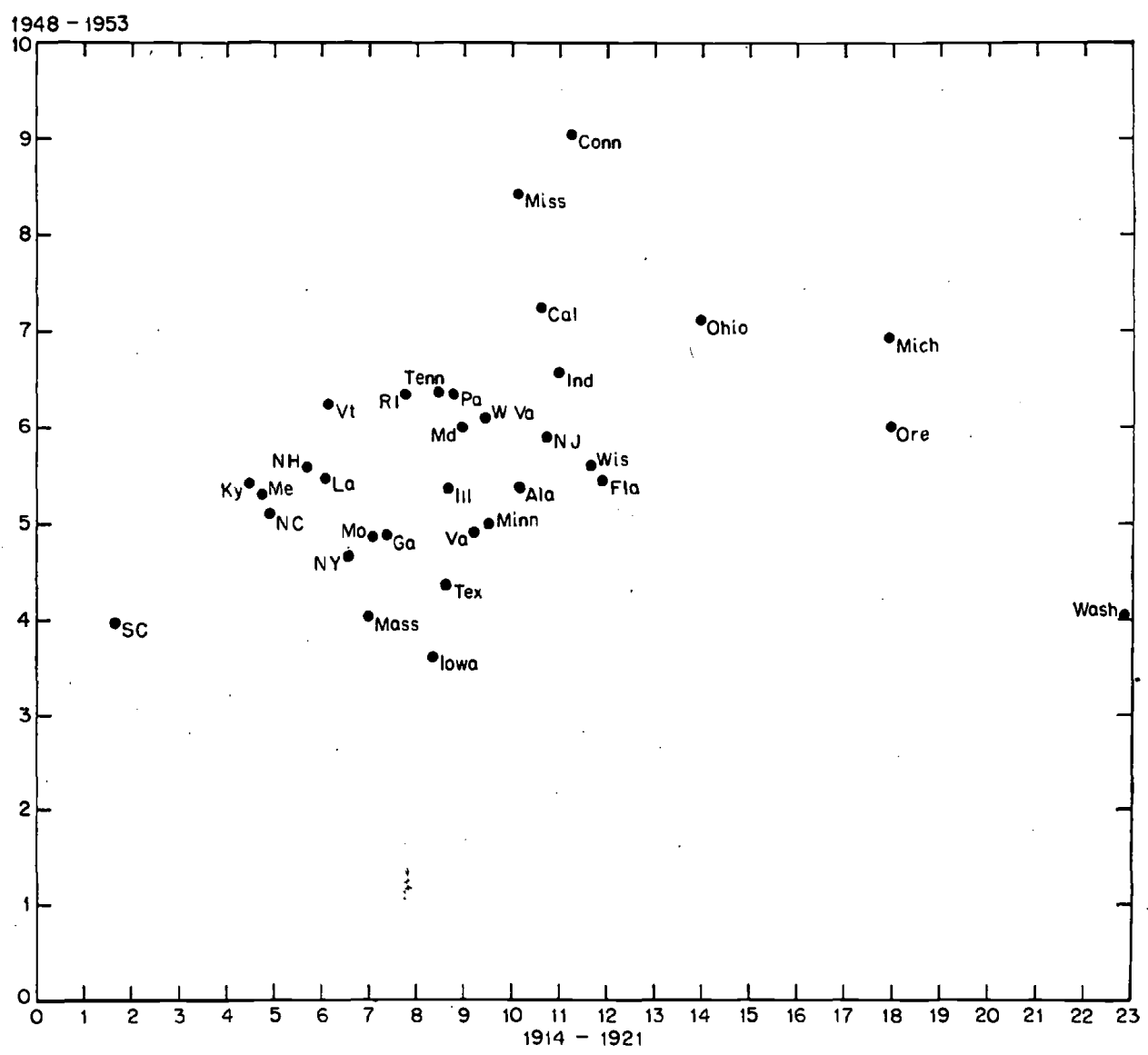

Chart 166. Average actual amplitudes in 33 states, 1914-1921 cycle and 1948-1953 cycle.

Appendix Table 200 shows the state cyclical decline rates for the periods 1919-1921, 1929-1931, 1931-1933, 1948-1949. The number following each decline rate is the rank of the state in order of severity during that cycle, the strongest decline rate receiving rank (1). Also shown is the mean decline rate for each period. It can be seen that the mean decline during 1931-1933 is considerably smaller than the others, and eight of the states actually experienced expansions.

The decline rates are significantly stable from cycle to cycle; however, the degree of stability is much weaker than that shown by either the amplitudes or the expansion rates. An analysis of variance on the ranks of the four declined rates yields an $F$ ratio of 1.80 , which is just significant at the 5 per cent level. ${ }^{19}$ When the 1931-1933 declines are excluded, and the analysis performed on the other three declines, the $F$ ratio is raised to 1.98 .

The weak relation between state-decline rates is shown by the correlation coefficient between decline-rate rankings, computed for successive pairs of time intervals and for other intervals. 


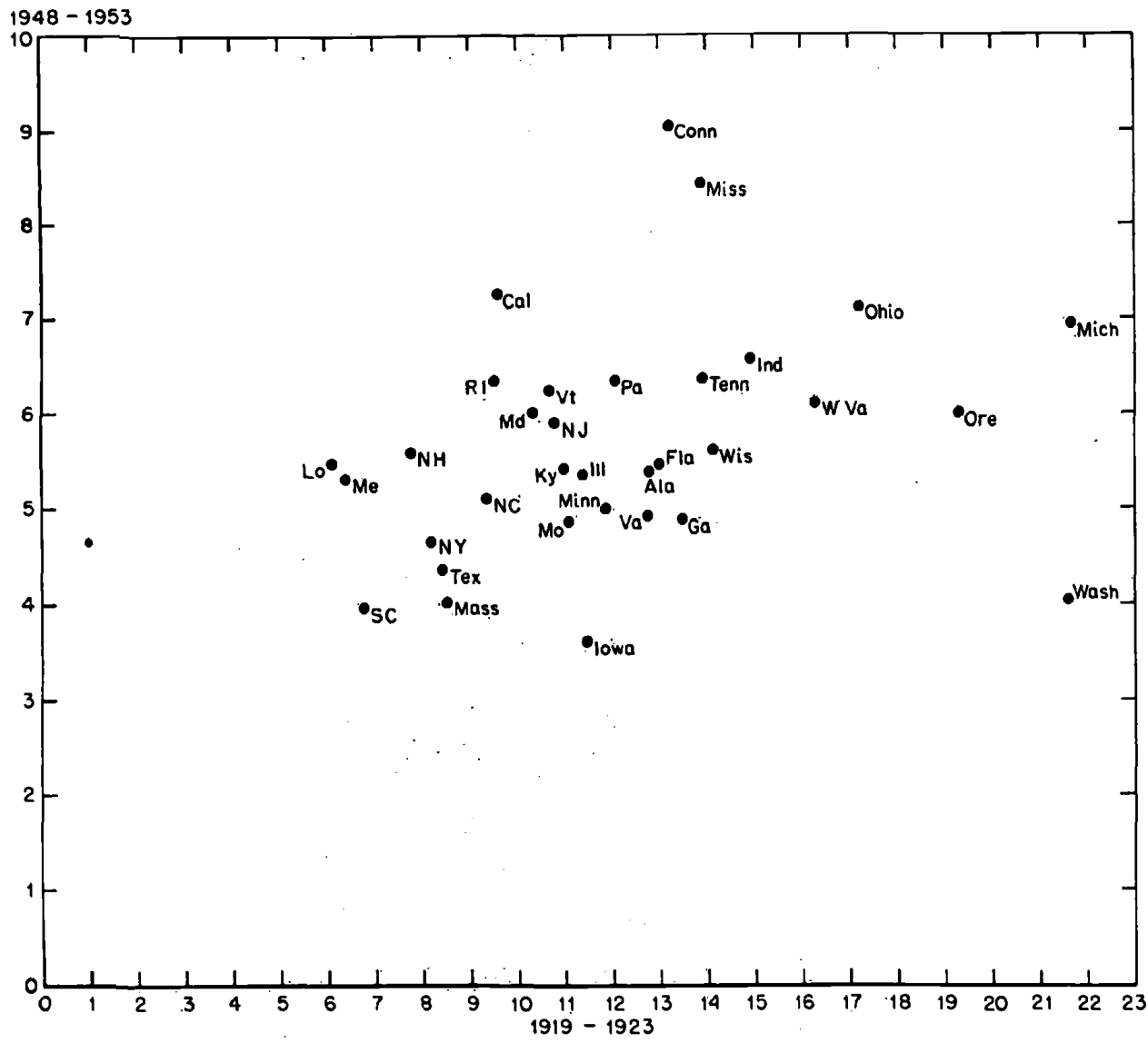

Chart 167. Average actual amplitudes in 33 states, 1919-1923 cycle and 1948-1953 cycle.

CORRELATION BETWEEN RANKINGS OF STATE

CYCLICAL DECLINE RATES

\begin{tabular}{l|r}
1919 to 1921,1929 to 1931 & +0.35 \\
1929 to 1931,1931 to 1933 & +0.25 \\
1931 to 1933,1948 to 1949 & -0.12 \\
1919 to 1921,1948 to 1949 & +0.23 \\
1929 to 1931,1948 to 1949 & +0.09
\end{tabular}

The 1931-1933 experience was different from that of the other periods, for the reason suggested earlier. Many states experienced sharp initial declines from 1929 to 1931, and then remained at their low positions or experienced slight declines from 1931 to 1933. States in this category include Ohio, Indiana, Mississippi, Louisiana, Kentucky, and Washington. In contrast, a group of states with initially mild declines in the first period had continued mild declines in the second; but those declines appear quite sharp in contrast to the more steady positions of the first group during that time. The second group includes Maine, New Hampshire, Massachusetts, New York, New Jersey, Minnesota, Missouri, 


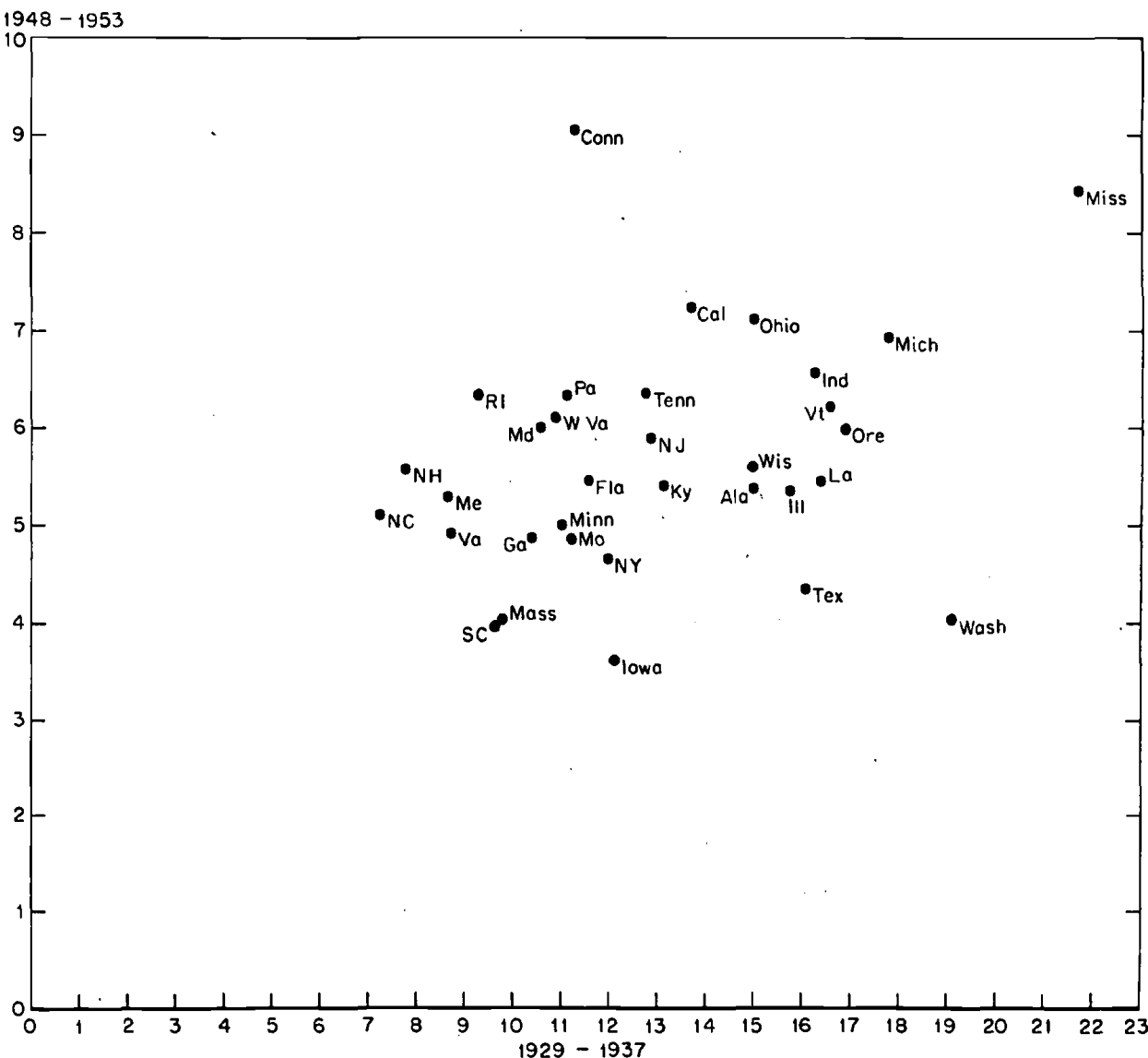

Chart 168. Average actual amplitudes in 33 states, 1929-1937 cycle (maximum change) snd 1948-1953 cycle.

and Florida. What appears to be a reversal of positions in the second period is explained by the differential timing and impact of the 1929-1933 decline, which make the 1931-1933 period fundamentally different in its cyclical declines from the other periods. Accordingly, it will be excluded in further analysis of declines and expansions.

The state cyclical expansion rates for the periods 1914-1919, 1921-1923, 1933-1935, 1935-1937, 1948-1953, 1949-1951 are also shown in Appendix Table 200, with state rank numbers given as before. The expansion rates show a greater degree of stability than the decline rates. An analysis of variance on the ranks of the five non-overlapping expansion rates (excluding 1949-1951) yields an $F$ ratio of 5.51, highly significant at the 1 per cent level..$^{20}$

The stability of state expansion rates is shown by the correlation coefficients between expansion rate rankings, computed for successive pairs of time intervals, and for the initial and final intervals. 
CORRELATION BETWEEN RANKINGS OF STATE CYCLICAL EXPANSION RATES

\begin{tabular}{l|r}
1914 to 1919,1921 to 1923 & +0.34 \\
1921 to 1923,1933 to 1935 & +0.31 \\
1933 to 1935,1935 to 1937 & +0.49 \\
1935 to 1937,1949 to 1953 & +0.44 \\
1914 to 1919,1949 to 1953 & +0.63
\end{tabular}

In addition to the stability of the expansion and decline rates, there is, with one exception, strong positive correlation between declines and expansions. The exception is the post World War II cycle. The rank correlation coefficients between decline rates and expansion rates is shown below.

\begin{tabular}{c|c|c}
\hline \hline Decline & Expansion & $\begin{array}{c}\text { Rank Correlation } \\
\text { Coefficient }\end{array}$ \\
\hline $1919-1921$ & $1914-1919$ & +0.60 \\
$1919-1921$ & $1921-1923$ & +0.47 \\
$1929-1931$ & $1933-1935$ & +0.53 \\
$1929-1931$ & $1935-1937$ & +0.58 \\
$1948-1949$ & $1949-1953$ & -0.17 \\
$1948-1949$ & $1949-1951$ & +0.23 \\
\hline
\end{tabular}

The behavior of the coefficients indicates that before 1948 the states with large decline rates also had large expansion rates; after 1948, some change occurs which actually reverses the pattern. In the 1948-1953 cycle, there is a tendency for states with large decline rates to have small expansion rates. This change is evidently in the average amplitude and amplitude variance-smaller in the postwar cycle relative to the prewar cycle.

There are two ways in which a negative correlation between decline rates and expansion rates could occur among states: one is by the occurrence of the negative correlation among industries; the other is through the dominating influence of state trend differences over amplitude differences.

The first possibility is ruled out by the data. In all cycles there were positive correlations between industry expansion rates and decline rates. It is true that, in the postwar cycle, both textiles and transport equipment experienced wide divergence between expansion and decline rates-the former showing relatively sharp decline and weak expansion, and the latter showing the opposite. Nevertheless, such divergences did not occur in enough industries to produce the negative correlation observed among states.

The second possibility seems a more reasonable explanation. Clearly, if there were no amplitude differences among states, trend differences would produce a negative correlation between expansion and decline rates. Strongly growing states would have weaker decline rates and sharper expansion rates, and weakly growing states would have the reverse. Once we admit the possibility of amplitude differences (perhaps due to industry-mix) we can explain the observation of negative correlation in one cycle and positive correlation in the others. Strong 
decline and expansion rates may co-exist in a state because of the cyclical experience of the industries located there. As the variance of state amplitudes and industry amplitudes diminishes, the influence of trend differences increases as a factor making for negative correlation. This explanation appears to be confirmed by the fact that the variances of state and industry amplitudes were much smaller after World War II than before. ${ }^{21}$

The next tabulation brings out sharply the influence of trend differences during a mild cycle. It shows the average ranks of cyclical decline rates and expansion rates for the strongly growing and weakly growing states. These are the same state groups shown in Table 161. They were chosen for their consistently high or consistently low growth over the 1909-1953 period. The tabulation makes clear that, before 1948 , the strongly growing states had on the average both stronger

\begin{tabular}{|c|c|c|c|c|}
\hline \multirow{2}{*}{ Average Group Ranks } & \multirow{2}{*}{$\begin{array}{c}\text { Strongly } \\
\text { Growing } \\
\text { States }\end{array}$} & \multirow{2}{*}{$\begin{array}{c}\text { Weakly. } \\
\text { Growing } \\
\text { States }\end{array}$} & \multicolumn{2}{|c|}{ Differences } \\
\hline & & & Expansions - & Declines \\
\hline 1914-1919 Expansion & 14 & 22 & -8 & \\
\hline 1919-1921 Decline & 18 & 20 & & -2 \\
\hline 1921-1923 Expansion & 10 & 25 & -15 & \\
\hline 1929-1931 Decline & 15 & 17 & & -2 \\
\hline 1933-1935 Expansion & 15 & 21 & -6 & \\
\hline 1935-1937 Expansion & 12 & 23 & -11 & \\
\hline 1948-1949 Decline & 20 & 11 & & +9 \\
\hline 1949-1953 Expansion & 14 & 20 & -6 & \\
\hline
\end{tabular}

expansions and stronger declines then the weakly growing states, though the difference in expansions is much greater than in contractions. In the mild cycle of 1948 , however, the strongly growing states have on the average stronger expansions but weaker declines than the weakly growing states. Thus, the negative correlation in the 1948-1953 cycle between expansion and decline rates was generated by the influence of trend on the cyclical decline rates of weakly growing states. Ordinarily, this influence is not felt in cycles with stronger amplitudes and larger amplitude variances.

The Influence of Industry-Mix. One possible reason for the stability of state cycle amplitudes is the influence of industry-mix. Industrial composition within a region determines the nature of the national cyclical impulses transmitted to it. If the region specializes in automobile production, for example, it will have more severe cycles than if it specializes in meat packing.

It is possible to isolate the influence of industry-mix by constructing a hypothetical cycle amplitude for each state. The process makes use of the assumption that each state industry behaves in the same fashion as its national counterpart, so that the only difference among states is the relative importance accorded to these national cyclical impulses. The hypothetical amplitude is computed from an index of hypothetical state employment. The index is formed through weighting the cyclical experience of each national industry by the rela-

21 On industry amplitudes, see the next part of this section and Appendix Table 203. 
tive importance of the industry in each state. ${ }^{22}$ In constructing the hypothetical cycles, the following state weights were used : for 1914-1921 and 1919-1923, the 1919 state weights; for 1929-1937, the 1939 weights; and for 1948-1953, the 1947 weights. Appendix Table 202 presents the hypothetical cyclical amplitudes for each state. They are computed for each cycle and cyclical measure for which an actual amplitude is shown in Appendix Table 199. In Table 202, the numbers next to each hypothetical amplitude show the rank of the state's amplitude during a single cycle. Also shown are the mean, variance, and coefficient of variation for each cyclical measure.

Examination of the hypothetical amplitudes indicates that, as one would expect, they are even more stable from cycle to cycle than the actual amplitudes are. In addition, there is a secular decline of the variance. The two types of computations performed on the ranks of the actual amplitudes may be repeated on the ranks of the hypothetical amplitudes.

(1) The tabulation shows rank correlation coefficients between different pairs of non-overlapping cyclical measures. Comparison of these rank correla-

\begin{tabular}{|c|c|c|c|c|}
\hline & $\begin{array}{c}\text { Maximum } \\
\text { Change }\end{array}$ & $\begin{array}{l}\text { Average } \\
\text { Change }\end{array}$ & \multirow{2}{*}{$\begin{array}{c}1948-1949- \\
1953\end{array}$} & \multirow{2}{*}{$\begin{array}{c}1948-1949- \\
1951\end{array}$} \\
\hline & \multicolumn{2}{|c|}{$[1929-1931-1933-1935-1937]$} & & \\
\hline 1914-1919-1921 & +0.69 & +0.79 & +0.68 & +0.58 \\
\hline $1919-1921-1923$ & +0.87 & +0.89 & +0.54 & +0.54 \\
\hline 1929-1931-1933-1935-1937 & & & & \\
\hline Maximum change & - & 一 & +0.50 & +0.52 \\
\hline Average change & - & - & +0.66 & +0.63 \\
\hline
\end{tabular}

tion coefficients with those for actual amplitudes reveals that all of the rank correlations are larger between hypothetical amplitudes, and that all coefficients are significant at the 5 per cent level.

(2) An analysis of variance on six and then on four non-overlapping hypothetical cycle measures indicates that the mean state ranks are highly significant, and in each case explain a much higher percentage of total variance than the mean actual state ranks do. ${ }^{23}$

${ }^{23}$ A numerical example will illustrate how this is done. Using year one as the base, euppose national industry $A$ has employment in year two of 95 and national industry B, 90. Further suppose that in year one industry A accounted for 10 per cent of the labor force in a state, industry $B$ the other 90 per cent. Then, the hypothetical decline in the state is $100-(0.10 \times 95+0.90 \times 90)$ which is $100-90.5=9.5$ per cent of the base year. Suppose, in year three, employment in national industry $A$ were to rise to 103 and in $B$ to 99 . Then, the hypothetical state employment in year three would be $0.10 \times 103+0.90 \times 99=99.4$. The three hypothetical cyclical observations are $100,90.599 .4$. If these are regarded as peak, trough, peak dates, then the average hypothetical amplitude would be:

$$
1 / 2\left[\frac{(100-90.5)+(99.4-90.5)}{1 / 3(100+90.5+99.4)}\right]=9.20 / 96.63=9.52
$$

cycle base units per year. Note that in these calculations the base is the simple average of the cycle values at the turning points.

23 The mean state ranks for the six cyclical measures account for 78 per cent of the total variance. The total variance is equal to 90.67 , the within-state variance equal to 24.09 , and the state mean variance equal to 423.35 . This leads to an $F$ ratio of 17.58 , which is highly significant at the 1 per cent level. This is to be compared with an $F$ ratio of 6.99 obtained from a similar test upon actual ranks. 
The greater stability of the hypothetical over the actual state cycles is implicit in the method of constructing them. The hypothetical series of each state is generated by combining national industrial time series for nineteen (or twenty) industries with individual state weights for each industry. The weights differ from state to state and from cycle to cycle, but the nineteen industrial time series remain the same. This is in contrast with the actual state cycle which, in a sense, combines individual state weights with individual state time series for the nineteen or twenty industries. The elimination of state-to-state differences in industrial behavior wi!l lead to two observed consequences: (1) The distribution of hypothetical state amplitudes will bear a closer relation from cycle to cycle than that of actual state amplitudes. (2) The variance of the distributions of hypothetical state amplitudes will be smaller than that of the actual state amplitudes. Both the variance and the coefficient of variation in Tables 165 and 174, bear out this general observation.

A fundamental question still remains, however: Why do the relative state amplitudes (both actual and hypothetical) show any regularity at all from cycle to cycle? Regularity must depend upon regularity of behavior of both the national and state industries. Regularity is used in two senses, implying two conditions: first, there must be stability in the distribution of amplitudes for national industries from cycle to cycle; and second, the state components of these industries must follow regularly the national behavior of the industry.

These two conditions are sufficient to explain the regularity of observed behavior in actual and hypothetical amplitudes. They are not necessary in the sense that state weights might conceivably shift over time to preserve the variability ranking of the states. The data on industrial variability satisfy the first condition, while the second is only partially satisfied (see below). Therefore, the second condition, while not ruled out by evidence, appears unimportant as an explanatory factor; there is considerable stability in the distribution of amplitudes of national industries from cycle to cycle. The cyclical amplitudes of the national industries and their ranking in each cycle are shown in Appendix Table $203 .{ }^{24}$ Chart 173 is a scatter diagram of the amplitudes in nineteen national industries during the 1948-1953 and 1929-1937 cycles. It gives a picture of the

For the four non-overlapping cyclical measures, the total variance is 90.67 , the within-state variance 25.14, and the state mean variance 287.25 . The mean state ranks account for 79 per cent of total variance. An $F$ ratio of 11.43 results, as compared with a ratio of 5.22 obtained from actual state ranks.

24 An analysis of variance on the mean industry ranks indicates that they explain from 84 to 85 per cent of the total variance, depending on the cycles chosen.

Using all six cyclical measures, we have:

Total variance
Industries
Within Industries

Mean Square

30

151.81

5.64

This yields an $F$ ratio of 26.92 , and 84 per cent of the variance explained. Using the four non-overlapping measurea we have:

$\begin{array}{lc} & \text { Mean Square } \\ \text { Total variance } & 30 \\ \text { Industries } & 102.22 \\ \text { Within industries } & 5.93\end{array}$

An $F$ ratio of 17.24 , and 85 per cent of the variance explained. The $F$ ratios are highly significant at the 1 per cent level. 


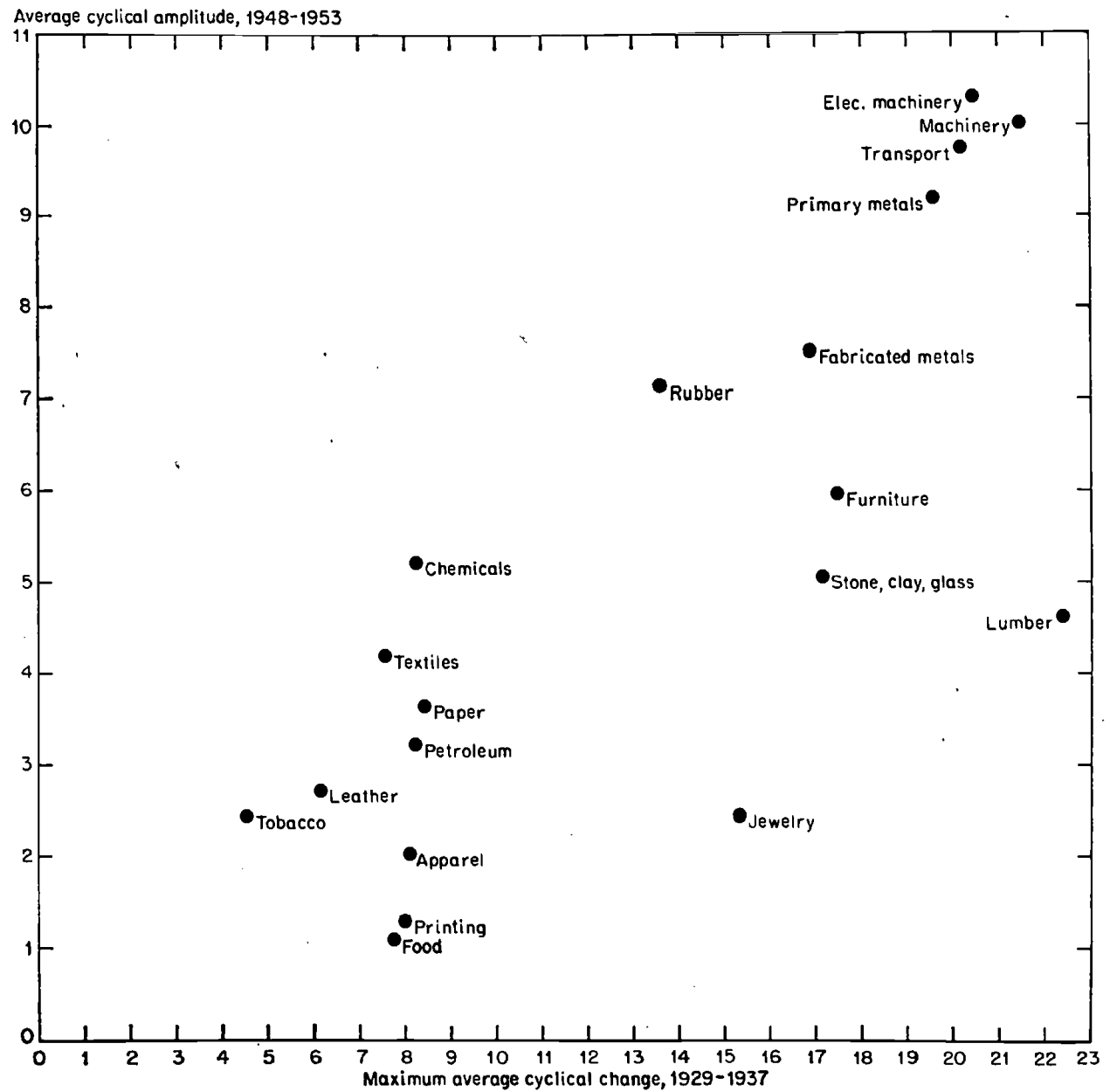

Chart 173. Cyclical amplitudes in 19 industries during 1929-1937 cycle and 19481953 cycle.

differences in behavior of the durable and nondurable goods industries, and of the stability of such differences in those periods.

The rank correlations between non-overlapping pairs of industry cycles are shown in the next tabulation. It should be compared with the correlation of

\begin{tabular}{|c|c|c|c|c|}
\hline & $\begin{array}{c}\text { Maximum } \\
\text { Change }\end{array}$ & $\begin{array}{l}\text { Average } \\
\text { Change }\end{array}$ & \multirow{2}{*}{$\begin{array}{c}1948-1949- \\
1953\end{array}$} & \multirow{2}{*}{$\begin{array}{c}1948-1949- \\
1951\end{array}$} \\
\hline & \multicolumn{2}{|c|}{ [1929-1931-1933-1935-1937] } & & \\
\hline $\begin{array}{l}\text { 1914-1919-1921 } \\
\text { 1919-1921-1923 } \\
\text { 1929-1931-1933-1935-1937 } \\
\text { Maximum change } \\
\text { Average change }\end{array}$ & $\begin{array}{l}+0.51 \\
+0.75\end{array}$ & $\begin{array}{l}+0.51 \\
+0.75\end{array}$ & $\begin{array}{l}+0.69 \\
+0.88 \\
+0.77 \\
+0.75\end{array}$ & $\begin{array}{l}+0.61 \\
+0.85 \\
+0.81 \\
+0.76\end{array}$ \\
\hline
\end{tabular}


TABLE 174a. INTERSTATE VARIABILITY IN HYPOTHETICAL CYCLICAL AMPLITUDES, 1914-1953

(as per cent of cycle base)

Full Cycle Amplitude per Year

\begin{tabular}{l|r|r|c|c|c|c}
\hline \hline \multicolumn{1}{c|}{ Cycle } & Mean & Highest & Lowest & Range & $\begin{array}{c}\text { Standard } \\
\text { Deviation }\end{array}$ & $\begin{array}{c}\text { Coefficient } \\
\text { of Variation }\end{array}$ \\
\hline $1914-21$ & 8.77 & 15.26 & 3.84 & 11.42 & 2.52 & 0.29 \\
$1919-23$ & 11.55 & 18.06 & 7.35 & 10.71 & 2.25 & 0.19 \\
1929-37 change & & & & & & \\
Maximum & 12.36 & 17.30 & 8.94 & 8.36 & 2.32 & 0.19 \\
Average & 8.83 & 12.92 & 5.94 & 6.98 & 1.78 & 0.20 \\
$1948-53$ & 5.58 & 8.75 & 3.73 & 5.02 & 1.10 & 0.20 \\
$1948-51$ & 7.27 & 12.32 & 5.25 & 7.07 & 1.35 & 0.19 \\
\hline
\end{tabular}

Note: The hypothetical amplitudes are based on national industry cycles weighted by state industrial composition.

hypothetical amplitudes, above. The state weights have changed, but in no systematic fashion. From 1919 to 1939 they changed in a manner to preserve the amplitude rankings of the states. This is seen in the higher correlation between hypothetical amplitudes than between industry amplitudes, in these intervals. The same reasoning leads to the conclusion that from 1939 to 1947 , the weights changed in a manner to disturb the amplitude rankings of the states.

The secular decline in the variance of hypothetical state amplitudes is shown in Table 174a. The secular decline in the variance of industry amplitudes is shown in Table 174b. Neither decline is as marked as the decline in variance of actual state amplitudes (Table 165). Nevertheless, the actual decline may be explained in part by the shift in state industrial composition. States that formerly specialized in highly cyclical industries have apparently become more diversified, notably between 1939 and 1947. While the coefficient of variation of hypothetical amplitudes is virtually unchanged, the coefficient of industry amplitudes has increased (from 0.45 to 0.58 ). This indicates that change in state industrial composition in this period has narrowed the range of state amplitudes.

TABLE 174b. INTERINDUSTRY VARIABILITY IN CYCLICAL AMPLITUDES, 1914-1953

(as per cent of cycle base)

Full Cycle Amplitude per Year, 19 Industries

\begin{tabular}{l|r|r|r|r|c|c}
\hline \hline \multicolumn{1}{c|}{ Cycle } & Mean & Highest & Lowest & Range & $\begin{array}{c}\text { Standard } \\
\text { Deviation }\end{array}$ & $\begin{array}{c}\text { Coefficient } \\
\text { of Variation }\end{array}$ \\
\cline { 2 - 3 } 1914-21 & 9.30 & 31.95 & -0.10 & 32.05 & 7.71 & 0.83 \\
1919-23 & 11.31 & 26.27 & 0.56 & 25.71 & 6.46 & 0.57 \\
1929-37 change & & & & & & \\
Maximum & 13.21 & 22.38 & 4.51 & 17.87 & 5.89 & 0.45 \\
Average & 9.74 & 17.08 & 3.42 & 13.66 & 4.40 & 0.45 \\
1948-53 & 5.15 & 10.31 & 1.08 & 9.23 & 2.97 & 0.58 \\
1948-51 & 6.65 & 11.58 & 1.13 & 10.45 & 3.43 & 0.52 \\
\hline
\end{tabular}


The same reasoning indicates that in the earlier period (1919 to 1939) change in state industrial composition acted to widen the range of state amplitudes. ${ }^{25}$ That the range of state amplitudes narrowed in the earlier period is an indication that another influence was also operating. This other influence is the severity of the cyclical contraction on the national level. We shall show in Section 4 how the variance of actual amplitudes is dependent upon cyclical contractions.

The usefulness of the hypothetical cycles as an explanatory factor may also be seen through their correlation with the actual amplitudes. Charts 176 and 177 are scatter diagrams of actual and hypothetical amplitudes during the19291937 and 1948-1953 cycles. They show the extent to which the actual amplitude may be predicted from the hypothetical: The diagonal line on the chart is the set of points for which actual and hypothetical amplitudes would be equal in magnitude.

The rank correlations between actual and hypothetical amplitudes are significant at the 5 per cent level for each of the six cyclical measures. These correlations are shown in the next tabulation. The correlation coefficients are found to be significantly different from each other; therefore, the six pairs of ranks may not be pooled to form an average rank correlation coefficient. ${ }^{26}$ On

RANK CORRELATION BETWEEN ACTUAL AND HYPOTHETICAL AMPLITUDES

\begin{tabular}{c|r}
\hline \hline $1914-1919-1921$ & +0.7989 \\
$1919-1921-1923$ & +0.7538 \\
$1929-1937$ change & +0.7971 \\
Maximum & +0.7726 \\
Average & +0.3371 \\
$1948-1949-1953$ & +0.4796 \\
\hline $1948-1949-1951$ & \\
\hline
\end{tabular}

the other hand, when the last two cyclical measures are eliminated, the first four correlations are not significantly different, and may be pooled. An average rank correlation of 0.78 between actual and hypothetical amplitudes may be used to describe the first four measures.

Apparently the difference between the postwar cycles and the prewar cycles was sufficient to rule out pooling all six correlations. The difference manifests itself in the weakness of the hypothetical amplitudes as a predictor of the actual amplitudes. It is unwarranted to conclude that this weakness occurred because. the postwar industrial cycles were unlike the prewar cycles in the same industries. The correlation coefficients for the industry cycles indicate no marked change over time in the degree to which interindustry differences in amplitude are preserved.

The weaker correlations between hypothetical and actual amplitudes indicate that the postwar cycle was characterized by sharper intraindustry-interstate differences in cyclical behavior than previously. The explanation, be-

25 Apparently, the shift in state industrial composition toward greater diversification between 1939 and 1947 acted to reduce the correlation between pre-war and post-war state cycle amplitudes.

20 A test of the homogeneity of the rank correlations indicated that pooling is not permissible. This test is derived from the ordinary covariance test on unranked variates and is shown in Appendix $\mathbf{A}$. 


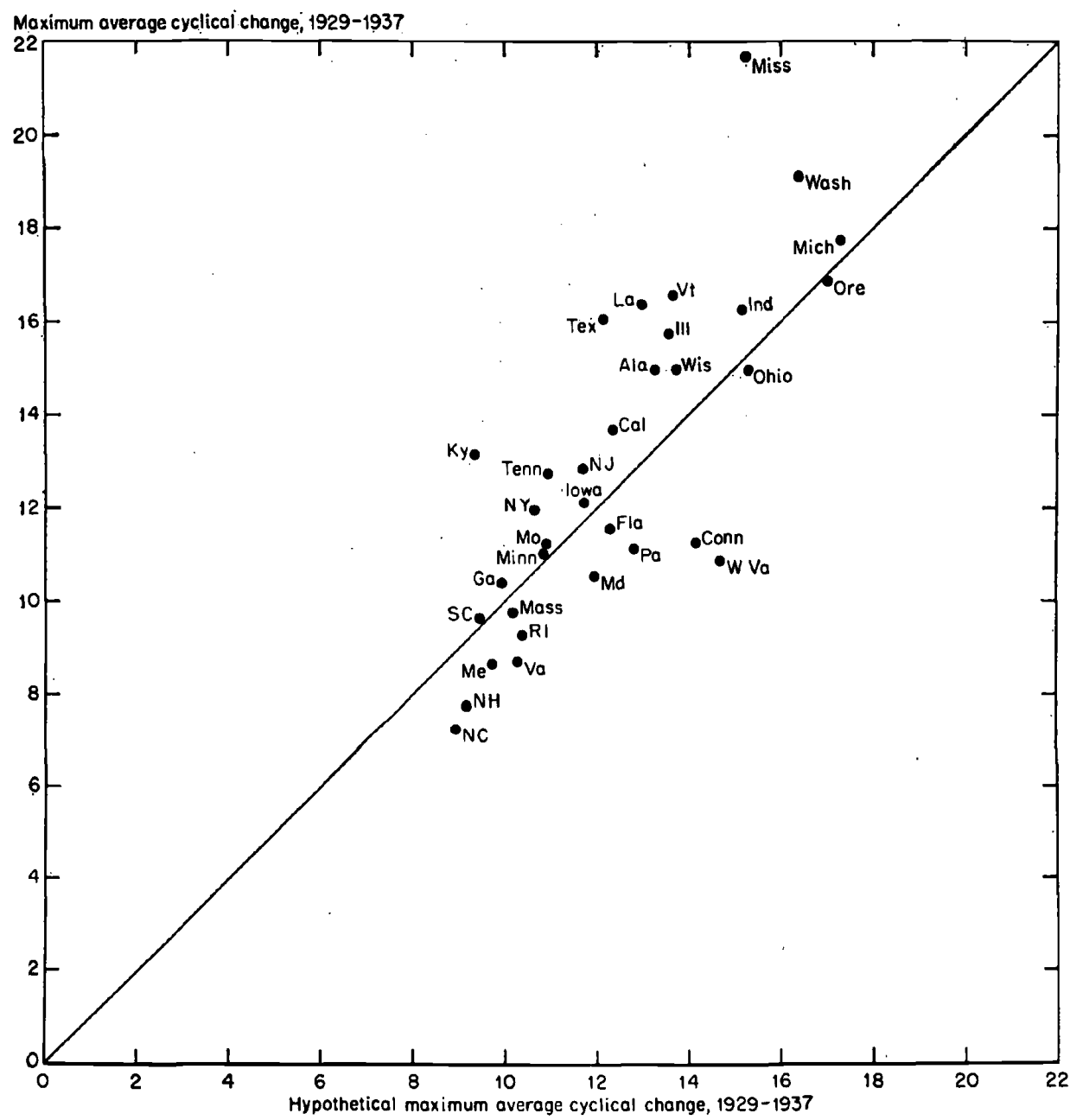

Chart 176. Actual and hypothetical cyclical amplitude in 33 states during 1939-1937 cycle.

lieved here to be found in the mild contraction of the postwar cycle, will be considered at length in the next section.

\section{EXPLANATIONS OF REgIONAL CYCLICAL PATTERNS}

There are two problems in the field of regional fluctuations which have received some attention by economists. One is the regional transmission of cyclical impulses. The other is the relation of the regional cycle to long-term growth patterns. Each of these will be treated in this section.

The Regional Transmission of Cycles. A number of writers have argued that the national cycle is transmitted through a major export industry. The regional cycle reflects, or in some way exaggerates, the national industrial impulses transmitted to it. Vining has written the following in support of this position:

"From the work that we have done, we have the impression, although it is a pretty innocent one, that the parts of a given industry, the products of which are marketed 


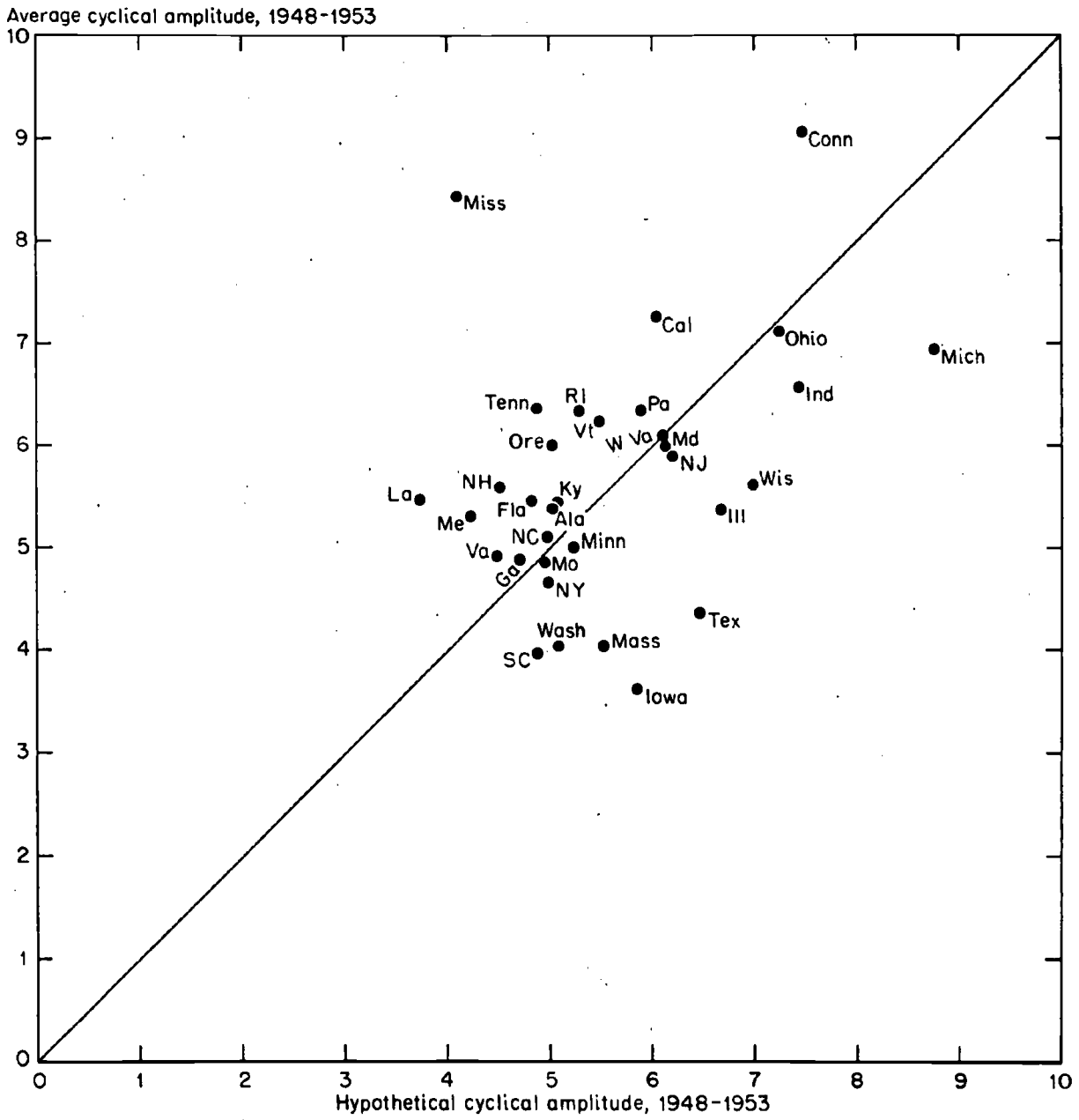

Chart 177. Actual and hypothetical cyclical amplitude in 33 states during 1948-1953 cycle.

pretty uniformly within the nation are affected essentially similarly by something that we call 'national' conditions. Some kind of unanalyzed average effect of changes taking place in the entire nation is imparted to these industries producing for a national market. The parts of these various special industries are geographically dispersed, and the similar responses at the different geographical points set in motion a series of reactions affecting the residentiary ${ }^{27}$ industries of the region within which these points are located." 28

A major implication of Vining's statement is that local industries will behave more like some "key" industry in the region than like their national counterparts. The reason is that many local manufacturing industries do not serve the national market, but sell to local households and to the export industries of the

27 The term residentiary is used to denote economic activities which are not initially affected by the "national" changes in aggregate demand, industries producing goods and services purchased by the households and export industries of the region.

${ }^{18}$ Rutledge Vining, The Region as an Economic Entity and Certain Variations to be Observed in the Study of Systems of Regions, p. 103. 
region. Cyclical impulses imparted to local industries will, therefore, be derived from the impulses the export industries receive from the national market.

There is some question whether the "key" industry concept can be subjected to an exact statistical test. Certainly the relations implied by the concept may be true for one group of industries and not for others. In addition, the particular "key" industry may change its identity from cycle to cycle, in which case the concept is not as useful as it first appears.

There is, however, one implication of the key industry hypothesis which can be tested with the existing data. ${ }^{29}$ If a single industry or group of industries dominates the cyclical behavior of a region, we can expect the data to show the following: Regions which contain industries of large national amplitude will tend to have greater actual amplitude than expected on the basis of composition, while regions containing industries of small national amplitude will tend to have smaller actual amplitude than expected on the basis of composition. This will arise through the repercussions from the export to the residentiary industries.

This relationship can be depicted graphically. In the following chart, actual amplitudes are plotted on the vertical axis, hypothetical amplitudes on the

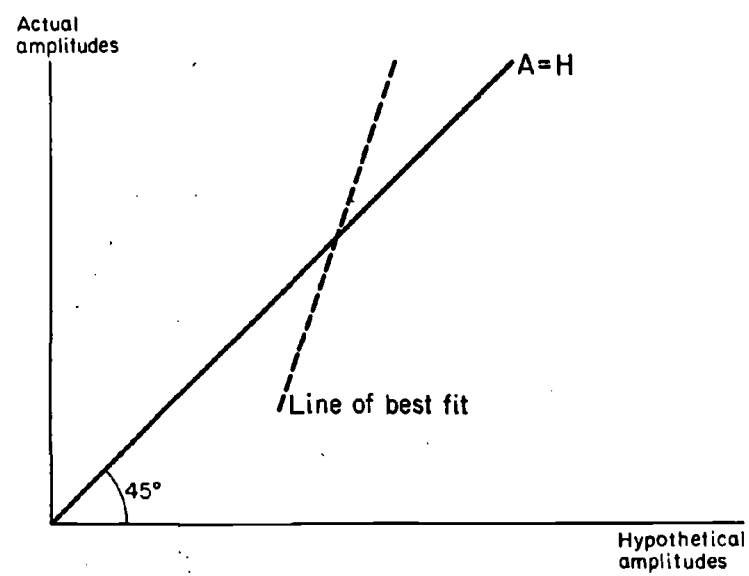

horizontal. The $45^{\circ}$ line shows the set of points for which actual and hypothetical amplitudes are equal. The dashed line is a line of "best fit" in some sense which describes the relation between actual and hypothetical amplitudes. To satisfy the key industry relation, the line of best fit must have a slope greater than unity as is shown in the diagram. Under these circumstances, states with high variability industries will have more amplitude than composition predicts, while states with low variability industries will have less amplitude than composition predicts. The pictured deviation of the line of best fit from the $45^{\circ}$ line indicates a positive correlation between the composition of a state and the net differences in cyclical variability between local and national industries. If the line of best fit had a slope less than unity, this correlation would be negative.

Examination of the six.cyclical measures shows that the key industry relation

20 In the test, I ignore the possibility of different regional multipliers arising from regional differences in the marginal propensities to consume, to import, to invest, etc. 
appears in only three cycles. That is, in three cycles the correlation between composition and intra-industry differences is positive. In the other three cycles, it is either zero or negative. Another way of saying the same thing is that the above estimate of the line of best fit (from least squares) indicates a slope greater than unity for three cycles, and equal to or less than unity for the other three cycles. This information is summarized in the following tabulation which shows:

Column 1. Slope of the regression of actual on hypothetical amplitudes.

2. Correlation coefficient between actual and hypothetical amplitudes.

3. Correlation coefficient between hypothetical amplitudes and the residual which reflects intra-industry differences in cyclical behavior. ${ }^{30}$

4. Average actual amplitude.

5. Average cyclical decline rate.

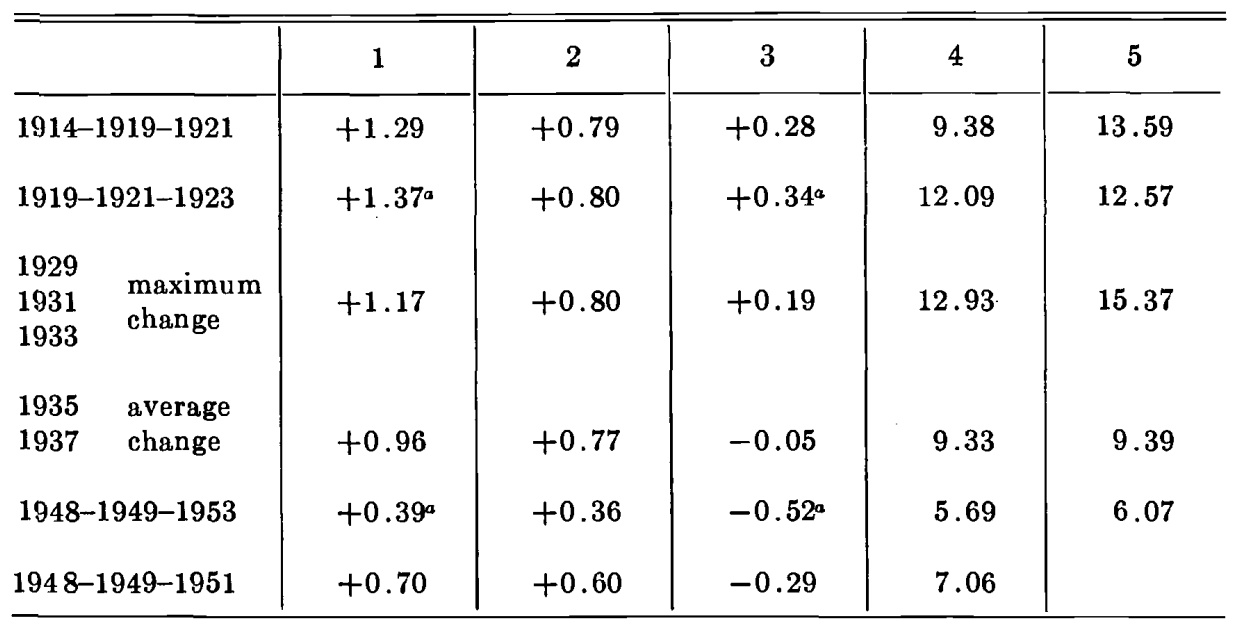

a For explanation, see footnote 30 .

It is clear that the key industry phenomenon appears verified in those cycles (or cyclical measures) with the largest amplitudes and largest average cyclical decline rates. This suggests that verification may be due to the diffusion-amplitude relation which Burns and Mitchell recognized in industrial cycles. ${ }^{31}$ They found a greater proportion of series responding to sharp swings of the business cycle, and a greater proportion of series declining in severe contractions. If this phenomenon were to appear in state data, it would generate precisely the results observed in this table. For in a mild cycle, or during a mild contraction,

${ }^{30}$ The residual is the difference between the actual and the hypothetical amplitude $|R=A-H|$. It reflects the difference between the cyclical behavior of the state's industries and their national counterparts. Positive correlation between $R$ and $H$ indicates the presence of the key industry effect. The two regression coefficients bearing an asterisk in Column 1 might be considered significantly different from unity, while the two correlation coefficients in Column 3 might be considered significantly different from zero. However, it is not valid to apply the probabilistic interpretation of statistical significance to these coefficients; the regression relation is not a stochastic equation. The value of the coefficients indicates only the relative contributions of the different terms in an identity. The regression of actual on hypothetical amplitudes may be written $A=\alpha H+\beta$. Substituting the identity $A=H+R$ into this yields $R=(\alpha-1) H+\beta$. The difference between $\alpha$ and unity indicates the degree of correlation present between $H$ (the hypothetical amplitude) and $R$ (the differences between state and national cyclical amplitudes). A test of the significance of this correlation is not relevant. What is relevant is the occurrence of a positive correlation in $H$ and $R$ when there are cycles with severe contractions.

st A. F. Burns and W. C. Mitchell, Measuring Business Cycles, New York: National Bureau of Economic Research, 1946, p. 106. 
sectional differences tend to dominate national patterns. The interstate, intraindustry differences in amplitude become larger relative to the inter-industry differences. The states with industrial components of large national amplitude tend to have smaller actual amplitude and the states with industrial components of small national amplitude tend to have greater actual amplitude. Consistent with this, the correlation between actual and hypothetical amplitudes also declines in mild cycles (Column 2 of the table). On the other hand, during severe cycles or during severe contractions, the state industrial components behave more like their national counterparts. The influence of sectional differences in intra-industry cyclical behavior tends to decline, and the correlation between actual and hypothetical amplitudes tends to increase.

These considerations suggest why the fourth cyclical measure does not reveal the key industry phenomenon, while the third does. They both measure amplitude on the same time interval (1929-31-33-35-1937). However, the third cyclical measure is an average of the maximum average decline and maximum average rise of the four two-year intervals, while the fourth cyclical measure is an average of all four annual changes. Therefore, the fourth cyclical measure includes the (generally) weak decline from 1931 to 1933, as well as the weaker of the later two rises (1933-35 and 1935-37).

It is reasonable to conclude that the phenomenon suggested by the key industry hypothesis may actually be explained by other considerations. Not only does the phenomenon fail to occur at times, but its occurrence also appears conditioned by the degree of diffusion experienced during the cycle. The key industry phenomenon is dominated by another of greater generality. While it may be useful for some purposes to treat the region's cycle as being transmitted through export industries, there is no invariant pattern of repercussions between export and residentiary industries. In the absence of such a pattern, the distinction between the two types of industries for the purposes of business cycle analysis may be questioned.

The Regional Cycle and Long-Term Growth Patterns. A number of writers have interpreted the regional business cycle as part of the more general problem of regional development. However, they have come to no agreement on the role of the regional cycle and few have formulated specific hypotheses. Nevertheless, some of these writers have constructed systems of economic relations from which it is possible to formulate testable hypotheses.

R. L. Steiner is one of the few who have made an explicit statement on this problem:

"Because of conservative financial practice, a high propensity to save, a large body of unproductive consumers, and the desire for safe rather than speculative investment, the residentiary activity of declining areas will tend to be less sensitive to the cycle. Needless to say, such conservatism also hampers population growth." 32

In addition to Steiner, Burns has analyzed the long cycle in residential construction in terms of rates of population growth. ${ }^{33}$ The apparatus Burns uses sug-

\footnotetext{
32 Robert L. Steiner, "Discussion of Interregional Variations in Economic Fluctuations," American Economic Review, May, 1949, p. 133.

"Arthur F. Burns, "Long Cycles in Residential Construction," The Frontiers of Economic Knouledge, National Bureau of Economic Research, 1954.
} 
gests the following relations:

"In a region where the demand for capital goods is greater than the supply (at a price equal to Long-Run Marginal Cost), investment will occur. Contrast this with a region where the demand equals the supply at Long-Run Marginal Cost. In the latter region, investment is zero. A shock (a decline of overall demand) affecting both regions equally will result in a drop in the demand for capital in both regions. This yields a sharp decline in investment activities in the growing region; but no similar effect in the stationary region."

Although based on a different set of economic relations, this hypothesis is in agreement with Steiner's. Growing regions will evidence greater cyclical variability than declining regions.

An entirely contradictory hypothesis may be derived from still other writers on this subject. For example, Jerome, in his work on migration and cycles stated:

"The very fact of a known source of additional labor available through increased immigration in boom periods probably has lessened the pressure for regularization of industry. ${ }^{{ }^{34}}$

Writing on cycles of coke production, Mitchell observed

“... the output of beehive coke changed its behavior drastically when byproduct furnaces became the chief producers." 35

The change in behavior Mitchell noticed was a sharp increase in the cyclical amplitude of beehive coke production after the beehive facilities became too costly to bear the major share of coke production. In his earlier works, Mitchell frequently pointed to the reintroduction of older machinery and more costly facilities during the upswing of the cycle.

Putting these ideas together, the following possible relation emerges: Greater cyclical amplitudes will be associated with pools of unemployed labor, with high cost production facilities, and with the declining segments of an industry. To the extent that these characteristics may be identified with declining regions, they suggest greater cyclical variation in declining regions and smaller cyclical variation in growing regions. This hypothesis is directly contrary to the one we have derived from Steiner and Burns. It has not received enough attention to be identified with any individual writer. ${ }^{36}$

The concept of marginal production facilities can be applied to progressive and unprogressive firms in the same industry. Let us assume that a progressive firm actively installs new equipment which cuts the variable costs of producing a given rate of output. This will shift the average variable cost curve downward ${ }^{37} \mathrm{~A}$ short-run price drop (the result of business depression) which makes production unprofitable to the unprogressive firm will allow the progressive firm

3 Harry Jerome, Migration and Business Cycles, p. 244.

3 Wesley Mitchell, What Happens During Business Cycles, National Bureau of Economic Research, 1951, p. 20.

so As far as we know, the first specific recognition of such a relation is to be found in a study of the business cycle in Rhode Island and other New England states.

Merton P. Stoltz, "The Growth and Stability of the Rhode Island Economy," Part I, Competitive Position of the Rhode Island Economy, Brown University College-Community Research Program, Providence, R. I., 1955.

s7 Profitable innovations which do not raise fixed costs are likely to be adopted by both progressive and unprogressive firms since they require no net investment. We assume that most innovations reduce the variable cost component of output. 
to stay in business, and earn some portion of its fixed costs. If in a boom the price returns to its earlier high level, the unprogressive firm can resume production profitably. If a single region is dominated by a group of unprogressive firms, we can expect its local industries to experience wider cyclical fluctuations than their national counterparts.

The same pattern will occur if local cost conditions inhibit the growth of particular industries. If costs are too high to permit the existing firms to earn the going rate of profit in the industry, they may gradually wear out their fixed equipment without replacement. During the course of this long-run adjustment process, they will react to cyclical price declines in the same fashion as above, for their variable costs will not permit them to compete against firms in regions where cost factors are more favorable. When price returns to its previous level, they may re-open and continue in production until the long-run adjustment process is completed.

The statistical implication of this second hypothesis is a negative relation between overall cyclical variability and the long-term growth trend in a region: regions with the least growth would tend to be the most vulnerable to cyclical swings. This hypothesis is to be contrasted with the relationship expressly stated by Steiner and implicitly derived from an analysis of Burns. There are no a priori grounds on which the two hypotheses may be compared. The hypothesis derived from Steiner and Burns is concerned with the sensitivity of investment to national fluctuations and the conservatism of investors in declining areas. The other hypothesis is concerned with excess capacity in plant, equipment and the labor force, and with the cost structure of unprogressive firms and declining regions. I shall refer to the first hypothesis as a positive relation between growth and variability, and to the second hypothesis as a negative relation.

In testing these hypotheses a question arises whether to use the actual cyclical amplitude or to correct the amplitude for the influence of industry-mix. A strong case can be made for the latter procedure. The actual amplitude of a state reflects primarily the national cyclical impulses filtered through the industry-mix. It is not possible to determine whether amplitude is related to growth on the state level until this influence has been eliminated. The variability attributable to composition cannot, by definition, be influenced by local factors. ${ }^{38}$ On the other hand, the variability in excess of that attributable to composition arises from the interaction of the cyclical patterns of the industries of a given region. It is this interaction which should be investigated. Accordingly, we computed a net amplitude for each state which is the ratio of the actual to the hypothetical amplitude.

The net amplitudes are shown in Appendix Table 204. A net amplitude in excess of 100 means that the actual was greater than the hypothetical, and conversely for net amplitudes less than 100 . The number next to the net amplitude is the state's rank order in that cycle. The state with greatest net amplitude receives rank number one and so on.

The analysis of the growth-amplitude relation has been carried out for a

ss It is true of course that state growth is also affected by composition, so that the growth and variability of a state may both be functions of its composition. This problem is treated below. 
large number of possible measures of the growth trend. In the following table we have indicated the time intervals over which trend measures were computed. The table also indicates whether these intervals preceded, coincided with, or followed particular cycles. In addition to short-time intervals, an average growth trend is computed for the entire period 1909 to 1953. In all but one case, trends are computed as peak-to-peak ratios, the later peak being the numerator. In one instance, the trend was computed as a trough-to-trough ratio (see Section 2, above). No post-cycle trend was computed for the 19291937 cycle because of the strong likelihood that the trend which accompanied the wartime expansion would not be influenced by events before 1937 .

We also experimented with another trend measure: the ratio of the cycle bases of successive cycles. However, this measure yielded state growth rankings which were almost identical with these computed under the initial procedure. Therefore, they were not incorporated into the analysis.

TIME INTERVALS FOR WHICH TREND MEASURES ARE COMPUTED

\begin{tabular}{l|l|l|l}
\hline \hline \multicolumn{1}{c|}{ Cycle Dates } & \multicolumn{1}{|c|}{ Pre-Cycle } & \multicolumn{1}{|c}{ Intra-Cycle } & \multicolumn{1}{|c}{ Post-Cycle } \\
\cline { 2 - 3 } $1914-1919-1921$ & $1904-14$ & $1909-19,1919-23$ & $1919-29$ \\
$1919-1921-1923$ & $1904-14,1909-19$ & $1919-23$ & $1919-29$ \\
$1929-1937$ & $1919-29$ & $1929-37$ & \\
$1948-1953$ & $1929,37,1937-47$ & $1948-53$ & \\
\hline
\end{tabular}

To produce Table 110 below, the states were classified into strongly growing and weakly growing groups, each group containing eleven states. The table shows the group mean rank of actual amplitude and net amplitude for each growth group. Next to the cycle period in the stub of the table can be seen the time intervals over which the trends have been computed.

Because the sample contains 33 states, the mean amplitude rank for the sample is 17. If a group mean rank is less than 17, the group is more variable than average; conversely if the group mean is more than 17 .

The table does not include results for two cyclical measures: the average cyclical change 1929-1937, and the average amplitude 1948-1951. These yield growth-variability patterns identical with those produced by the other cyclical measures over the same time intervals.

Examination of the table yields the following conclusions:

1. Over the entire period, the strongly growing states were on the average more variable (in actual amplitude) than the weakly growing states. There are only four contradictory cases out of the 17 observed, one in the 1914-19-21 cycle, one in the 1929-37 cycle, and two in the 1948-53 cycle.

2. Over the entire period, the strongly growing states, on the average, experienced greater net amplitude than the weakly growing states. However, exceptions to this average pattern are much more numerous, occurring twice in the first cycle (1914-19-21), once in the third (1929-37), and three times in the fourth (1948-53). In fact, the fourth cycle (1948-53) contradicts this pattern entirely. For this cycle, the strongly growing states show less or the same net 
TABLE 184. RELATION BETWEEN GROWTH AND AMPLITUDE

\begin{tabular}{|c|c|c|c|c|c|}
\hline \multirow{3}{*}{ Cycle Period } & \multirow{3}{*}{ Trend Period } & \multicolumn{4}{|c|}{ Mean Ranks } \\
\hline & & \multicolumn{2}{|c|}{ Actual Amplitude } & \multicolumn{2}{|c|}{ Net Amplitude } \\
\hline & & $\begin{array}{l}\text { Strongly } \\
\text { Growing } \\
\text { States }\end{array}$ & $\begin{array}{l}\text { Weakly } \\
\text { Growing } \\
\text { States }\end{array}$ & $\begin{array}{c}\text { Strongly } \\
\text { Growing } \\
\text { States }\end{array}$ & $\begin{array}{c}\text { Weakly } \\
\text { Growing } \\
\text { States }\end{array}$ \\
\hline 1914-1919-1921 & $\begin{array}{l}\text { 1. } 1909-1953 \\
\text { 2. } 1904-1914 \\
\text { 3. } 1909-1919 \\
\text { 4. } 1919-1923 \\
\text { 5. } 1919-1929\end{array}$ & $\begin{array}{r}16 \\
13 \\
7 \\
18 \\
17\end{array}$ & $\begin{array}{l}21 \\
24 \\
25 \\
16 \\
19\end{array}$ & $\begin{array}{l}17 \\
15 \\
14 \\
18 \\
18\end{array}$ & $\begin{array}{l}17 \\
21 \\
20 \\
14 \\
16\end{array}$ \\
\hline 1919-1921-1923 & $\begin{array}{r}\text { 6. } 1909-1953 \\
\text { 7. } 1904-1914 \\
\text { 8. } 1909-1919 \\
\text { 9. } 1919-1923 \\
\text { 10. } 1919-1929\end{array}$ & $\begin{array}{l}14 \\
15 \\
11 \\
14 \\
15\end{array}$ & $\begin{array}{l}22 \\
21 \\
22 \\
19 \\
22\end{array}$ & $\begin{array}{l}14 \\
16 \\
17 \\
13 \\
13 \\
15\end{array}$ & $\begin{array}{l}22 \\
19 \\
19 \\
17 \\
21\end{array}$ \\
\hline $\begin{array}{l}\text { 1929-1937 } \\
\quad \text { (maximum change) }\end{array}$ & $\begin{array}{l}\text { 11. } 1909-1953 \\
\text { 12. } 1919-1929 \\
\text { 13. } 1929-1937\end{array}$ & $\begin{array}{l}14 \\
15 \\
20\end{array}$ & $\begin{array}{l}19 \\
19 \\
15\end{array}$ & $\begin{array}{l}13 \\
14 \\
19\end{array}$ & $\begin{array}{l}19 \\
18 \\
14\end{array}$ \\
\hline 1948-1953 & $\begin{array}{l}\text { 14. } 1909-1953 \\
\text { 15. } 1929-1937 \\
\text { 16. } 1937-1947 \\
\text { 17. } 1948-1953\end{array}$ & $\begin{array}{l}17 \\
17 \\
17 \\
16\end{array}$ & $\begin{array}{l}15 \\
19 \\
15 \\
17\end{array}$ & $\begin{array}{l}18 \\
17 \\
18 \\
21\end{array}$ & $\begin{array}{l}10 \\
17 \\
15 \\
13\end{array}$ \\
\hline
\end{tabular}

amplitude than the weakly growing for all the trend measures computed.

3 . The strength of the relation between strong growth and high net amplitude appears to vary with the interval over which the trend is computed. For a number of cycles a positive relation for pre-cycle intervals can frequently be discerned, but this weakens and sometimes becomes a negative relation for post-cycle intervals.

The above table raises three interesting questions:

1. To what extent is the relation between growth and actual amplitude a consequence of industry-mix?

2. To what extent does the apparently different behavior of the fourth (1948-53) cycle represent the influence of industry-mix?

3. To what extent is there a net amplitude-retardation relation? That is, to what extent is high net amplitude seen in states which had high relative growth before the cycle and low relative growth during or after the cycle?

An answer to the first question is provided in Table 185. It shows the group mean hypothetical amplitude for rapidly and slowly growing states. A mean hypothetical amplitude is computed in each trend interval and each cycle for which actual and net amplitudes are shown in the preceding table. As one would expect, the actual mean amplitudes strongly reflect the influence of industrial composition. Only in two out of seventeen instances do the mean 
TABLE 185. RELATION BETWEEN GROWTH AND HYPOTHETICAL AMPLITUDE

\begin{tabular}{|c|c|c|c|}
\hline \multicolumn{4}{|c|}{ Mean Rank } \\
\hline \multirow[b]{2}{*}{ Cycle Period } & \multirow[b]{2}{*}{ Trend Period } & \multicolumn{2}{|c|}{ Hypothetical Amplitude } \\
\hline & & $\begin{array}{l}\text { Strongly Grow- } \\
\text { ing States }\end{array}$ & $\begin{array}{l}\text { Weakly Grow- } \\
\text { ing States }\end{array}$ \\
\hline 1914-1919-1921 & $\begin{array}{l}\text { 1. } 1909-1953 \\
\text { 2. } 1904-1914 \\
\text { 3. } 1909-1919 \\
\text { 4. } 1919-1923 \\
\text { 5. } 1919-1929\end{array}$ & $\begin{array}{r}15 \\
11 \\
7 \\
17 \\
16\end{array}$ & $\begin{array}{l}23 \\
24 \\
25 \\
18 \\
20\end{array}$ \\
\hline $1919-1921-1923$ & $\begin{array}{r}\text { 6. } 1909-1953 \\
\text { 7. } 1904-1914 \\
\text { 8. } 1909-1919 \\
\text { 9. } 1919-1923 \\
\text { 10. } 1919-1929\end{array}$ & $\begin{array}{r}15 \\
11 \\
8 \\
16 \\
16\end{array}$ & $\begin{array}{l}21 \\
22 \\
25 \\
20 \\
21\end{array}$ \\
\hline 1929-1937 (maximum change) & $\begin{array}{l}\text { 11. } 1909-1953 \\
\text { 12. } 1919-1929 \\
\text { 13. } 1929-1937\end{array}$ & $\begin{array}{l}17 \\
18 \\
19\end{array}$ & $\begin{array}{l}18 \\
19 \\
17\end{array}$ \\
\hline $1948-1953$ & $\begin{array}{l}\text { 14. } 1909-1953 \\
\text { 15. } 1929-1937 \\
\text { 16. } 1937-1947 \\
\text { 17. } 1948-1953\end{array}$ & $\begin{array}{l}16 \\
18 \\
17 \\
12\end{array}$ & $\begin{array}{l}21 \\
20 \\
16 \\
20\end{array}$ \\
\hline
\end{tabular}

hypothetical amplitudes show an order which is the reverse of the mean actual amplitudes. These occur in Cycle 1 (1914-19-21) for trend period 1919-1923 and in Cycle 4 (1948-53) for trend period 1909-1953.

Thus we can assert quite confidently that industry-mix plays an important role in explaining the positive relation between growth and actual amplitude. The rapidly growing states contained industries with higher national amplitude than the weakly growing states. However, industry-mix does not account entirely for the state growth patterns. Therefore, it is not correct to conclude that industry-mix accounts entirely for this positive relation. Many states in the rapidly growing group were not heavily dependent on industries with the most rapid national growth rates. This would be true of California, Texas, Tennessee, North Carolina, Alabama, Georgia, Oregon and Kentucky. ${ }^{39}$ It is doubtless true that these states contained industries with greater national variability than the weakly growing group. Nevertheless, the use of industrymix leads to the prediction that a different group of states is growing most rapidly.

This proposition was confirmed by the partial failure to reproduce the

\footnotetext{
80 In the period 1909 to 1953 the most rapidly growing national industries were Electrical Machinery, Petroleum, Transportation, Rubber, Primary Metals, Chemicals, Paper, Food, Fabricated Metals and Non-Electrical Machinery. The most rapidly growing states mentioned above are not hesvily dependent on this group.
} 
growth rankings of the states from the hypothetical employment indexes. For the period 1919-23, the rank correlation between actual and hypothetical growth is +.35 . For the period 1929-37, the correlation is +.16 . For the period 1948-53, this rank correlation is +.56 . These are the only intervals for which the data are in a form to permit this calculation. It is clear that while the first and third coefficients are significant, the second is not. In the first interval (1919-23) it was possible to predict on the basis of composition 6 of the 11 states with most and 5 of the 11 states with least growth; for the period (192937 ) it was possible to predict only 2 of the 11 states with most growth, and 5 of the 11 with least growth. In the third interval (1948-53) it was possible to predict 5 of 11 for the group with most growth and 6 of 11 for the group with least growth. In the absence of uniformly high correlations we can conclude that industry-mix does not account entirely for the observed growth patterns, and therefore does not account entirely for the observed positive relation between growth and actual amplitude.

The apparently different behavior of the 1948-53 cycle has been noted in a number of places in this study. In order to discuss its implications for the growth-net amplitude relation, I shall review the characteristics of this cycle which distinguish it from its predecessors.

1. The actual amplitude of the 1948-53 cycle was about one-half that of its predecessors. The average decline rate for the 1948-53 cycle was also about one-half of previous decline rates.

2. The variance of amplitudes of the 1948-53 cycle was about one-fifth that of its predecessors.

3. The decline rates and expansion rates are negatively correlated for the 1948-53 cycle and positively correlated for its predecessors.

4. The correlation between actual and hypothetical amplitudes is +.36 for the $1948-53$ cycle and about +.80 for its predecessors.

5 . There is a negative correlation between composition and net differences in cyclical variability between local and national industries for the 1948-53 cycle, and a positive correlation for its predecessors. That is, for the 1948-53 cycle, the states with industries of large national amplitude had less amplitude than predicted by composition and conversely for states with industries of small national amplitude. This is reversed for the earlier cycles.

We have argued in previous sections that the phenomena noted under 2,4 and 5 were attributable to the smaller average amplitude, smaller average cyclical decline and smaller variance of amplitudes in the 1948-53 cycle. These are responsible for the apparent influence of trend differences in 3 and the importance of intra-industry behavior differences in 4 and 5 .

The question now arises: What of the negative relation between growth and net amplitude observed for this cycle? Is this also the result of the above characteristics, or to their interplay with industrial composition? It is possible to regard the results for the 1948-53 cycle as the consequence of such forces. That is, the negative relation between growth and net amplitude might be generated by the combination of the following circumstances:

(a) The most variable national industries have the highest growth rates.

(b) States containing the most variable industries are less variable than 
composition predicts; states containing the least variable industries are more variable than composition predicts. The key industry relation is absent.

(c) State growth trends depend upon composition.

These conditions are satisfied for the 1948-53 cycle. For the 19 industries, there is a positive rank correlation of +.62 between amplitude and growth; therefore, condition (a) is satisfied. We saw previously that for this cycle conditions (b) and (c) were satisfied. A further check is provided by testing the growth-net variability relation against the growth ranking predicted by composition. This yields an average net amplitude rank of 22 for the group with rapid growth and of 10 for the group with weak growth. We conclude that the negative relation between growth and net amplitude found for the 1948-53 cycle is a statistical accident, as it were, compounded of the forces mentioned

TABLE 187. RANK CORRELATION BETWEEN GROWTH TREND AND CYCLICAL AMPLITUDE FOR 19 INDUSTRIES

\begin{tabular}{c|c|c|c|c}
\hline \hline & \multicolumn{3}{|c}{ Cycle Interval } \\
\cline { 2 - 5 } Trend Intervals & $1914-1919-1921$ & $1919-1921-1923$ & $1929-1937$ & $1948-1953$ \\
\hline $1919-1923$ & -0.44 & -0.24 & & \\
$1919-1929$ & -0.14 & -0.08 & +0.11 & \\
$1929-1937$ & & & -0.20 & -0.12 \\
$1937-1947$ & & & +0.56 \\
$1948-1953$ & & & & +0.62 \\
\hline
\end{tabular}

above. It is more difficult to determine whether the other findings of both negative and positive relations are also accidents without better knowledge of the influence of composition on growth. Certainly for the 1929-37 cycle such an accident is impossible in view of the almost zero correlation between hypothetical and actual growth. Some evidence on this question is given in Table 187. It shows the rank correlations between amplitude and growth trend for 19 industries. Only in the 1948-53 cycle and the 1914-19-21 cycle do the correlations appear large enough to generate an accidental growth-net amplitude relation among the states. ${ }^{40}$ However, an examination of the 1914-19-21 cycle makes it clear that this was not the case for that cycle. If the states are ranked by hypothetical growth for the 1919-23 period, the net amplitude relations do not duplicate the observed negative relation between growth and net amplitude. The group with the greatest hypothetical growth has a mean net amplitude rank of 15, while the group with least hypothetical growth has a mean rank of 17. Thus, if a statistical accident has occurred, it can only be recognized for the 1948-53 cycle. For the other cycles, the observed relations between growth and net amplitude both positive and negative are independent of the industrial composition of the states and of any possible interaction between composition and growth.

40 In the 1914-19-21 cycle, there was a positive correlation between composition and intra-industry differences in cyclical amplitude. In order that the negative relation between growth and net amplitude be an accident, it is therefore necessary that condition (a) be reversed. That is, the most variable industries must have the least growth. While these conditions are satisfied, it is clear from the discussion that the correlations are too small to have produced an accidental result. 
The behavior of net amplitudes in Table 184 suggests the existence of a retardation relation between net amplitude and growth. It appears that states with greater net amplitude had higher relative growth rates prior to the cycle than they experienced during or after the cycle. The sequence of events is: high growth rank, high net amplitude rank; lower growth rank. The evidence is presented in Table 188. In the stub, next to each cycle period, are shown the time intervals over which retardation is measured. The intervals are keyed to Table 184. Retardation is measured by comparing a state's growth rank in each period. A state which moved from growth rank 1 to rank 10 , or growth rank 20 to rank 30 has retarded, while a state which has moved

TABLE 188. RELATION BETWEEN RETARDATION AND AMPLITUDE

\begin{tabular}{|c|c|c|c|c|c|}
\hline \multicolumn{6}{|c|}{ Average Ranks } \\
\hline \multirow[b]{2}{*}{ Cycle Period } & \multirow[b]{2}{*}{ Retardation Intervals } & \multicolumn{2}{|c|}{ Actual Amplitude } & \multicolumn{2}{|c|}{ Net Amplitude } \\
\hline & & $\begin{array}{l}\text { Acceler- } \\
\text { ating } \\
\text { States. }\end{array}$ & $\begin{array}{c}\text { Retarding } \\
\text { States }\end{array}$ & $\begin{array}{l}\text { Acceler- } \\
\text { ating } \\
\text { States }\end{array}$ & $\begin{array}{c}\text { Retarding } \\
\text { States }\end{array}$ \\
\hline $1914-1919-1921$ & $\begin{array}{l}1904-14 ; 1919-23 \\
1904-14 ; 1919-29 \\
1909-19 ; 1919-23 \\
1909-19 ; 1919-29\end{array}$ & $\begin{array}{l}23 \\
20 \\
24 \\
22\end{array}$ & $\begin{array}{r}11 \\
12 \\
9 \\
11\end{array}$ & $\begin{array}{l}21 \\
19 \\
19 \\
18\end{array}$ & $\begin{array}{l}13 \\
13 \\
14 \\
12\end{array}$ \\
\hline $1919-1921-1923$ & $\begin{array}{l}1904-14 ; 1919-23 \\
1904-14 ; 1919-29 \\
1909-19 ; 1919-23 \\
1909-19 ; 1919-29\end{array}$ & $\begin{array}{l}18 \\
16 \\
18 \\
17\end{array}$ & $\begin{array}{l}14 \\
15 \\
15 \\
15\end{array}$ & $\begin{array}{l}17 \\
16 \\
14 \\
13\end{array}$ & $\begin{array}{l}15 \\
15 \\
18 \\
15\end{array}$ \\
\hline $1929-1937$ & $1919-29 ; 1929-37$ & 22 & 15 & 25 & 14 \\
\hline $1948-1953$ & $\begin{array}{l}1929-37 ; 1948-53 \\
1937-47 ; 1948-53\end{array}$ & $\begin{array}{l}18 \\
14\end{array}$ & $\begin{array}{l}16 \\
19\end{array}$ & $\begin{array}{l}21 \\
19\end{array}$ & $\begin{array}{l}15 \\
16\end{array}$ \\
\hline
\end{tabular}

from growth rank 10 to rank 1 has accelerated. The accelerating states are those which have moved up the most in growth rank, while the retarding states have moved down the most. A state can retard and still have a higher numerical growth rate in the second period. There is no contradiction in this, as retarding simply means growing more slowly relative to the rest of the states. The retardation ranks for each state are shown in Appendix Table 205.

The table indicates quite clearly a relation between retardation and net amplitude. In 9 of 11 cases the retarding states have higher average net amplitude than the accelerating states. There is evidence of a relation between retardation and actual amplitude as well, occurring in 10 out of 11 cases.

Before inquiring into the economic implications of the relation between retardation and amplitude, it is well to ask whether its appearance may be a statistical accident, and if not, what is its statistical significance. There is even less evidence on this than in the prior case. Only for the 1948-1953 cycle is it possible to inquire whether the retardation-net amplitude relation could result 
from composition. The phenomenon would occur as an accident in the 19481953 cycle if the following conditions were satisfied:

(a) The most variable national industries accelerated in growth during or after the cycle relative to growth before the cycle.

(b) States containing the most variable industries had less variability than predicted by composition; conversely for states containing the least variable industries.

(c) State retardation patterns depend upon composition. Concerning (a):

The most variable industries in the 1948-53 cycle did accelerate in growth between 1929-37 and 1948-53. The rank correlation between amplitude and acceleration is +.60 . However, they did not accelerate between 1937-47 and 1948-53. The rank correlation between amplitude and acceleration is only +.06 . Therefore, Condition (a) is met incompletely. We have seen previously that Condition (b) is met for this cycle, and it also appears that state retardation patterns do depend partly on composition. The hypothetical growth rates between 1929 and 1937 and between 1948 and 1953 were used to construct hypothetical state retardation patterns. The hypothetical retardation pattern allowed successful prediction of 6 out of the 11 accelerating states and 4 out of 11 retarding states. Further, the rank correlation between the hypothetical and actual state retardation pattern for these intervals is +0.38 .

A final check is provided by testing the retardation-net amplitude relation against the acceleration and retardation ranks predicted by composition. This yields an average net amplitude rank of 15 for both the accelerating group and the retarding group. Thus, it appears that composition cannot generate the observed phenomena. Although of the right sign, the above correlations are too small to permit us to write the findings off as statistical accident.

There is no information on earlier hypothetical state retardation to judge whether the findings for the other cycles are or are not accidental. The correlation between amplitude and acceleration for 19 industries during the 1929-1937 cycle is of the right sign to produce an accident. Observing industrial retardation over the periods $1919-29$ and $1929-37$, the rank correlation is $-.24 .{ }^{41} \mathrm{How}-$ ever, in the light of the previous case, the magnitude of this correlation would appear too small to generate the expected result.

-We conclude that the relation between retardation and net amplitude must be accepted as the behavior of the states when corrected for effects of composition. These findings cannot be generated by other characteristics of the states. The relation must be accepted and interpreted in the light of the economic hypotheses presented earlier.

The rank correlations between net amplitude and acceleration are negative in 9 out of 11 cases, indicating that high net amplitude is associated with retardation of the relative growth position of the state. Most of them are too small in magnitude to be considered statistically significant. As shown in Table 190 , the correlations range from +0.08 to -0.44 . The significant coefficients appear in the first and third cycles; they are $-0.38,-0.36$, and -0.44 .

1 This correlation must be negative to produce an accidental result because the key industry effect was operative in this cycle. That is, states containing highly variable industries had greater amplitude than conposition predicted, and conversely for states containing stable industries. 
Interpretation of Statistical Findings. One major conclusion emerges from the previous analysis:

In almost all cases the states which accelerated in growth had less cyclical amplitude than composition would suggest, while the states which retarded in growth had more cyclical amplitude than composition would suggest.

What is the economic significance of this conclusion, and how does it relate to the conflicting hypotheses about growth and amplitude suggested earlier? It will be recalled that the first hypothesis suggested that rapidly growing regions would be more variable than weakly growing, while the second suggested they would be less variable than weakly growing.

Although it may seem paradoxical, the statistical findings appear to support the second hypothesis. Even though there is evidence of a positive relation be-

TABLE 190. RANK CORRELATION BETWEEN NET AMPLITUDE AND ACCELERATION OF GROWTH FOR 33 STATES

\begin{tabular}{|c|c|c|c|c|}
\hline \multirow{2}{*}{ Time Intervals } & \multicolumn{4}{|c|}{ Cycle } \\
\hline & $1914-19-21$ & $1919-21-23$ & $1929-37$ & $1948-53$ \\
\hline $\begin{array}{l}1904-14 ; 1919-23 \\
1904-14 ; 1919-29 \\
1909-19 ; 1919-23 \\
1909-19 ; 1919-29 \\
1919-29 ; 1929-37 \\
1929-37 ; 1948-53 \\
1937-47 ; 1948-53\end{array}$ & $\begin{array}{l}-.38 \\
-.36 \\
-.28 \\
-.29\end{array}$ & $\begin{array}{l}-.07 \\
-.06 \\
+.10 \\
+.08\end{array}$ & -.44 & $\begin{array}{l} \\
-.21 \\
-.21\end{array}$ \\
\hline
\end{tabular}

tween growth and net variability, this relation tends to fade out for post-cycle trend periods. As noted previously, the positive relation holds for pre-cycle trends, and then weakens, frequently becoming a negative relation. Indeed, it is this shift which generates the relation between retardation and net amplitude.

There is no way of reconciling the appearance of a retardation-net amplitude relation with the analysis underlying the first hypothesis. Growing states were supposed to be more variable than declining because:

1. Conservative financial practices and high marginal propensity to save in declining regions make residentiary activities less sensitive to the cycle.

2. The declining demand for capital in all regions during a cyclical decline has most impact on the regions where investment had been the greatest.

There is nothing in these relations to suggest that growing states should retard after experiencing a cycle. Why shouldn't the growth pattern continue undisturbed after the cycle is terminated?

On the other hand, the second hypothesis does provide a set of constructs which enable us to interpret sensibly the retardation-net amplitude relation. If retardation were to replace absolutely low growth in the original assumption underlying the second hypothesis, it would still be consistent with some of the major implications. For retardation may be regarded as a change in the growth trend. States which retard have lower relative growth rates than previ- 
ously. This may be indicative of the appearance of unprogressive firms, high cost production facilities and local cost characteristics which inhibit growth at the old relative rate. These conditions will cause industries in the region to have sharper cyclical amplitudes than their national counterparts. Conversely, acceleration may indicate the appearance of cost characteristics which stimulate growth. Under this argument the characteristics which change the growth ranking will also change the cyclical behavior of the affected states.

It is worth noting that the retardation-net amplitude relation bears a strong degree of similarity to findings by Arthur F. Burns. ${ }^{42}$ Burns said,

"We may therefore conclude from our analysis of American experience since 1870; first that periods of sharp advance in the trend of general production, which are characterized invariably by considerable difference in production trends, have been followed invariably by severe business depressions; second that most of the business depressions of marked severity have been preceded by a sharp advance in the trend of general production and considerable divergence in the trends of individual industries."

Burns recognized that this evidence gave limited support to the old notion that the severity of a business depression is associated with the intensity of the period of expansion preceding it. ${ }^{43}$ However, he was dealing with trend cycles and pointed out that his data could not provide a thorough test of the notion.

The same warning must be attached to the findings of this study. It would be a mistake to use the retardation-net amplitude relation in support of such a hypothesis. Retardation does not imply strong pre-cycle growth as such; only that the post-cycle growth rank is lower than the pre-cycle growth rank. It is true that the retardation-net amplitude relation appears strongest where there is strong pre-cycle growth among the most variable states. Nevertheless, the relation also appears where the most variable states have weak pre-cycle growth (e.g., the 1948-53 cycle). It may be contended that strong expansions imply strong declines, but there is no confirmation of it in these findings.

In conclusion, the retardation-net amplitude relation among states suggests that a change in state growth trends alters the cyclical behavior of state industries relative to their national counterparts. When the state loses its growth position, its industrial components evidence stronger cyclical amplitudes. This is a fruitful hypothesis to test against data on later state cycles.

\section{APPENDIX A: THE HOMOGENEITY OF RANK CORRELATIONS}

The test of homogeneity of rank correlations is derived from the following test on unranked numbers. Ordinarily if we have $m$ sets of $n$ observations on $X, Y$, the individual correlation coefficient of the $i$ th set is:

$$
r_{i}=\sigma_{X_{i} Y_{i}} / \sigma_{X_{i}} \sigma_{Y}
$$

The pooled correlation coefficient is:

12 Arthur F. Burns, Production Trends in the U. S. Since 1870, National Bureau of Economic Research, New York, 1934, p. 251 .

is In later work by Burns and Mitchell, this hypothesis is tested and found not significant. See Measurino Business Cycles, op. cit., p. 428-31. 


$$
r=\frac{\sum_{i}^{m} \sum_{j}^{n} X_{i j} Y_{i j}-m n \bar{X} \bar{Y}}{\sqrt{\left(\sum_{i}^{m} \sum_{j}^{n} X_{i j}{ }^{2}-m n \bar{X}^{2}\right)\left(\sum_{i}^{m} \sum_{j}^{n} Y_{i j}{ }^{2}-m n \bar{Y}^{2}\right)}}=\frac{m n \sigma_{X Y}}{m n \sigma_{X} \sigma_{Y}}
$$

The test on the homogeneity of the individual coefficients is performed by comparing the following two expressions to see whether the use of additional ciegrees of freedom to estimate the $r_{i}$ produces a significant reduction in the error sums of squares:

\section{Error Sum of Squares}
(1) individual correlations: $\sum_{i}^{m} n \sigma_{Y_{i}}{ }^{2}\left(1-r_{i}{ }^{2}\right)$
(2) pooled correlations: $m n \sigma_{Y}{ }^{2}\left(1-r^{2}\right)$

With ranked numbers and equal numbers of observations in each set, the variance of $X$ and $Y$ are equal to each other in each set and the mean of $X$ and $Y$ are equal to each other in each set.

$$
\sigma^{2}=\frac{1}{12}\left(n^{2}-1\right) ; \quad \bar{X}=\frac{n+1}{2} .
$$

This means that

$$
m n \sigma_{Y}{ }^{2}=\sum_{i}^{m} \sum_{j}^{n} Y_{i j}{ }^{2}-m n \bar{Y}^{2}=m n \sigma^{2}
$$

Further

$$
m n \sigma_{X Y}=\sum_{i}^{m} \sum_{j}^{n} X_{i j} Y_{i j}-m n \bar{X} \bar{Y}=\sum_{i}^{m} n \sigma_{Y_{i} X_{i}}
$$

The pooled

$$
r=\sum_{i=1}^{m} n_{\sigma_{Y_{i} X_{i}}} / m n \sigma^{2}
$$

The individual

$$
r_{i}=\sigma_{Y_{i} X_{i}} / \sigma^{2}
$$

Therefore,

$$
r=\frac{\sum_{i}^{m} n \sigma^{2} r_{i}}{m n \sigma^{2}}=\frac{\sum_{i}^{m} r_{i}}{m}
$$

The error sums of squares reduce as follows:

(1) individual correlations 


$$
\sum_{i}^{m} n \sigma_{Y_{i}}{ }^{2}\left(1-r_{i}{ }^{2}\right)=m n \sigma^{2}\left(1-\frac{\sum_{i=1}^{m} r_{i}{ }^{2}}{m}\right)
$$

(2) pooled correlations

$$
m n \sigma^{2}\left(1-r^{2}\right)=m n \sigma^{2}\left[1-\left(\frac{\sum^{m} r_{i}}{m}\right)^{2}\right]
$$

It was stated in section 3 that the following rank correlation coefficients are not homogeneous:

$$
\begin{aligned}
& +.7989 \\
& +.7726 \\
& +.7538 \\
& +.3371 \\
& +.7971 \\
& +.4796 \\
& \sum r_{i}{ }^{2} / m=.4638 ; \quad\left(\frac{\sum r_{i}}{m}\right)^{2}=.4310 \quad r=.6565
\end{aligned}
$$

with $n=33, \sigma^{2}=90.67$. With $m=6, m n \sigma^{2}=17,952$.

The error sums of squares are as follows:

$$
\begin{aligned}
& \text { pooled: } \\
& 17,952(1-.4310)=10,214.69 \\
& \text { individual: } \\
& 17,952(1-.4638)=9,625.86 \\
& 588.83
\end{aligned}
$$

The pooled correlation uses 1 degree of freedom ( 1 covariance), leaving $m(n-1)$ -1 or 191 degrees of freedom. The individual correlations use up 6 degrees of freedom (1 covariance per column), leaving 186.

\begin{tabular}{l|c|c|c}
\hline \hline & $\begin{array}{c}\text { Error Sum of } \\
\text { Squares }\end{array}$ & d. of f. & Mean .Square \\
\hline Pooled Correlation & $\begin{array}{r}10,214.69 \\
9,625.86\end{array}$ & 191 & 53.48 \\
Individual Correlations & 186 & 51.75 \\
\cline { 2 - 4 } & 588.83 & 5 & 117.77 \\
\hline
\end{tabular}

$F=2.28$, significant at the 5 per cent level.

Therefore, pooling is not permissible, as the rank correlation coefficients are not homogeneous. The individual 'correlations reduce the error variance by a significant amount over the reduction ascribed to the pooled regression.

On the other hand, the first four correlation coefficients are homogeneous. We have

$$
\sum r_{i}{ }^{2} / m=.6097 \quad\left(\frac{\sum r_{i}}{m}\right)^{2}=.6093 \quad r=.7806
$$

With $n=33, m=4, m n \sigma^{2}=11,968$. 
The error sums of squares are as follows:

$$
\begin{array}{ll}
\text { pooled: } & 11,968(1-.6093)=4,675.90 \\
\text { individual: } & 11,968(1-.6097)=4,671.11
\end{array}
$$

\begin{tabular}{l|c|c|c}
\hline \hline & Error S. S. & d. of f. & Mean Square \\
\cline { 2 - 4 } Pooled correlation & $4,675.90$ & 127 & 36.82 \\
Individual correlations & $4,671.11$ & 124 & 37.67 \\
\hline
\end{tabular}

There is no reduction in the mean square error of the pooled correlation. Obviously, the individual correlations do not reduce the error sum of squares significantly.

\author{
APPENDIX B: BASIC TABLES
}

TABLE 194. MANUFACTURING PRODUCTION WORKERS AND MANU-

\begin{tabular}{|c|c|c|c|c|c|c|c|c|}
\hline & \multicolumn{8}{|c|}{ Manufacturing Production Workers } \\
\hline & 1904 & 1909 & 1914 & 1919 & 1921 & 1923 & 1929 & 1931 \\
\hline Maine & 73.4 & 78.3 & 80.2 & 86.2 & 73.4 & 81.1 & 68.8 & 66.0 \\
\hline New Hampshire & 64.1 & 77.1 & 77.4 & 81.9 & 66.5 & 74.1 & 65.2 & 52.8 \\
\hline Vermont & 31.7 & 32.3 & 31.3 & 31.5 & 24.6 & 29.6 & 26.5 & 17.9 \\
\hline Massachusetts & 479.4 & 573.8 & 595.2 & 700.0 & 568.0 & 653.9 & 648.2 & 427.1 \\
\hline Rhode Island & 96.2 & 112.3 & 112.0 & 138.1 & 111.1 & 132.6 & 125.3 & 95.4 \\
\hline Connecticut & 178.4 & 207.0 & 222.2 & 287.3 & 206.2 & 257.3 & 250.7 & 191.2 \\
\hline New York & 828.3 & 970.4 & $1,018.3$ & $1,177.4$ & 963.5 & $1,103.5$ & $1,065.3$ & 814.0 \\
\hline New Jersey & 259.0 & 317.3 & 362.6 & 493.3 & 370.3 & 434.0 & 432.7 & 326.5 \\
\hline Pennsylyania & 713.3 & 820.0 & 862.4 & $1,044.4$ & $801: 0$ & $1,017.1$ & 955.2 & 728.0 \\
\hline Ohio & 347.2 & 426.0 & 486.3 & 691.0 & 467.3. & 661.1 & 713.5 & 485.5 \\
\hline Indiana & 141.0 & 171.1 & 180.5 & 250.7 & 188.1 & 265.3 & 297.4 & 200.2 \\
\hline Illinois & 353.8 & 434.3 & 474.8 & 602.2 & 473.5 & 598.8 & 654.2 & 456.1 \\
\hline Michigan & 169.4 & 223.8 & 261.9 & 459.0 & 295.3 & 491.1 & 518.7 & 362.9 \\
\hline Wisconsin & 143.1 & 172.6 & 183.6 & 247.8 & 178.7 & 234.0 & 253.9 & 176.5 \\
\hline Minnesota & 60.6 & 73.8 & 80.4 & 96.7 & 71.6 & 87.0 & 91.2 & 70.6 \\
\hline Iowa & 42.3 & 52.7 & 63.8 & 64.6 & 50.1 & 62.8 & 70.8 & 53.5 \\
\hline Miesouri & 122.6 & 140.8 & 140.0 & 177.8 & 142.8 & 182.0 & 100.6 & 146.6 \\
\hline
\end{tabular}
FACTURING EMPLOYEES IN 33 STATES FOR SELECTED YEARS FROM 1904 TO $1953^{\mathrm{a}}$

(in thousands)

- Data for 1948-53 are 12-month moving averages eñding peak or trough date. Data are Employees in Manu facturing. Data for prior years are annual average production workers in manufacturing. Census data for years prior to 1935 have been adjusted for comparability with later years by the exclusion of production workers in "Railroad repair shops" and in "Manufactured gas." These are the most important items which were excluded from 1938 and later censuses. 
TABIE 194 (continued)

\begin{tabular}{|c|c|c|c|c|c|c|c|c|c|}
\hline & \multicolumn{5}{|c|}{ Manufacturing Production Workers } & \multicolumn{4}{|c|}{ Manufacturing Employees } \\
\hline & 1933 & 1935 & 1937 & 1939 & 1947 & 1948 & 1949 & 1951 & 1953 \\
\hline Maine & 58.8 & 68.6 & 75.5 & 74.0 & 90.4 & 114.6 & 103.0 & 115.1 & 117.1 \\
\hline N. H. & 49.1 & 53.8 & 56.5 & 55.4 & 66.4 & 83.3 & 74.0 & 82.6 & 82.8 \\
\hline Vt. & 14.4 & 18.9 & 23.7 & 20.5 & 30.2 & 38.2 & 34.0 & 38.7 & 40.5 \\
\hline Mass. & 392.7 & 437.5 & 496.0 & 458.4 & 601.6 & 727.9 & 671.2 & 738.1 & 742.0 \\
\hline R. I. & 92.1 & 100.9 & 108.0 & 106.1 & 128.1 & 154.4 & 133.7 & 155.9 & 148.8 \\
\hline Conn. & 182.5 & 223.0 & 262.6 & 233.0 & 331.6 & 408.2 & 345.8 & 423.3 & 455.8 \\
\hline N. Y. & 703.4 & 878.6 & 995.7 & 949.4 & $1,424.7$ & $1,902.3$ & $1,753.9$ & $1,918.7$ & $2,021.7$ \\
\hline N. J. & 288.9 & 373.5 & 436.7 & 431.6 & 601.7 & 781.0 & 705.1 & 812.1 & 848.9 \\
\hline Pa. & 677.5 & 814.7 & 954.3 & 853.4 & $1,219.4$ & $1,544.3$ & $1,361.4$ & $1,563.0$ & $1,625.8$ \\
\hline Ohio & 456.3 & 579.5 & 694.2 & 595.5 & 988.4 & $1,241.8$ & $1,101.7$ & $1,315.0$ & $1,425.7$ \\
\hline Ind. & 189.0 & 248.2 & 313.3 & 275.3 & 457.6 & 556.3 & 510.7 & 617.3 & 677.6 \\
\hline III. & 401.4 & 525.9 & 668.8 & 591.0 & 954.4 & $1,222.9$ & $1,117.8$ & $1,246.7$ & $1,330.4$ \\
\hline Mich. & 343.9 & 531.7 & 660.7 & 520.2 & 821.7 & $1,058.3$ & 957.5 & $1,141.6$ & $1,224.8$ \\
\hline Wis. & 152.9 & 197.0 & 234.1 & 198.6 & 343.0 & 437.9 & 399.9 & 463.1 & 476.8 \\
\hline Minn. & 62.3 & 76.2 & 89.9 & 78.0 & 145.2 & 199.0 & 185.8 & 207.7 & 225.4 \\
\hline Iowa & 47.0 & 56.5 & 67.9 & 64.8 & 112.5 & 152.3 & 147.2 & 168.4 & 174.2 \\
\hline Mo. & 134.7 & 157.7 & 188.8 & 176.0 & 269.7 & 351.6 & 332.9 & 372.9 & 414.5 \\
\hline
\end{tabular}

\begin{tabular}{|c|c|c|c|c|c|c|c|c|}
\hline & \multicolumn{8}{|c|}{ Manufacturing Production Workers } \\
\hline & 1904 & 1909 & 1914 & 1919 & 1921 & 1923 & 1929 & 1931 \\
\hline Maryland & 87.6 & 100.4 & 103.7 & 129.1 & 99.5 & 117.6 & 123.0 & 102.5 \\
\hline Virginis & 71.5 & 94.2 & 91.6 & 106.0 & 77.9 & 97.7 & 107.4 & 92.2 \\
\hline West Virginia & 38.4 & 56.1 & 62.3 & 70.6 & 50.8 & 73.1 & 75.2 & 57.2 \\
\hline North Carolina & 83.4 & 118.7 & 133.7 & 161.9 & 131.9 & 168.2 & 205.2 & 175.5 \\
\hline South. Carolina & 58.1 & 71.4 & 70.2 & 76.7 & 74.4 & 94.2 & 108.8 & 86.8 \\
\hline Georgia & $85 . \dot{9}$ & 96.9 & 96.7 & 113.7 & 90.8 & 127.7 & 151.3 & 113.9 \\
\hline Florida & 40.0 & 64.7 & 52.8 & 69.9 & 49.4 & 69.9 & 61.1 & 47.1 \\
\hline Kentucky & 51.5 & 56.4 & 55.6 & 56.1 & 46.8 & 61.6 & $65: 0$ & 46.7 \\
\hline Tennessee & 54.0 & 65.9 & 66.3 & 83.6 & 66.2 & 93.8 & 118.6 & 88.0 \\
\hline Alabama & 55.6 & 64.5 & 70.3 & 97.3 & 75.3 & 99.5 & 112.0 & 79.5 \\
\hline Mississippi & 35.9 & 46.7 & 43.3 & 53.2 & 38.9 & 51.1 & 49.7 & 27.1 \\
\hline Louisians & 53.4 & 72.8 & 74.2 & 92.7 & 80.0 & 88.6 & 82.4 & 64.2 \\
\hline Texas & 41.1 & 58.9 & 62.7 & 88.4 & 72.9 & 85.0 & 119.1 & 83.6 \\
\hline Washington & 41.5 & 63.4 & 61.6 & 123.4 & 70.4 & 102.9 & 108.9 & 66.4 \\
\hline Oregon & 17.1 & 28.5 & 26.4 & 54.5 & 37.4 & 59.3 & 62.6 & 42.3 \\
\hline California & 88.8 & 101.9 & 122.0 & 216.5 & 180.9 & 224.7 & 272.5 & 204.4 \\
\hline Total (33 States) & $5,007.6$ & $6,033.0$ & $6,416.3$ & $8,213.5$ & $6,295.4$ & $7,970.2$ & $8,148.9$ & $6,026.2$ \\
\hline Total $^{b}$ (U. S.) & $5,173.8$ & $6,255.7$ & $6,592.5$ & $8,403.2$ & $6,468.8$ & $8,186.9$ & $8,362.2$ & $6,153.6$ \\
\hline
\end{tabular}

b U. S. production worker totals prior to 1947 taken from S. Fabricant, Employment in Manufacturing 1899 19\$9, op. cit. p. 212.

Sources: (1) U. S. Department of Commerce, Buresu of the Census; Census of Manufactures for the years 1914, $1919,1921,1923,1929,1931,1933,1935,1937,1939,1947$

(2) U. S. Department of Labor, Bureau of Labor Statisties; State Employment 1099-1053. 
TABLE 194 (Continued)

\begin{tabular}{|c|c|c|c|c|c|c|c|c|c|}
\hline & \multicolumn{5}{|c|}{ Manufacturing Production Workers } & \multicolumn{4}{|c|}{ Manufacturing Employees } \\
\hline & 1933 & 1935 & 1937 & 1939 & 1947 & 1948 & 1949 & 1951 & 1953 \\
\hline Md. & 95.1 & 117.2 & 145.9 & 140.9 & 188.6 & 235.2 & 216.4 & 254.8 & 269.2 \\
\hline V8. & 81.4 & 113.7 & 132.6 & 132.1 & 190.0 & 236.7 & 217.9 & 243.2 & 257.2 \\
\hline W. Va. & 61.6 & 74.2 & 83.5 & 74.4 & 109.0 & 140.3 & 123.5 & 138.2 & 136.5 \\
\hline N. Car. & 186.9 & 227.1 & 258.8 & 269.2 & 350.2 & 418.2 & 387.1 & 435.9 & 450.4 \\
\hline S. Car. & 102.9 & 108.6 & 129.7 & 126.4 & 175.7 & 210.0 & 199.1 & 218.4 & 226.5 \\
\hline $\mathrm{Gr}$. & 124.2 & 139.6 & 159.5 & 155.9 & 225.8 & 280.7 & 263.6 & 304.4 & 316.2 \\
\hline Fla." & 42.0 & 51.4 & 52.0 & 51.1 & 68.0 & 94.9 & 90.8 & 109.6 & 121.8 \\
\hline Ky. & 48.7 & 60.8 & 69.0 & 62.5 & 110.6 & 139.9 & 130.0 & 151.7 & 159.8 \\
\hline Tenn. & 89.8 & 112.4 & 135.1 & 131.0 & 192.4 & 259.9 & 235.4 & 264.7 & 291.7 \\
\hline Ala. & 81.4 & 94.3 & 120.3 & 115.7 & 185.6 & 228.2 & 203.2 & 226.4 & 234.8 \\
\hline Miss. & 26.9 & 36.4 & 46.0 & 45.9 & 69.6 & 91.6 & 77.1 & 94.5 & 98.3 \\
\hline La. & 50.7 & 61.7 & 76.1 & 70.5 & 111.6 & 152.4 & 136.1 & 146.0 & 163.0 \\
\hline Texas & 82.2 & 99.1 & 129.5 & 125.1 & 242.0 & 340.6 & 335.8 & 401.4 & 438.3 \\
\hline Wash. & 64.2 & 79.6 & 101.3 & 82.3 & 123.5 & 174.7 & 165.1 & 191.8 & 195.3 \\
\hline Ore. & 39.4 & 51.0 & 66.0 & 57.5 & 92.1 & 137.7 & 124.7 & 147.7 & 146.6 \\
\hline Cal. & 181.2 & 239.1 & 302.2 & 271.3 & 530.3 & 734.2 & 699.3 & 892.5 & $1,064.1$ \\
\hline Total (33 States) & $5,625.5$ & $7,008.4$ & $8,332.2$ & $7,593.0$ & $11,549.5$ & $14,849.5$ & 13.540 .7 & $15,601.4$ & $16,603.5$ \\
\hline Total $^{\text {b }}$ U. S. & 5.797 .0 & 7.193 .9 & $8,584.1$ & $7,868.9$ & 12,890 & 15,357 & 14,008 & 16,082 & 17,238 \\
\hline
\end{tabular}

\section{TABLE 196. PRODUCTION WORKER EMPLOYMENT IN MANU- FACTURING BY MAJOR INDUSTRY GROUP FOR SELECTED YEARS ${ }^{a}$}

(in thousands)

\begin{tabular}{|c|c|c|c|c|c|c|c|c|}
\hline & \multicolumn{8}{|c|}{ Manufacturing Production Workers } \\
\hline & 1914 & 1919 & 1921 & 1923 & 1929 & 1931 & 1933 & 1935 \\
\hline $\begin{array}{l}\text { Food and kindred products }{ }^{b} \\
\text { Tobscco nis nufacturers } \\
\text { Textile mill products } \\
\text { Apparel \& related products } \\
\text { Lumber \& products } \\
\text { Furniture \& fixtures } \\
\text { Paper \& allied products } \\
\text { Printing \& publishing industries } \\
\text { Chemicsls \& allied products } \\
\text { Petroleum \& cosl products } \\
\text { Rubber products } \\
\text { Leather \& lesther products } \\
\text { Stone, clay \& glass products } \\
\text { Primary metal industries } \\
\text { Fabricated metal products } \\
\text { Machinery (except electrical) } \\
\text { Electrical Machinery } \\
\text { Transportation equipment } \\
\text { Instruments } \\
\text { Jewelry. silverware \& costume }\end{array}$ & $\begin{array}{r}506.1 \\
176.5 \\
975.6 \\
548.3 \\
671.6 \\
149.4 \\
164.2 \\
285.7 \\
207.7 \\
50.7 \\
74.0 \\
308.2 \\
335.3 \\
412.7 \\
366.9 \\
516.2 \\
118.1 \\
310.9\end{array}$ & $\begin{array}{r}699.1 \\
157.1 \\
1,076.1 \\
553.7 \\
663.4 \\
159.5 \\
202.9 \\
303.6 \\
293.5 \\
97.2 \\
158.5 \\
350.1 \\
294.6 \\
620.0 \\
446.5 \\
823.4 \\
212.3 \\
855.2\end{array}$ & $\begin{array}{r}583.1 \\
150.0 \\
1,012.4 \\
514.7 \\
520.7 \\
142.0 \\
180.6 \\
283.8 \\
212.3 \\
86.5 \\
103.3 \\
280.4 \\
251.2 \\
378.9 \\
328.8 \\
527.3 \\
161.2 \\
404.0\end{array}$ & $\begin{array}{r}642.2 \\
146.3 \\
1,190.3 \\
545.5 \\
692.9 \\
191.9 \\
214.0 \\
309.8 \\
264.3 \\
103.1 \\
137.9 \\
345.6 \\
348.6 \\
626.2 \\
473.3 \\
705.1 \\
234.9 \\
606.3\end{array}$ & $\begin{array}{r}733.4 \\
116.1 \\
1,120.2 \\
606.1 \\
603.4 \\
219.3 \\
244.5 \\
358.0 \\
275.0 \\
105.4 \\
149.1 \\
318.5 \\
346.5 \\
760.2 \\
490.3 \\
618.7 \\
353.6 \\
583.4 \\
0\end{array}$ & $\begin{array}{r}631.2 \\
99.8 \\
904.2 \\
531.2 \\
326.7 \\
146.9 \\
203.2 \\
317.8 \\
226.5 \\
86.6 \\
99.3 \\
272.8 \\
234.0 \\
472.1 \\
341.0 \\
400.7 \\
224.7 \\
373.6\end{array}$ & $\begin{array}{r}660.4 \\
99.7 \\
971.6 \\
531.4 \\
293.9 \\
123.2 \\
199.8 \\
264.1 \\
233.9 \\
85.1 \\
106.3 \\
282.0 \\
188.8 \\
465.7 \\
286.1 \\
307.1 \\
170.1 \\
307.4\end{array}$ & $\begin{array}{r}786.2 \\
90.5 \\
1,069.6 \\
630.7 \\
384.2 \\
151.1 \\
235.7 \\
304.8 \\
272.0 \\
98.1 \\
114.7 \\
310.8 \\
257.2 \\
631.2 \\
384.1 \\
462.7 \\
234.1 \\
480.9\end{array}$ \\
\hline $\begin{array}{l}\text { Total for Industries used } \\
\text { United States Total }\end{array}$ & $\begin{array}{r}72.1 \\
6,250.2 \\
6,592.5\end{array}$ & $\begin{array}{r}85.1 \\
8,051.8 \\
8,403.2\end{array}$ & $\begin{array}{r}67.3 \\
6,188 \cdot 5 \\
6,468 \cdot 8\end{array}$ & $\begin{array}{r}76.3 \\
7.854 .5 \\
8.186 .9\end{array}$ & $\begin{array}{r}75.0 \\
8,076.7 \\
8,362.2\end{array}$ & $\begin{array}{r}53.7 \\
5,946.0 \\
6,153.6\end{array}$ & $\begin{array}{r}45.2 \\
5,603.8 \\
5,797.0\end{array}$ & $\begin{array}{r}61.6 \\
6,960.2 \\
7,193.9\end{array}$ \\
\hline
\end{tabular}

a For years prior to 1948 , data are annual averages of production worker employment.

For 1948 and later years, data are 12 -month moving averages of manufacturing employees ending at cycle peaks or troughs.

b For the years 1914, 1919, 1921, 1923. Food excludes Beverages.

For the years 1929-37 inclusive, a separate Beverage cstegory was introduced. Food includes Beverages for all years after 1047 .

c The Instruments category was not reconstructed for years prior to 1947 , because data were unavailable. The category of clocks and watches was included in the jewelry group for these years. 
TABLE 196 (Continued)

\begin{tabular}{|c|c|c|c|c|c|c|c|}
\hline & \multicolumn{3}{|c|}{$\begin{array}{c}\text { Manufacturing } \\
\text { Production Workers }\end{array}$} & \multicolumn{4}{|c|}{ Employees in Manufacturing } \\
\hline & 1937 & 1939 & 1947 & $\begin{array}{c}\text { Monthly } \\
\text { peak } \\
\text { date } \\
1948\end{array}$ & $\begin{array}{c}\text { Monthly } \\
\text { trough } \\
\text { date } \\
1949\end{array}$ & $\begin{array}{c}\text { Post- } \\
\text { Korean } \\
\text { peak date } \\
1951\end{array}$ & $\begin{array}{c}\text { Terminal. } \\
\text { peak } \\
\text { date } \\
\mathbf{1 9 5 3}\end{array}$ \\
\hline $\begin{array}{l}\text { Food \& kindred products } \\
\text { Tobacco manufactures } \\
\text { Textile mill products } \\
\text { Apparel \& related products } \\
\text { Lumber \& products } \\
\text { Furniture \& fixtures } \\
\text { Paper \& allied products } \\
\text { Printing \& publishing industries } \\
\text { Chenicals \& allied products } \\
\text { Petroleum \& coal products } \\
\text { Rubber products } \\
\text { Leather \& leather products } \\
\text { Stone, clay \& plass prodycts } \\
\text { Primary metal industries } \\
\text { Fabricated metal products } \\
\text { Machinery (except el ectrical) } \\
\text { Electrical machineryd } \\
\text { Transportation equipment } \\
\text { Instruments } \\
\text { Jewelry, silverware \& costume jew- }\end{array}$ & $\begin{array}{r}847.7 \\
92.2 \\
1,138.2 \\
693.1 \\
441.4 \\
195.2 \\
264.5 \\
353.1 \\
309.7 \\
108.9 \\
129.8 \\
332.0 \\
330.3 \\
838.5 \\
505.2 \\
666.5 \\
317.5 \\
629.1 \\
0\end{array}$ & $\begin{array}{r}802.1 \\
87.5 \\
1,081.7 \\
752.8 \\
442.9 \\
189.4 \\
270.2 \\
324.4 \\
275.7 \\
107.7 \\
120.7 \\
327.2 \\
311.4 \\
711.9 \\
451.1 \\
536.1 \\
247.9 \\
524.5 \\
0\end{array}$ & $\begin{array}{r}1,209.4 \\
110.4 \\
1,252.3 \\
1,030.7 \\
781.3 \\
300.6 \\
406.3 \\
478.3 \\
525.2 \\
184.5 \\
220.5 \\
372.2 \\
442.0 \\
1,074.8 \\
822.5 \\
1,212.7 \\
706.2 \\
1,048.5 \\
207.2\end{array}$ & $\begin{array}{r}1,547.5 \\
116.5 \\
1,374.6 \\
1,170.5 \\
821.7 \\
352.4 \\
472.5 \\
731.3 \\
700.3 \\
248.2 \\
260.4 \\
415.4 \\
515.9 \\
1,244.2 \\
970.1 \\
1,532.7 \\
903.5 \\
1,270.5 \\
260.3\end{array}$ & $\begin{array}{r}1,513.4 \\
105.7 \\
1,219.3 \\
1,150.7 \\
736.0 \\
320.6 \\
453.8 \\
729.4 \\
654.6 \\
234.6 \\
226.9 \\
383.9 \\
476.1 \\
1,059.6 \\
860.9 \\
1,253.7 \\
1,760.1 \\
1,166.2 \\
232.2\end{array}$ & $\begin{array}{r}1,547.0 \\
104.4 \\
1,321.3 \\
1,207.2 \\
847.4 \\
380.4 \\
513.3 \\
755.4 \\
746.5 \\
254.1 \\
263.7 \\
396.0 \\
652.6 \\
1,315.2 \\
1,068.7 \\
1,641.9 \\
1,019.5 \\
1,510.3 \\
302.2\end{array}$ & $\begin{array}{r}1,558.0 \\
105.8 \\
1,212.5 \\
1,238.7 \\
792.3 \\
378.5 \\
532.7 \\
791.9 \\
808.0 \\
261.2 \\
280.4 \\
382.2 \\
544.0 \\
1,340.9 \\
1,142.5 \\
1,715.5 \\
1,221.7 \\
1,952.7 \\
334.7\end{array}$ \\
\hline $\begin{array}{l}\text { elry } \\
\text { Total for Industries used } \\
\text { United States Total }\end{array}$ & $\begin{array}{r}72.2 \\
8,292.1 \\
8,584.1\end{array}$ & $\begin{array}{r}99.9 \\
7,645.1 \\
7,868.9\end{array}$ & $\begin{array}{l}101 \cdot 4 \\
12,487.5 \\
12,890\end{array}$ & $\begin{array}{l}124.5 \\
15,032.4 \\
15,357\end{array}$ & $\begin{array}{l}118.0 \\
13,655.7 \\
14,008\end{array}$ & $\begin{array}{l}127.2 \\
15,872.3 \\
16,082\end{array}$ & $\begin{array}{l}120.8 \\
16,725.0 \\
17,238\end{array}$ \\
\hline
\end{tabular}

d Data for these categories are available for years 1947 and following. For prior years, the categories were reconstructed from their definition in the 1947 Census. Data for the components of the categories were taken from the Censuses for respective years and from Fabricant.

Source: 1. U. . Department of Commerce, Bureau of the Census, Census of Manufactures, for the years 1914, $1919,1021,1923,1929.1931,1933,1935,1937,1939,1947$.

2. U. S. Department of Labor, Bureau of Labor Statistics, Employment, Hours and Earnings in Manufacturing Industries 1909, 1914-38, 1939-54.

3. Solomon Fabricant, Employment in Manufacturino, 1919-89. National Buresu of Economic Research, Inc., New York, N. Y. 
TABLE 198. TRENDS IN STATE EMPLOYMENT $1909-1953^{*}$

\begin{tabular}{|c|c|c|c|c|c|c|c|}
\hline & $1919 / 1909$ & $1923 / 1919$ & $1929 / 1923$ & $1937 / 1929$ & $1947 / 1937$ & $1953 / 1948$ & $\begin{array}{c}\text { State } \\
\text { Average } \\
\text { Rank }\end{array}$ \\
\hline Maine & $110.10(29)$ & $94.10(22)$ & $84.90(32)$ & $109.64(9)$ & $118.07(29)$ & $102.18(29)$ & 25.00 \\
\hline New Hampshire & $106.17(31)$ & $90.49(28)$ & $88.03(31)$ & $86.68(31)$ & $114.72(33)$ & $99.40(31)$ & 30.83 \\
\hline Vermont & $97.61(33)$ & $93.88(23)$ & $89.59(30)$ & $89.35(30)$ & $117.25(30)$ & $106.02(26)$ & 28.67 \\
\hline Massachusettg & $122.00(24)$ & $93.41(25)$ & $83.83(33)$ & $90.49(29)$ & $115.89(32)$ & $101.94(30)$ & 28.83 \\
\hline Rhode Island & $123.02(22)$ & $96.02(18)$ & $94.52(27)$ & $86.22(32)$ & $116.05(31)$ & $96.37(33)$ & 27.17 \\
\hline Connecticut & $138.80(11)$ & $89.54(30)$ & $97.43(24)$ & $104.7 \theta(16)$ & $118.66(28)$ & $111.66(15)$ & 20.67 \\
\hline New York & $121.34(25)$ & $93.72(24)$ & $96.54(26)$ & $93.46(24)$ & $137.19(18)$ & $106.28(25)$ & 23.67 \\
\hline New Jersey & $155.51(\theta)$ & $87.97(31)$ & $99.70(23)$ & $100.94(18)$ & $132.01(21)$ & $108.82(17)$ & 19.33 \\
\hline Pennsylvania & $127.37(17)$ & $97.39(14)$ & $93.91(28)$ & $99.91(19)$ & $125.57(24)$ & $105.28(27)$ & 21.50 \\
\hline Obio & $162.21(5)$ & $95.68(19)$ & $107.92(13)$ & $97.29(22)$ & $138.25(15)$ & $114.81(7)$ & 13.50 \\
\hline & $146.57(9)$ & $105.83(8)$ & $112.09(9)$ & $105.35(15)$ & $134.12(9)$ & $121.80(4)$ & 9.00 \\
\hline Illin & 138. & $99.44(13)$ & 109. & (17) & $137.72(17)$ & $108.79(18)$ & 14.67 \\
\hline Michigan & $205.12(3)$ & $106.99(7)$ & $105.62(15)$ & $127.37(1)$ & $122.80(26)$ & $115.73(6)$ & 9.67 \\
\hline Wisconsin & $143.63(10)$ & $94.41(21)$ & $108.52(12)$ & $92.18(28)$ & $141.32(11)$ & $108.88(16)$ & 16.33 \\
\hline Minnesota & $131.10(13)$ & $90.03(29)$ & $104.76(19)$ & $98.63(20)$ & $152.48(6)$ & $113.27(11)$ & 16.33 \\
\hline Iowa & $122.52(23)$ & $97.12(15)$ & $112.82(7)$ & $95.89(23)$ & $160.19(3)$ & $114.38(9)$ & 13.33 \\
\hline Missouri & $126.39(20)$ & $102.33(11)$ & $104.78(18)$ & $97.99(21)$ & $140.50(13)$ & $117.80(5)$ & 14.67 \\
\hline Maryland & $128.59(14)$ & $91.14(27)$ & $104.59(20)$ & $118.61(5)$ & $126.19(23)$ & $114.46(8)$ & 16.17 \\
\hline Virginia & $112.60(28)$ & $92.16(26)$ & $109.88(10)$ & $123.56(3)$ & $4(10)$ & $108.68(19)$ & 16.00 \\
\hline West Virginia & $125.83(21)$ & $103.54(10)$ & $102.89(21)$ & $110.93(7)$ & $128.89(22)$ & $97.29(32)$ & 18.83 \\
\hline North Carolina & $127.97(15)$ & $110.74(4)$ & $122.02(3)$ & $126.08(2)$ & $134.83(19)$ & $107.70(21)$ & 10.67 \\
\hline South Carolina & $107.51(30)$ & $122.82(1)$ & $113.32(6)$ & $121.49(4)$ & $134.81(20)$ & $107.86(20)$ & 13.50 \\
\hline Georgis & $117.35(26)$ & $112.31(2)$ & $.118 .50(5)$ & $105.43(14)$ & $139.56(14)$ & $112.65(12)$ & 12.17 \\
\hline Florida & $127.91(16)$ & $85.73(32)$ & $102.03(22)$ & $85.07(33)$ & $124.69(25)$ & $128.35(3)$ & 21.83 \\
\hline Kentucky & $99.51(32)$ & $109.81(5)$ & $8(16)$ & $106.13(12)$ & $157.97(4)$ & $114.22(10)$ & 13.17 \\
\hline Tennessee & $126.98(19)$ & $112.11(3)$ & $126.46(2)$ & $113.99(6)$ & $9(12)$ & $112.24(13)$ & 9.17 \\
\hline Alabama & $150.89(7)$ & $102.23(12)$ & $112.55(8)$ & $107.43(11)$ & $153.15(5)$ & $102.89(28)$ & 11.83 \\
\hline Mississippi & $114.00(27)$ & $96.10(17)$ & $97.17(25)$ & $92.65(26)$ & $147.81(7)$ & $107.31(22)$ & 20.67 \\
\hline Louisiana & $127.25(18)$ & $95.66(20)$ & $93.03(29)$ & $92.25(27)$ & $145.38(8)$ & $106.96(23)$ & 20.83 \\
\hline Texas & $150.13(8)$ & $96.17(16)$ & $140.19(1)$ & $108.71(10)$ & $184.89(1)$ & $128.68(2)$ & 6.33 \\
\hline Washington & $194.70(4)$ & $83.34(33)$ & $105.88(14)$ & $92.96(25)$ & $120.69(27)$ & $111.79(14)$ & 19.50 \\
\hline Oregon & $205.49(2)$ & $108.71(6)$ & $105.52(17)$ & $105.50(13)$ & $137.93(16)$ & $106.46(24)$ & 13.00 \\
\hline California & $212.40(1)$ & $103.75(9)$ & $121.28(4)$ & $110.90(8)$ & $168.21(2)$ & $144.93(1)$ & 4.17 \\
\hline United States & 134.33 & 97.43 & 102.14 & 102.65 & 150.16 & 112.25 & \\
\hline
\end{tabular}

- Trend measures are computed by expressing the later date as a percentage of the prior date. Following the trend value is a number in parentheses giving the rank of the state trend in that time interval. Column 7 shows the average state rank.

Source: Table 194. 
TABLE 199. AVERAGE ANNUAL CYCLICAL AMPLITUDES IN 33 STATES DURING 4 CYCLES

\begin{tabular}{|c|c|c|c|c|c|c|c|c|}
\hline \multirow[b]{3}{*}{ Maine } & \multirow[t]{2}{*}{ 1914-19-21 } & \multirow[t]{2}{*}{$\begin{array}{c}. \cdot \\
\text { 1919-21-23 }\end{array}$} & $\begin{array}{l}\text { Maximum } \\
\text { Change }\end{array}$ & $\begin{array}{l}\text { Average } \\
\text { Change }\end{array}$ & \multirow[t]{2}{*}{$1948-49-53$} & \multirow[t]{2}{*}{$1948-49-51$} & \multirow{2}{*}{$\begin{array}{c}\text { Average } \\
\text { State } \\
\text { Cyclica] } \\
\text { Varia- } \\
\text { bility } \\
\text { Rank }^{\text {a }}\end{array}$} & \multirow{2}{*}{$\begin{array}{l}\text { Rank o } \\
\text { Average } \\
\text { Rank }\end{array}$} \\
\hline & & & \multicolumn{2}{|c|}{$[1929-31-33-35-37]$} & & & & \\
\hline & $4.74(31)$ & $6.36(32)$ & $8.64(31)$ & $6.17(31)$ & $5.30(22)$ & $7.57(12)$ & 25.6 & 29 \\
\hline New Hampshire & $5.70(29)$ & $7.76(30)$ & $7.74(32)$ & $5.32(33)$ & $5.58(16)$ & $7.61(11)$ & 23.7 & 26.5 \\
\hline Vermont & 6.13(27) & $10.67(22)$ & $16.58(5)$ & $13.26(2)$ & $6.24(10)$ & $7.30(14)$ & 15.3 & 15 \\
\hline Massachusetts & $7.00(25)$ & $8.50(27)$ & $9.76(27)$ & $7.03(28)$ & $4.03(31)$ & $5.28(28)$ & 27.7 & 32 \\
\hline Rhode Island & $7.75(22)$ & $9.50(25)$ & $9.26(29)$ & $5.89(32)$ & $6.34(8.5)$ & $9.91(3)$ & 17.8 & 19 \\
\hline Connecticut & $11.22(7)$ & $13.20(11)$ & $11.26(20)$ & $8.35(22)$ & $9.05(1)$ & $10.80(1)$ & 8.2 & $\mathbf{5}$ \\
\hline New York & $6.58(26)$ & $8.18(29)$ & $11.96(18)$ & $9.17(17)$ & $4.66(28)$ & $4.98(30)$ & 26.1 & 31 \\
\hline New Jersiey & $10.72(9)$ & $10.79(21)$ & $12.84(15)$ & $9.80(13)$ & $5.90(14)$ & $7.10(18)$ & 15.2 & 14 \\
\hline Pennsylvania & $8.75(17)$ & $12.04(15)$ & $11.11(22)$ & $8.40(21)$ & $6.34(8.5)$ & $8.46(6)$ & 13.6 & 11 \\
\hline Ohio & $13.93(4)$ & $17.21(4)$ & $14.99(10)$ & $10.56(11)$ & $7.12(4)$ & $8.51(5)$ & 5.5 & 2 \\
\hline Indiana & $10.99(8)$ & $14.90(6)$ & $16.26(7)$ & $11.66(7)$ & $6.57(6)$ & $7.42(13)$ & 8.0 & $\mathbf{5}$ \\
\hline Illinois & $8.68(18)$ & $11.37(18)$ & $15.75(9)$ & $12.02(5)$ & $5.36(21)$ & $6.00(24)$ & 17.6 & 18 \\
\hline Michigan & $17.90(3)$ & $21.65(1)$ & $17.76(3)$ & $12.70(3)$ & $6.94(5)$ & $10.64(2)$ & 2.8 & 1 \\
\hline Wisconsin & $11.66(6)$ & $14.13(7)$ & $14.97(12)$ & $11.22(8)$ & $5.61(15)$ & $7.25(17)$ & 11.0 & 7.5 \\
\hline Minnesota & $9.51(13)$ & $11.87(16)$ & $11.02(23)$ & $9.03(18)$ & $5.00(24)$ & $5.48(26)$ & 19.9 & 20 \\
\hline Iowa & $8.36(21)$ & $11.45(17)$ & $12.11(17)$ & $9.43(14)$ & $3.62(33)$ & $4.88(32)$ & 23.7 & 26.5 \\
\hline Missouri & $7.09(24)$ & $11.06(19)$ & $11.21(21)$ & $8.28(23)$ & $4.86(27)$ & $4.95(31)$ & 24.6 & 28 \\
\hline Maryland & $8.96(16)$ & $10.32(23)$ & $10.53(25)$ & $8.44(20)$ & $6.00(12.5)$ & $7.62(10)$ & 16.8 & 17 \\
\hline Virginia & $9.21(15)$ & $12.74(14)$ & $8.70(30)$ & $6.64(29.5)$ & $4.92(25)$ & $5.38(27)$ & 22.15 & 23 \\
\hline West Virginia & $9.44(14)$ & $16.26(5)$ & $10.87(24)$ & $7.86(24)$ & $6.10(11)$ & $7.96(9)$ & 12.6 & 10 \\
\hline North Carolina & $4.91(30)$ & $9.35(26)$ & $7.21(33)$ & $6.64(29.5)$ & $5.10(23)$ & $6.44(20)$ & 26.05 & 30 \\
\hline Bouth Carolina & $1.67(33)$ & $6.77(31)$ & $9.62(28)$ & $7.35(26)$ & $3.97(32)$ & $4.65(33)$ & 31.2 & 33 \\
\hline Georgia & $7.37(23)$ & $13.46(10)$ & $10.38(26)$ & $7.52(25)$ & $4.88(26)$ & $6.02(23)$ & 21.5 & 22 \\
\hline Florida & $11.91(5)$ & $12.98(12)$ & $11.56(19)$ & $7.18(27)$ & $5.46(18)$ & $6.12(22)$ & 16.0 & 16 \\
\hline Kentucky & $4.48(32)$ & $10.99(20)$ & $13.14(14)$ & $8.76(19)$ & $5.42(19)$ & $7.28(15)$ & 20.5 & 21 \\
\hline Tennessee & $8.46(20)$ & $13.88(8)$ & $12.73(16)$ & $9.41(15)$ & $6.36(7)$ & $6.41(21)$ & 14.3 & 12 \\
\hline Alabama & $10.16(11)$ & $12.76(13)$ & $14.98(11)$ & $9.40(16)$ & $5.38(20)$ & $7.27(16)$ & 14.7 & 13 \\
\hline Mississippi & $10.12(12)$ & $13.87(9)$ & $21.68(1)$ & $14.08(1)$ & $8.43(2)$ & $9.89(4)$ & 5.6 & 3 \\
\hline Louisiana & $6.08(28)$ & $6.11(33)$ & $16.38(6)$ & $10.99(10)$ & $5.47(17)$ & $5.61(25)$ & 22.2 & 24 \\
\hline Texas & $8.63(19)$ & $8.41(28)$ & $16.06(8)$ & $10.25(12)$ & $4.36(29)$ & $5.26(29)$ & 23.0 & 25 \\
\hline Washington & $22.83(1)$ & $21.60(2)$ & $19.10(2)$ & $12.16(4)$ & $4.04(30)$ & $6.56(19)$ & 11.0 & 7.5 \\
\hline Oregon & $17.93(2)$ & $19.30(3)$ & $16.87(4)$ & $11.90(6)$ & $6.00(12.5)$ & $8.24(7)$ & 5.9 & 4 \\
\hline California & $10.60(10)$ & $9.58(24)$ & $13.67(13)$ & $11.06(9)$ & $7.25(3)$ & $7.99(8)$ & 11.2 & 9 \\
\hline $\begin{array}{l}\text { United States } \\
\text { Average }\end{array}$ & 9.29 & 11.88 & 12.49 & 9.27 & 5.81 & 7.04 & & \\
\hline $\begin{array}{l}\text {-33 States- } \\
\text { (1) Mean cyclical }\end{array}$ & & & & & & & & \\
\hline amplitude & 9.38 & 12.09 & 12.93 & 9.33 & 5.69 & 7.06 & & $\cdot$ \\
\hline (2) Variance & 16.92 & 14.81 & 11.63 & 4.98 & 1.41 & 2.68 & & \\
\hline $\begin{array}{l}\text { (3) Coefficient of } \\
\text { variation }\end{array}$ & 0.44 & $0 . \dot{3} 2$ & 0.26 & 0.24 & 0.21 & 0.23 & & \\
\hline
\end{tabular}

The average state rank is computed by averaging the six ranks. giving one-half weight each to the two ranks for the 1929-1937 cycle. This was done to avoid giving that cycle double weight. 
TABLE 200. AVERAGE CYCLICAL DECLINE RATES AND
EXPANSION RATES-33 STATES

\begin{tabular}{|c|c|c|c|c|c|c|}
\hline & \multicolumn{4}{|c|}{ Cyclical Decline Rates } & \multirow{2}{*}{$\begin{array}{c}\text { Average } \\
\text { Decline } \\
\text { Rank }^{\mathbf{b}}\end{array}$} & \multirow{2}{*}{$\begin{array}{c}\text { Rank of } \\
\text { Average } \\
\text { Decline } \\
\text { Rank }\end{array}$} \\
\hline & $1919-21$ & $1929-31$ & $1931-33$ & $1948-49$ & & \\
\hline Maine & $7.98(30)$ & $9.81(29)$ & $2.16(18)$ & $.6 .53(13)$ & 24.00 & 29.5 \\
\hline New Hampshire & $10.23(26)$ & $11.18(28)$ & $3.39(12)$ & $8.11(5)$ & 19.67 & 19 \\
\hline Vermont & $12.11(20)$ & $21.27(4)$ & $8.72(1)$ & $7.81(6)$ & 10.00 & $\mathbf{5}$ \\
\hline Massachusetts & $10.63(23)$ & $13.16(25)$ & $3.74(10)$ & $5.25(21.5)$ & 23.17 & 28 \\
\hline Rhode Island & $11.17(22)$ & $14.31(16)$ & $1.60(21)$ & $9.83(3)$ & 13.67 & 12 \\
\hline Connecticut & $16.99(7)$ & $13.40(24)$ & $1.96(19.5)$ & $10.76(1)$ & 10.67 & 7 \\
\hline New York & $10.15(27)$ & $14.10(19)$ & $6.20(2)$ & $5.21(23)$ & 23.00 & 27 \\
\hline New Jersey & $15.04(13)$ & $14.29(17)$ & $5.05(6.5)$ & $6.43(14)$ & 14.67 & 15 \\
\hline Pennsylvania & $13.48(15)$ & $13.76(21)$ & $3.06(13)$ & $7.60(7)$ & 14.33 & 14 \\
\hline Ohio & $20.40(4)$ & $19.46(6)$ & $2.50(16)$ & $6.97(10)$ & 6.67 & 3 \\
\hline Indiana & $15.17(11)$ & $19.48(5)$ & $2.24(17)$ & $5.44(20)$ & 12.00 & 9 \\
\hline Illinois & $12.44(18)$ & $18.30(9)$ & $5.05(6.5)$ & $6.02(17.5)$ & 14.83 & 16 \\
\hline Michigan & $24.16(2)$ & $16.11(12)$ & $1.96(19.5)$ & $6.92(11)$ & 8.33 & 4 \\
\hline Wisconsin & $17.00(6)$ & $19.08(8)$ & $5.82(3)$ & $6.02(17.5)$ & 10.50 & 6 \\
\hline Minnesota & $15.09(12)$ & $13.14(26)$ & $5.32(5)$ & $4.85(26)$ & 21.33 & 21.5 \\
\hline Iows & $12.88(17)$ & $14.64(15)$ & $5.46(4)$ & $2.54(32)$ & 21.33 & 21.5 \\
\hline Missouri & $9.31(28)$ & $13.50(23)$ & $3.64(11)$ & $3.39(30)$ & 27.00 & 32 \\
\hline
\end{tabular}

\begin{tabular}{|c|c|c|c|c|c|c|c|c|}
\hline & \multicolumn{6}{|c|}{ Cyclical Expansion Rates } & \multirow{2}{*}{$\begin{array}{c}\text { Average } \\
\text { Expansion } \\
\text { Rank }^{\circ}\end{array}$} & \multirow{2}{*}{$\begin{array}{c}\text { Rank of } \\
\text { Average } \\
\text { Expansion } \\
\text { Rank }\end{array}$} \\
\hline . & $1914-19$ & $1921-23$ & $1933-35$ & $1935-37$ & $1949-53$ & $1949-51$ & & \\
\hline Me. & $1.50(30)$ & $4.78(33)$ & $7.48(25)$ & $5.24(30)$ & $4.07(26)$ & $8.61(14)$ & 28.8 & 31 \\
\hline N. H. & $1.18(31)$ & $5.13(31)$ & $4.31(31)$ & $2.42(32)$ & $3.04(30)$ & $7.11(20)$ & 31.0 & 33 \\
\hline Vt. & $0.16(33)$ & $8.98(23)$ & $11.15(7)$ & $11.88(11)$ & $4.68(22)$ & $6.79(22)$ & 19.2 & 19 \\
\hline Mass. & $3.38(24)$ & $6.70(29)$ & $4.86(30)$ & $6.38(29)$ & $2.81(33)$ & $5.31(30)$ & 29.0 & 32 \\
\hline R. I. & $4.33(19)$ & $8.42(25)$ & $4.20(32)$ & $3.44(31)$ & $2.84(31)$ & $9.99(5)$ & 27.6 & 30 \\
\hline Conn. & $5.46(12)$ & $10.20(21)$ & $9.12(18)$ & $8.92(18.5)$ & $7.34(3)$ & $10.85(3)$ & 14.5 & 12 \\
\hline N. Y. & $3.02(26)$ & $6.48(30)$ & $9.82(14)$ & $6.57(28)$ & $4.12(25)$ & $4.74(33)$ & 24.6 & 29 \\
\hline N. J. & $6.40(9)$ & $7.36(28)$ & $11.38(6)$ & 8.50(22) & $5.38(13)$ & $7.77(18)$ & 15.6 & 15 \\
\hline $\mathrm{Pa}$. & $4.03(20)$ & $11.33(16)$ & $8.30(22)$ & $8.46(23)$ & $5.08(16)$ & $9.32(12)$ & 19.4 & 20 \\
\hline Ohio & $7.47(5)$ & $15.98(8)$ & $10.52(10)$ & $9.78(15)$ & $7.28(4)$ & $10.05(4)$ & 8.4 & 5 \\
\hline Ind. & $6.81(7)$ & $16.46(6)$ & $11.88(4)$ & $13.05(7)$ & $7.70(2)$ & $9.40(11)$ & 5.2 & 2 \\
\hline Ill. & $4.93(13)$ & $11.22(17)$ & $11.51(5)$ & $13.20(5)$ & $4.71(20)$ & $5.99(27)$ & 12.0 & 9 \\
\hline Mich. & $11.64(3)$ & $23.58(1)$ & $19.40(1)$ & $13.34(3)$ & $6.97(7)$ & $14.36(1)$ & 3.0 & 1 \\
\hline Wisc. & $6.32(10)$ & $12.56(12)$ & $10.86(9)$ & $9.14(17)$ & $5.20(14)$ & $8.51(15)$ & 12.4 & 10.5 \\
\hline Minn. & $3.94(21)$ & $9.04(22)$ & $8.91(20)$ & $8.76(21)$ & $5.16(15)$ & $6.12(26)$ & 19.8 & 21 \\
\hline Ia. & $3.84(22)$ & $10.66(18)$ & $8.04(24)$ & $9.58(16)$ & $4.70(21)$ & $7.22(19)$ & 20.2 & 22.5 \\
\hline Mo. & $4.88(14)$ & $11.68(15)$ & $7.08(27)$ & $8.92(18.5)$ & $6.33(9)$ & $6.51(25)$ & 16.7 & 16 \\
\hline
\end{tabular}

- Decline Rates and Expansion Rates are changes in cycle values per year expressed in cycle base units. 
TABLE 200-(Continued)

\begin{tabular}{|c|c|c|c|c|c|c|}
\hline & \multicolumn{4}{|c|}{ Cyclical Decline Rates } & \multirow{2}{*}{$\begin{array}{l}\text { Average } \\
\text { Decline } \\
\text { Rankb }^{b}\end{array}$} & \multirow{2}{*}{$\begin{array}{c}\text { Rank of } \\
\text { Average } \\
\text { Decline } \\
\text { Rank }\end{array}$} \\
\hline & $1919-21$ & $1929-31$ & $1931-33$ & $1948-49$ & & \\
\hline Maryland & $13.34(16)$ & $8.78(31)$ & $+3.20(30)$ & $5.80(19)$ & 22.00 & 23.5 \\
\hline Virginia & $15.28(10)$ & $7.06(32)$ & $0.34(24)$ & $5.25(21.5)$ & 21.17 & 20 \\
\hline West Virginia & $16.18(8)$ & $12.78(27)$ & $+3.08(29)$ & $9.38(4)$ & 13.00 & 11 \\
\hline North Carolina & $7.20(32)$ & $6.98(33)$ & $+5.02(32)$ & $6.29(15)$ & 26.67 & 31 \\
\hline South Carolina & $1.57(33)$ & $9.34(30)$ & $+7.50(33)$ & $4.36(27)$ & 30.00 & 33 \\
\hline Georgia & $11.36(21)$ & $13.56(22)$ & $+3.74(31)$ & $5.03(25)$ & 22.67 & 26 \\
\hline Florida & $17.86(5)$ & $13.84(20)$ & $5.02(8)$ & $3.93(28)$ & 17.67 & 18 \\
\hline Kentucky & $8.80(29)$ & $15.80(13)$ & $+1.72(27)$ & $5.12(24)$ & 22.00 & 23.5 \\
\hline Tennessee & $12.12(19)$ & $15.04(14)$ & $+1.76(28)$ & $7.01(9)$ & 14.00 & 13 \\
\hline Algbama & $13.63(14)$ & $16.66(11)$ & $+0.96(26)$ & $6.71(12)$ & 12.33 & 10 \\
\hline Mississippi & $15.83(9)$ & $30.36(1)$ & $0.24(25)$ & $10.16(2)$ & 4.00 & 1 \\
\hline Louisiana & $7.69(31)$ & $21.70(3)$ & $2.74(15)$ & $6.27(16)$ & 16.67 & 17 \\
\hline Texas & $10.38(24)$ & $17.32(10)$ & $0.66(23)$ & $1.52(33)$ & 22.33 & 25 \\
\hline Washington & $31.14(1)$ & $25.32(2)$ & $1.28(22)$ & $3.34(31)$ & 11.33 & 8 \\
\hline Oregon & $21.64(3)$ & $19.40(7)$ & $2.76(14)$ & $7.02(8)$ & 6.00 & 2 \\
\hline California & $10.29(25)$ & $14.19(18)$ & $4.83(9)$ & $3.52(29)$ & 24.00 & 29.5 \\
\hline United States & & & & & & \\
\hline Average & 13.52 & 15.30 & 2.47 & 5.73 & & \\
\hline 33 State Average & 13.59 & 15.37 & 1.78 & 6.07 & & \\
\hline
\end{tabular}

\begin{tabular}{|c|c|c|c|c|c|c|c|c|}
\hline & \multicolumn{6}{|c|}{ Cyclical Expansion Rates } & \multirow{2}{*}{$\begin{array}{c}\text { A verage } \\
\text { Expansion } \\
\text { Runk }^{0}\end{array}$} & \multirow{2}{*}{$\begin{array}{c}\text { Rank of } \\
\text { Average } \\
\text { Expansion } \\
\text { Rank }\end{array}$} \\
\hline & $1914-19$ & $1921-23$ & $1933-35$ & $1935-37$ & $1949-53$ & $1949-51$ & & \\
\hline Md. & $4.58(16)$ & $7.85(26)$ & $9.50(15)$ & $12.28(10)$ & $6.19(10)$ & $9.43(10)$ & 15.4 & 13.5 \\
\hline Va. & $3.14(25)$ & $10.52(20)$ & $10.34(13)$ & $8.84(20)$ & $4.60(24)$ & $5.52(29)$ & 20.4 & 24 \\
\hline W. Va. & $2.70(27)$ & $17.22(3)$ & $8.96(19)$ & $6.60(27)$ & $2.82(32)$ & $6.54(24)$ & 21.6 & 26 \\
\hline N. Car. & $2.62(28)$ & $12.06(14)$ & $7.10(26)$ & $7.44(24)$ & $3.91(28)$ & $6.59(23)$ & 24.0 & 28 \\
\hline S. Car. & $1.78(29)$ & $12.12(13)$ & $2.65(33)$ & $9.90(14)$ & $3.58(29)$ & $4.94(32)$ & 23.6 & 27 \\
\hline Ga. & $3.39(23)$ & $16.62(5)$ & $5.59(29)$ & $7.20(25)$ & $4.72(19)$ & $7.01(21)$ & 20.2 & 22.5 \\
\hline Fla. & $5.96(11)$ & $8.81(24)$ & $9.28(16)$ & $0.58(33)$ & $7.00(6)$ & $8.31(16)$ & 18.0 & 18 \\
\hline $\mathrm{Ky}$. & $0.17(32)$ & $13.50(9)$ & $10.47(11)$ & $7.06(26)$ & $5.73(11)$ & $9.45(8.5)$ & 17.8 & 17 \\
\hline Tenn. & $4.81(15)$ & $17.00(4)$ & $10.42(12)$ & $10.44(13)$ & $5.71(12)$ & $5.81(28)$ & 11.2 & 8 \\
\hline Ala. & $6.69(8)$ & $13.36(10)$ & $6.66(28)$ & $13.31(4)$ & $4.05(27)$ & $7.83(17)$ & 15.4 & 13.5 \\
\hline Miss. & $4.41(18)$ & $12.78(11)$ & $12.70(2)$ & $13.00(8)$ & $6.70(8)$ & $9.62(7)$ & 9.4 & 6 \\
\hline La. & $4.48(17)$ & $4.96(32)$ & $8.46(21)$ & $11.07(12)$ & $4.67(23)$ & $4.95(31)$ & 21.0 & 25 \\
\hline Texas & $6.89(6)$ & $7.38(27)$ & $8.23(23)$ & $14.79(1)$ & $7.21(5)$ & $9.01(13)$ & 12.4 & 10.5 \\
\hline Wash. & $14.53(1)$ & $16.41(7)$ & $9.14(17)$ & $12.89(\theta)$ & $4.75(18)$ & $9.79(6)$ & 10.4 & 7 \\
\hline Ore. & $14.23(2)$ & $21.65(2)$ & $11.12(8)$ & $14.34(2)$ & $4.97(17)$ & $0.45(8.5)$ & 6.2 & 3 \\
\hline Cal. & $10.92(4)$ & $10.56(19)$ & $12.06(3)$ & $13.15(6)$ & $10.98(1)$ & $12.46(2)$ & 6.6 & 4 \\
\hline U. \$. Average & 5.06 & 11.17 & 9.67 & 9.63 & 5.89 & 8.36 & & . \\
\hline 33 State Average & 5.17 & 11.82 & 9.14 & 9.41 & 5.30 & 8.04 & & \\
\hline
\end{tabular}

b The average decline rank excludes the decline from 1931 to 1933. This is explained in the text, Section 3.

- The average expansion rank excludes the expansion Irom 1949 to 1951. This expansion is excluded because its ranking is virtually identical with the expansion from 1949 to 1953. 
TABLE 202. HYPOTHETICAL AVERAGE ANNUAL CYCLICAL AMPLITUDES IN THIRTY-THREE STATES DURING FOUR CYCLES

\begin{tabular}{|c|c|c|c|c|c|c|c|}
\hline & \multirow[t]{2}{*}{$1914-19-21$} & \multirow[t]{2}{*}{$1919-21-23$} & $\begin{array}{c}\text { Maximum } \\
\text { Change }\end{array}$ & $\begin{array}{l}\text { Average } \\
\text { Change }\end{array}$ & \multirow{2}{*}{$\begin{array}{c}1948-49-53 \\
\cdots\end{array}$} & \multirow[t]{2}{*}{$1948-49-51$} & \multirow{2}{*}{$\begin{array}{c}\text { Average } \\
\text { State } \\
\text { Rank }\end{array}$} \\
\hline & & & \multicolumn{2}{|c|}{ [1929-31-33-35-37] } & & & \\
\hline Maine & $7.23(25.5)$ & $9.66(27)$ & $9.72(29)$ & $6.37(30)$ & $4.23(31)$ & $6.73(23)$ & 27.58 \\
\hline New Hampshire & $5.27(31)$ & $8.34(31)$ & $9.16(32)$ & $5.98(32)$ & $4.51(29)$ & $6.60(25)$ & 30.00 \\
\hline Vermont & $5.47(30)$ & $10.05(26)$ & $13.66(10)$ & $9.88(10)$ & $5.48(15)$ & $7.47(11)$ & $17.00^{\circ}$ \\
\hline Massachusetts & $7.08(27)$ & $9.57(28)$ & $10.17(27)$ & $7.29(26)$ & $5.52(14)$ & $6.96(18)$ & 23.33 \\
\hline Rhode Island & $6.58(29)$ & $8.71(30)$ & $10.36(25)$ & $6.88(28)$ & $5.29(16)$ & $7.92(10)$ & 23.00 \\
\hline Connecticut & $9.75(11)$ & $12.61(11)$ & $14.15(8)$ & $10.65(7)$ & $7.47(2)$ & $9.33(2)$ & 6.83 \\
\hline New York & $7.32(24)$ & $9.49(29)$ & $10.63(24)$ & $8.10(23)$ & $4.99(22)$ & $5.79(30)$ & 25.33 \\
\hline New Jersey & $10.78(6)$ & $12.17(13)$ & $11.69(20)$ & $8.80(15)$ & $6.19(8)$ & $7.32(13)$ & $.12 .50=$ \\
\hline Pennsylvania & $10.39(8)$ & $13.18(6)$ & $12.80(14)$ & $9.29(13)$ & $5.89(12)$ & $8.32(6)$ & 9.83 \\
\hline Ohio & $12.40(4)$ & $15.15(2)$ & $15.30(4)$ & $11.42(2)$ & $7.24(4)$ & $9.05(3)$ & 3.17 \\
\hline Indiana & $11.49(5)$ & $14.63(4)$ & $15.15(6)$ & $11.39(3)$ & $7.43(3)$ & $8.46(5)$ & 4.33 \\
\hline Illinois & $9.68(12)$ & $11.67(14)$ & $13.57(11)$ & $10.39(9)$ & $6.66(6)$ & $8.21(8)$ & 10.00 \\
\hline Michigan & $15.26(1)$ & $18.06(1)$ & $17.30(1)$ & $12.92(1)$ & $8.75(1)$ & $12.32(1)$ & 1.00 \\
\hline Wisconsin & $10.44(7)$ & $13.01(9)$ & $13.73(9)$ & $10.44(8)$ & $6.98(5)$ & $8.47(4)$ & 7.00 \\
\hline Minnesota & $7.76(20)$ & $10.37(25)$ & $10.84(23)$ & $8.18(21)$ & $5.23(17)$ & $6.83(22)$ & 21.33 \\
\hline Iowa & $9.02(14)$ & $10.75(20.5)$ & 11.72(19) & $8.70(19)$ & $5.85(13)$ & $7.07(17)$ & 17.08 \\
\hline Missouri & $8.37(17)$ & $10.72(22)$ & $10.89(22)$ & $8.11(22)$ & $4.95(24)$ & $5.99(28)$ & 22.50 \\
\hline Maryland & $10.16(10)$ & $11.21(18)$ & $11.94(18)$ & $9.10(14)$ & $6.13(9)$ & $7.26(14)$. & 13.83 \\
\hline Virginia & $8.03(19)$ & $10.58(23)$ & $10.27(26)$ & $7.08(27)$ & $4.49(30)$ & $5.43(32)$ & 26.17 \\
\hline West Virginia & $8.45(16)$ & $13.75(5)$ & $14.68(7)$ & $10.77(6)$ & $6: 10(10)$ & $8.00(9)$ & 8.83 \\
\hline North Carolina. & $3.84(33)$ & $7.35(33)$ & $8.94(33)$ & $5.94(33)$ & $4.98(23)$ & $6.94(19)$ & 29.00 \\
\hline South Carolina & $4.44(32)$ & $7.66(32)$ & $9.46(30)$ & $6.26(31)$ & $4.88(25)$ & $6.87(21)$ & 28.50 \\
\hline Georgia & $7.23(25.5)$ & $10.77(19)$ & $9.94(28)$ & $6.49(29)$ & $4.71(28)$ & $6.24(26)$ & 25.92 \\
\hline Florida & $8.21(18)$ & $11.39(15)$ & $12.28(16)$ & $8.23(20)$ & $4.82(27)$ & $5.58(31)$ & 21.17 \\
\hline Kentucky & $7.43(23)$ & $10.45(24)$ & $9.34(31)$ & $7.60(24)$ & $5.06(19)$ & $6.69(24)$ & 24.17 \\
\hline Tennessee & $7.48(22)$ & $10.75(20.5)$ & $10.94(21)$ & $7.47(25)$ & $4.87(26)$ & $6.14(27)$ & 23.58 \\
\hline Alabams & $8.95(15)$ & $12.96(10)$ & $13.26(12)$ & $8.79(16)$ & $5.02(20)$ & $8.23(7)$ & 13.33 \\
\hline Mississippi & $6.84(28)$ & $12.25(12)$ & $15.22(5)$ & $9.75(11)$ & $4.10(32)$ & $5.25(33)$ & 20.17 \\
\hline Louisiana & $7.60(21)$ & $11.25(17)$ & $12.99(13)$ & $8.72(17.5)$ & $3.73(33)$ & $5.97(29)$ & 21.75 \\
\hline Texas & $9.49(13)$ & $11.28(16)$ & $12.14(17)$ & $8.72(17.5)$ & $6.46(7)$ & $7.43(12)$ & 13.75 \\
\hline Washington & $13.23(3)$ & $15.08(3)$ & $16.38(3)$ & $11.16(\cdot 5)$ & $5.08(18)$ & $7.10(15)$ & 7.83 \\
\hline Oregon & $10.35(9)$ & $13.15(7.5)$ & $17.02(2)$ & $11.18(4)$ & $5.01(21)$ & $6.88(20)$ & 10.58 \\
\hline California & $13.25(2)$ & $13.15(7.5)$ & $12.35(15)$ & $9.36(12)$ & $6.03(11)$ & $7.09(16)$ & 10.58 \\
\hline $\begin{array}{l}\text { Mean Cyclica] } \\
\text { amplitude }\end{array}$ & 8.77 & 11.55 & 12.36 & 8.83 & 5.58 & 7.27 & \\
\hline Veriance & 6.37 & 5.07 & 5.39 & 3.17 & 1.20 & 1.81 & \\
\hline $\begin{array}{l}\text { Coefficient of } \\
\text { variation }\end{array}$ & $.2 \theta$ & .19 & .19 & .20 & .20 & .19 & \\
\hline
\end{tabular}


TABLE 203. AVERAGE ANNUAL AMPLITUDE OF CYCLES OF EMPLOYMENT IN 19 INDUSTRIES

\begin{tabular}{|c|c|c|c|c|c|c|c|}
\hline \multirow[t]{2}{*}{. } & \multirow[b]{2}{*}{$1914-19-21$} & \multirow[b]{2}{*}{$1919-21-23$} & $\begin{array}{c}\text { Maximum } \\
\text { Average } \\
\text { Change }\end{array}$ & $\begin{array}{c}\text { Average of } \\
\text { all } 4 \\
\text { Changes }\end{array}$ & \multirow[t]{2}{*}{$1948-49-53$} & \multirow[t]{2}{*}{ 1948-49-51 } & \multirow[t]{2}{*}{$\begin{array}{c}\text { Average } \\
\text { Rank }\end{array}$} \\
\hline & & & \multicolumn{2}{|c|}{$[1929-31-33-35-37]$} & & & \\
\hline Food & $8.10(9)$ & $6.82(15)$ & $7.73(16)$ & $5.86(14)$ & $1.08(19)$ & $1.47(18)$ & 15.17 \\
\hline Tobacco & $-.10(19)$ & $0.56(19)$ & $4.51(19)$ & $3.42(19)$ & $2.42(16)$ & $2.01(17)$ & 18.17 \\
\hline Textiles & $2.54(15)$ & $5.53(16)$ & $7.54(17)$ & $5.40(17)$ & $4.19(11)$ & $7.08(10)$ & 14.33 \\
\hline Apparel & $1.91(18)$ & $3.24(18)$ & $8.08(14)$ & $5.72(15)$ & $2.02(17)$ & $2.33(16)$ & 16.33 \\
\hline Lumber & $5.63(12)$ & $12.58(8)$ & $22.38(1)$ & $13.93(4)$ & $4.63(10)$ & $8.49(8)$ & 7.17 \\
\hline Furniture & $3.58(14)$ & $10.24(11)$ & $17.43(6)$ & $12.57(8)$ & $5.97(7)$ & $9.71(5)$ & 8.50 \\
\hline Paper & $5.17(13)$ & $6.99(14)$ & $8.41(11)$ & $5.96(13)$ & $3.63(12)$ & $5.19(13)$ & 12.67 \\
\hline Printing & $2.31(16)$ & $3.83(17)$ & $7.98(15)$ & $7.16(11)$ & $1.28(18)$ & $1.13(19)$ & 16.00 \\
\hline C hemicals & $12.14(6)$ & $12.97(7)$ & $8.22(12)$ & $6.25(12)$ & $5.21(8)$ & $5.55(11)$ & 9.33 \\
\hline Petroleum & $9.37(8)$ & $7.14(13)$ & $8.21(13)$ & $5.69(16)$ & $3.21(13)$ & $3.71(15)$ & 13.00 \\
\hline Rubber & $19.88(2)$ & $16.95(4)$ & $13.54(10)$ & $8.38(10)$ & $7.13(6)$ & $9.13(7)$ & 6.50 \\
\hline Leather & $6.91(11)$ & $10.36(10)$ & $6.14(18)$ & $4.32(18)$ & $2.70(14)$ & $3.90(14)$ & 14.17 \\
\hline Stone, clay, glass & $2.30(17)$ & $11.81(9)$ & $17.10(7)$ & $13.78(5)$ & $5.08(9)$ & $7.90(.9)$ & 9.33 \\
\hline Primary metals & $17.21(3)$ & $22.54(2)$ & $19.55(5)$ & $13.16(7)$ & $9.19(4)$ & $11.58(1)$ & 3.67 \\
\hline Fabricated metals & $9.81(7)$ & $15.75(5)$ & $16.84(8)$ & $13.18(6)$ & $7.53(5)$ & $10.61(3)$ & 5.67 \\
\hline Machinery & $16.83(4)$ & $17.29(3)$ & $21.47(.2)$ & $17.08(1)$ & $10.02(2)$ & $11.56(2)$ & 2.33 \\
\hline Elec. machinery & $13.54(5)$ & $15.38(6)$ & $20.41(3)$ & $15.91(2)$ & $10.31(1)$ & $10.13(4)$ & 3.50 \\
\hline Transport & $31.95(1)$ & $26.27(1)$ & $20.18(4)$ & $15.73(3)$ & $9.76(3)$ & $9.49(\mathrm{~B})$ & 3.00 \\
\hline Jewelry & $7.68(10)$ & $8.79(12)$ & $15.31(9)$ & $11.54(9)$ & $2.43(15)$ & $5.35(12)$ & 11.17 \\
\hline Instruments & & & & & 8.22 & 8.87 & \\
\hline Unites States & & & & & & & \\
\hline Average & 9.29 & 11.88 & 12.49 & 0.27 & 5.81 & 7.04 & \\
\hline 19 Industries & & & & & & & \\
\hline $\begin{array}{l}\text { Mean cyclical } \\
\text { amplitude }\end{array}$ & 9.30 & 11.31 & 13.21 & 9.74 & 5.15 & 6.65 & \\
\hline Variance & 59.48 & 41.68 & 34.63 & 19.33 & 8.82 & 11.77 & \\
\hline $\begin{array}{l}\text { Coefficient of } \\
\text { variation }\end{array}$ & 0.83 & 0.57 & 0.45 & 0.45 & 0.58 & 0.52 & \\
\hline
\end{tabular}


TABLE 204. RATIOS OF ACTUAL TO HYPOTHETICAL CYCLICAL AMPLITUDE

\begin{tabular}{|c|c|c|c|c|c|c|c|}
\hline & \multirow{2}{*}{$1914-19-21$} & \multirow[b]{2}{*}{$1910-21-23$} & $\begin{array}{c}\text { Maximum } \\
\text { Change }\end{array}$ & $\begin{array}{c}\text { Average } \\
\text { Change }\end{array}$ & \multirow[b]{2}{*}{$1948-49-53$} & \multirow[b]{2}{*}{$1948-49-51$} & \multirow{2}{*}{$\begin{array}{c}\text { Average } \\
\text { State } \\
\text { Rank }\end{array}$} \\
\hline & & & \multicolumn{2}{|c|}{$[1929-31-33-35-37]$} & & & \\
\hline Maine & $65.56(31)$ & $65.84(32)$ & $88.89(26)$ & $96.88(23)$ & $125.30(4)$ & $112.48(7)$ & 20.50 \\
\hline New Hampshire & $108.18(17)$ & $93.05(23)$ & $84.50(30)$ & $88.96(29)$ & $123.72(5)$ & $115.30(5)$ & 18.17 \\
\hline Vermont & $112.07(14)$ & $106.17(16)$ & $121.38(5)$ & $134.21(2)$ & $113.87(10)$ & $97.72(15)$ & 10.33 \\
\hline Massachuset ts & $98.87(20)$ & $88.82(26)$ & $95.97(23)$ & $96.43(24)$ & $73.01(31)$ & $75.86(29)$ & 25.50 \\
\hline Rhode Island & $117.78(7)$ & $109.07(13)$ & $89.38(25)$ & $85.61(31)$ & $119.85(8)$ & $125.13(2)$ & 14.33 \\
\hline Connecticut & $115.08(9)$ & $104.68(18)$ & $79.58(32)$ & $78.40(32)$ & $121.15(6)$ & $115.76(4)$ & 16.83 \\
\hline New York & $89.89(24)$ & $86.20(29)$ & $112.51(10)$ & $113.21(11)$ & $93.39(24)$ & $86.01(25)$ & 20.50 \\
\hline New Jersey & $99.44(19)$ & $88.66(27)$ & $109.84(12)$ & $111.36(13)$ & $95.32(23)$ & $96.99(16)$ & 18.33 \\
\hline Pennsylvania & $84.22(28)$ & $91.35(25)$ & $88.80(28)$ & $90.42(28)$ & $107.64(13)$ & $101.68(12)$ & 22.33 \\
\hline Ohio & $112.34(13)$ & $113.60(11)$ & $97.97(22)$ & $92.47(27)$ & $98.34(19)$ & $94.03(18)$ & 18.33 \\
\hline Indiana & $95.65(21)$ & $101.85(20)$ & $107.33(14)$ & $102.37(20)$ & $88.43(25)$ & $87.71(23)$ & 20.50 \\
\hline Illinois & $89.85(25)$ & $97.43(22)$ & $116.08(8)$ & $115.69(9)$ & $80.48(27)$ & $73.08(30)$ & 20.17 \\
\hline Michigan & $117.30(8)$ & $119.88(7)$ & $102.68(18)$ & $98.30(22)$ & $79.30(30)$ & $86.36(24)$ & 13.17 \\
\hline Wisconsin & $111.69(16)$ & $108.61(14)$ & $109.03(13)$ & $107.47(17)$ & $80.37(28)$ & $85.71(26)$ & 19.00 \\
\hline Minnesota & $122.55(6)$ & $114.46(9)$ & $101.68(20)$ & $110.39(14)$ & $95.60(22)$ & $80.23(28)$ & 18.50 \\
\hline Iowa & $92.68(22)$ & $106.51(15)$ & $103.33(16)$ & $108.39(16)$ & $61.88(33)$ & $69.02(32)$ & 22.33 \\
\hline Missouri & $84.71(27)$ & $103.17(19)$ & $102.94(17)$ & $102.10(21)$ & $98.18(20)$ & $82.64(27)$ & 21.83 \\
\hline Maryland & $88.19(26)$ & $92.08(24)$ & $88.19(27)$ & $92.7 B(26)$ & $97.88(21)$ & $6(10)$ & 22.33 \\
\hline Virgin & 114. & ( 6$)$ & $84.71(29)$ & $93.79(25)$ & 109.58 & $99.08(14)$ & 16.00 \\
\hline West Virginia & $111.72(15)$ & $118.25(8)$ & $74.05(33)$ & $72.98(33)$ & $100.00(18)$ & $99.50(13)$ & 20.00 \\
\hline North Carolina & $127.88(5)$ & $127.21(4)$ & $80.65(31)$ & $111.78(12)$ & $102.41(17)$ & $92.80(20)$ & 14.83 \\
\hline South Carolina & $37.61(33)$ & $88.38(28)$ & $101.69(10)$ & $117.41(7)$ & $81.35(26)$ & $67.69(33)$ & 24.33 \\
\hline Georgia & $101.94(18)$ & $124.98(5)$ & $104.43(15)$ & $115.87(8)$ & $103.61(16)$ & $96.47(17)$ & 13.17 \\
\hline Florida & $145.07(4)$ & $113.98(10)$ & $94.14(24)$ & $87.24(30)$ & $113.28(11)$ & $109.68(8)$ & 14.50 \\
\hline Kentucky & $60.30(32)$ & $105.17(17)$ & $140.69(2)$ & $115.26(10)$ & $107.11(15)$ & $108.82(9)$ & 14.17 \\
\hline Tennessee & $113.10(12)$ & $129.12(3)$ & $116.36(7)$ & $125.97(4)$ & $130.60(3)$ & $104.40(11)$ & 6.67 \\
\hline Alabama & $113.52(11)$ & $98.48(21)$ & $112.97(9)$ & $106.94(18)$ & $107.17(14)$ & $88.34(22)$ & 15.83 \\
\hline Mississippi & $147.95(3)$ & $113.22(12)$ & $142.44(1)$ & $144.41(1)$ & $205.61(1)$ & $188.38(1)$ & 3.17 \\
\hline Louisiana & $80.00(29.5)$ & $54.31(33)$ & $126.10(4)$ & $126.03(3)$ & $146.85(2)$ & 93.97(19) & 15.08 \\
\hline Texas & $90.49(23)$ & $74.69(30)$ & $132.29(3)$ & $117.55(\theta)$ & $67.49(32)$ & $70.79(31)$ & 20.83 \\
\hline Washington & $172.56(2)$ & $143.43(2)$ & $116.61(\theta)$ & $108.96(15)$ & $79.53(29)$ & $92.39(21)$ & 12.50 \\
\hline Oregon & $173.24(1)$ & $146.77(1)$ & $99.12(21)$ & $106.44(19)$ & $119.76(9)$ & $119.77(3)$ & 9.00 \\
\hline California & $80.00(29.5)$ & $72.85(31)$ & $110.69(11)$ & $118.16(5)$ & $120.23(7)$ & $112.69(6)$ & 14.92 \\
\hline
\end{tabular}

Rank 1 = greatest net amplitude. 
TABLE 205. ACCELERATION AND RETARDATION RANKS FOR 33 STATES 1904 TO 1953"

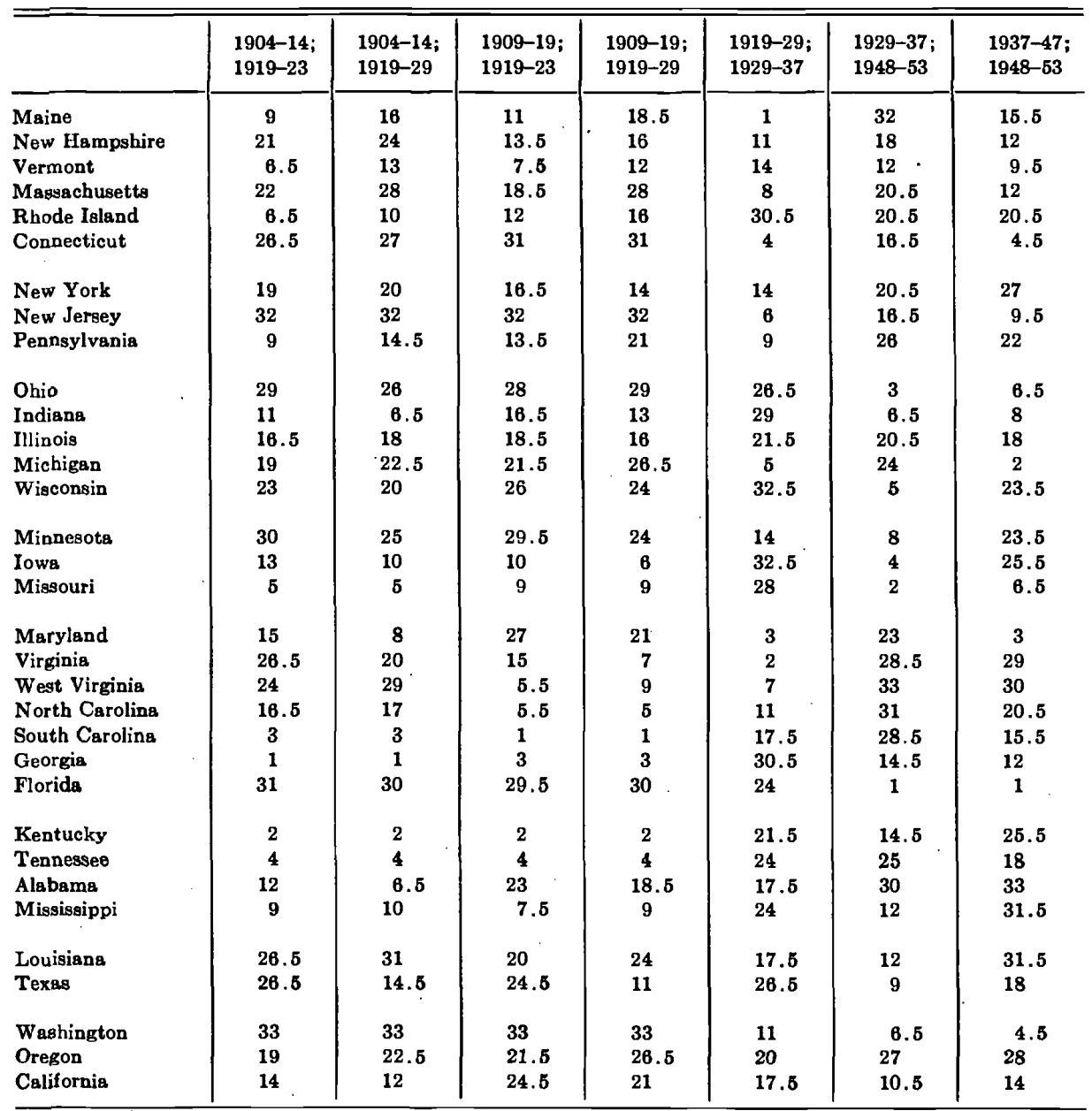

${ }^{a}$ Acceleration and Retardation indicate changes in state growth rankings over relevant time intervals. A state which moves up in growth ranking is said to accelerate from the earlier to the later period. It would receive a top rank number (1-16). A state which moves down in the growth ranking is said to retard. It receives a low rank number (17-33). The acceleration and retardation rank numbers are assigned on the basis of the number of growth ranks gained or lost. 

PRODUCTION WORKER EMPLOYMENT$1919^{\circ}$ IN 33 STATES

\begin{tabular}{|c|c|c|c|c|c|c|c|c|c|c|c|}
\hline & Maine & N. H. & Vt. & Mass. & R: I. & Conn. & N. Y. & N. J. & Penn. & Obio & Ind. \\
\hline Food & 6.48 & 0.82 & 8.13 & 4.85 & 1.53 & 1.66 & 8.08 & 4.49 & 5.06 & 5.23 & 8.84 \\
\hline Tobacco & 0.19 & 1.39 & - & 0.46 & 0.13 & 0.50 & 1.98 & 2.24 & 3.09 & 1.70 & 1.85 \\
\hline Textiles & 28.04 & 46.92 & 19.45 & 34.90 & 58.21 & 18.32 & 11.57 & 20.83 & 16.71 & 2.13 & 3.04 \\
\hline Apparel & 1.14 & 0.63 & 3.96 & 3.36 & 0.81 & 5.20 & 21.42 & 5.55 & 4.31 & 3.40 & 2.48 \\
\hline Lumber & 15.63 & 9.85 & 16.32 & 1.61 & 0.77 & 0.69 & 2.10 & 1.06 & 2.31 & 1.94 & 4.68 \\
\hline Furniture & 0.34 & 0.82 & 4.10 & 1.10 & 0.12 & 0.23 & 2.39 & 0.59 & 1.23 & 1.48 & 6.00 \\
\hline Paper & 15.78 & 6.86 & 7.06 & 3.91 & 0.70 & 1.84 & 4.20 & 1.65 & 1.86 & 2.21 & 1.92 \\
\hline Printing & 1.79 & 1.04 & 2.24 & 2.76 & 1.17 & 1.16 & 6.25 & 1.18 & 2.60 & 2.98 & 2.91 \\
\hline Chemicals & 0.41 & 0.24 & 0.50 & 1.91 & 0.84 & .5 .48 & 4.79 & 7.78 & 2.43 & 2.69 & 2.44 \\
\hline Petroleum & - & - & - & 0.14 & 0.30 & - & 0.44 & 2.75 & 2.33 & 1.23 & 1.15 \\
\hline Rubber & 1.30 & - & - & 3.89 & 5.00 & 4.54 & 0.65 & 3.89 & 0.60 & 9.88 & 1.79 \\
\hline Leather & 12.49 & 21.38 & 0.85 & 16.88 & 0.28 & 0.53 & 5.50 & 2.26 & 3.01 & 2.71 & 0.99 \\
\hline Stone, clay, glass & 2.07 & 1.24 & 21.67 & 0.93 & 0.39 & - & 1.68 & 3.90 & 6.36 & 6.58 & 8.37 \\
\hline Primary metals & 0.63 & - & - & 1.78 & 1.67 & 2.64 & 2.75 & 5.72 & 20.88 & 14.88 & 11.44 \\
\hline Fabricated metals & 0.64 & 0.51 & 1.69 & 4.88 & 2.18 & 30.12 & 6.84 & 5.58 & 5.46 & 10.35 & 4.87 \\
\hline Non-Electric machinery & 4.72 & 4.80 & 14.03 & 8.52 & 11.82 & 13.95 & 7.78 & 10.31 & 9.46 & 15.73 & 14.90 \\
\hline Electrical machinery & - & 0.56 & - & 3.73 & 1.15 & 5.58 & 3.49 & 5.76 & 2.43 & 4.12 & 5.22 \\
\hline Transport Equipment & 8.33 & 2.87 & - & 2.86 & 3.10 & 3.37 & 6.82 & 13.42 & 9.87 & 10.66 & 10.09 \\
\hline Jewelry & - & - & $\cdot-$ & 1.52 & 9.83 & 4.21 & 1.29 & 1.02 & - & 0.10 & - \\
\hline
\end{tabular}

\begin{tabular}{|c|c|c|c|c|c|c|c|c|c|c|c|}
\hline & Ill. & Mich. & Wisc: & Minn. & Iowa & Mo. & Md. & Va. & W. V 8 . & N. C. & S. C. \\
\hline Food & 17.82 & 4.62 & 9.33 & 23.02 & 33.43 & 16.01 & 14.38 & 9.34 & 3.70 & 1.49 & 3.10 \\
\hline Tobacco & 0.63 & 1.41 & 0.83 & 1.00 & 2.16 & 2.16 & 2.17 & 10.01 & 1.68 & 9.48 & - \\
\hline Textiles & 2.30 & 1.64 & 5.62 & 6.74 & 2.09 & 3.28 & 6.57 & 11.00 & $1.6 ̧ 5$ & 54.14 & 66.43 \\
\hline Appare & 9.99 & 1.25 & 2.44 & 2.90 & 2.00 & 8.87 & 16.09 & 2.71 & 1.31 & 0.26 & 0.28 \\
\hline Lumber & 2.47 & 5.43 & 12.93 & 18.39 & 6. 66 & 6.39 & 4.55 & 23.13 & 20.02 & 17.33 & 16.87 \\
\hline Furniture & 2.84 & 4.42 & 4.76 & 2.31 & 1.88 & 2.18 & 1.61 & 1.55 & 1.21 & 5.37 & $\dot{-}$ \\
\hline Paper & 2.43 & 2.81 & 6.67 & 4.00 & 0.62 & 1.74 & 2.82 & 2.75 & 1.58 & 0.48 & 0.27 \\
\hline Printing & 6.75 & 1.80 & 2.49 & 7.37 & 7.83 & 6.76 & 3.71 & 2.83 & 1.81 & 1.07 & 1.35 \\
\hline Chemicals & 3.04 & 3.85 & 1.25 & 2.81 & 1.88 & 3.73 & 5.60 & 6.63 & 3.32 & 3.55 & 6.80 \\
\hline Petroleum & 1.40 & 0.16 & 0.38 & 0.98 & 0.36 & 1.62 & 1.75 & 1.83 & 4.05 & 0.18 & 0.36 \\
\hline Rubber & 0.17 & 1.14 & 2.42 & 0.21 & 1.39 & 1.02 & 0.10 & - & 0.17 & - & - \\
\hline Leather & 3.19 & 1.28 & 7.68 & 4.34 & 2.22 & 12.67 & 1.70 & 4.49 & 2.55 & 1.12 & - \\
\hline Stone, clay, glass & 2.71 & 1.06 & 1.17 & 3.86 & 8.74 & 6.27 & 3.03 & 4.44 & 26.13 & 1.79 & .1 .08 \\
\hline Primary metals & 6.32 & 1.71 & 2.98 & 1.72 & 2.72 & 2.64 & $5.36^{\prime}$ & 4.39 & 19.84 & 0.12 & - \\
\hline Fabricated metals & 10.07 & 8.27 & 5.93 & 4.65 & 4.38 & 6.36 & 8.55 & 1.21 & 2.00 & 0.22 & 0.14 \\
\hline Non-Electric machinery & 17.07 & 14.20 & 19.76 & 10.51 & 16.00 & 6.75 & 3.86 & 2.37 & 2.72 & 1.78 & 0.75 \\
\hline Electrical machinèry & 5.09 & 0.85 & 2.50 & 1.06 & - & 3.73 & 0.12 & - & - & 0.18 & - \\
\hline Transport equipment & 5.51 & 43.97 & 10.86 & 3.77 & 5.62 & 7.56 & 17.13 & 11.31 & 6.20 & 1.41 & 2.47 \\
\hline Jewelry & 0.19 & 0.03 & $=-$ & 0.17 & - & 0.26 & - & - & - & - & - \\
\hline
\end{tabular}

\begin{tabular}{|c|c|c|c|c|c|c|c|c|c|c|c|}
\hline & Ga. & Fla. & Ky. & Tenn. & Ala. & Mise. & La. & Texas & Wash. & Ore. & Calif. \\
\hline Food & 4.79 & 5.08 & 12.54 & 9.08 & 3.00 & 4.63 & 17.98 & 17.74 & 9.22 & 12.70 & 23.06 \\
\hline Tobacco & 0.25 & 17.87 & 7.20 & 0.31 & - & - & 2.45 & 1.29 & 0.12 & 0.17 & 0.83 \\
\hline Textiles & 39.51 & 0.33 & 5.59 & 22.58 & 22.15 & 5.26 & 2.57 & 3.93 & 0.64 & 2.85 & 1.78 \\
\hline Apparel & 1.66 & - & 5.80 & 2.42 & 0.43 & - & 1.43 & 2.00 & 0.74 & 0.90 & 3.64 \\
\hline Lumber & 21.39 & 52.21 & 21.53 & 21.38 & 32.48 & 76.59 & 54.42 & 24.81 & 45.24 & 46.14 & 12.46 \\
\hline Furniture & 1.59 & 0.16 & 3.00 & 5.10 & - & - & 0.97 & 1.27 & 0.81 & 1.68 & 1.72 \\
\hline Paper & 1.36 & - & 1.50 & 1.29 & - & 0.39 & 1.06 & 0.46 & 1.56 & 1.86 & 1.02 \\
\hline Printing & 2.53 & 1.70 & 5.18 & 3.66 & 1.31 & 1.14 & 1.70 & 6.27 & 1.92 & 2.81 & 4.89 \\
\hline Chemicals & 9.61 & 2.91 & 2.35 & 7.43 & 4.38 & 5.53 & 2.91 & 7.28 & 0.42 & 1.17 & 3.22 \\
\hline Petroleum & 0.35 & 0.31 & 3.93 & 1.06 & 3.85 & - & 3.20 & 9.40 & 0.61 & 0.18 & 2.78 \\
\hline Rubber & 0.14 & - & 0.12 & - & - & - & - & - & 0.20 & 0.23 & 0.53 \\
\hline Leather & 1.07 & - & 3.64 & 1.95 & 0.10 & - & 0.49 & 1.32 & 0.30 & 0.86 & 1.36 \\
\hline Stone, clay, glass & 3.33 & 1.61 & 5.85 & 4.07 & 2.20 & 0.90 & 0.91 & 4.28 & 1.30 & 0.63 & 2.73 \\
\hline Primary metals & 0.65 & - & 4.64 & 3.97 & 20.33 & - & - & 1.96 & 2.55 & 1.36 & 2.61 \\
\hline Fabricated metals & 0.63 & 0.14 & 3.09 & 2.65 & 0.58 & 0.16 & 0.60 & 1.02 & 1.13 & 2.71 & 2.93 \\
\hline Non-Electric machinery & 4.37 & 1.33 & 7.18 & 7.08 & 3.02 & 0.88 & 2.49 & 4.29 & 3.53 & 7.28 & 7.23 \\
\hline Electrical machinery & - & - & 0.50 & - & - & - & - & - & 0.15 & - & 0.89 \\
\hline Transport equipment: & 6.78 & 16.24 & 6.31 & 5.96 & 6.17 & 4.52 & B. 81 & 12.58 & 29.38 & 16.35 & 25.89 \\
\hline Jewelry & - & - & - & - & - & - & - & 0.11 & 0.17 & - & 0.32 \\
\hline
\end{tabular}


TABLE 207. INDUSTRIAL COMPOSITION OF MANUFACTURING PRODUCTION WORKER EMPLOYMENT IN 33 STATES-1939

\begin{tabular}{l|r|r|r|r|r|r|r|r|r|r|r}
\hline \hline & Maine & N. H. & Vt. & Mass. & R. I. & Conn. & N. Y. & N. J. & Penn. & Ohio & Ind. \\
\hline Food & 7.58 & 2.01 & 5.78 & 6.52 & 2.77 & 2.54 & 9.50 & 6.98 & 7.27 & 7.18 & 10.07 \\
Tobacco & - & 0.93 & - & 0.07 & - & 0.24 & 0.28 & 2.51 & 1.99 & 0.60 & 0.49 \\
Textiles & 30.37 & 28.68 & 23.94 & 28.29 & 57.84 & 17.31 & 8.74 & 13.83 & 17.09 & 1.56 & 3.25 \\
Apparel & 1.49 & 0.93 & 3.36 & 8.51 & 2.42 & 9.27 & 28.68 & 15.90 & 11.31 & 4.39 & 6.41 \\
Lumber & 0.49 & 7.84 & 17.43 & 1.15 & 0.38 & 0.45 & 1.17 & 0.89 & 0.99 & 1.07 & 2.43 \\
Furniture & 0.56 & 1.70 & 6.49 & 1.83 & 0.31 & 0.59 & 2.36 & 1.00 & 1.50 & 2.00 & 5.32 \\
Paper & 15.98 & 8.04 & 6.91 & 5.27 & 1.17 & 2.23 & 4.65 & 2.95 & 2.63 & 3.31 & 2.09 \\
Printing & 1.40 & 2.29 & 3.32 & 4.37 & 1.68 & 2.67 & 7.39 & 2.81 & 3.50 & 4.37 & 2.79 \\
Chemicals & 0.38 & 0.41 & 0.49 & 1.78 & 0.61 & 1.54 & 3.68 & 8.60 & 2.70 & 2.74 & 2.44 \\
Petroleum & - & - & - & 0.47 & - & 0.14 & 0.49 & 2.17 & 1.87 & 1.07 & 3.23 \\
Rubber & 0.11 & - & - & 3.30 & 3.79 & 3.78 & 0.73 & 2.51 & 0.56 & 6.41 & 2.44 \\
Leather & 22.84 & 38.68 & 3.13 & 15.19 & 0.41 & 1.26 & 6.14 & 2.52 & 3.37 & 3.18 & 0.96 \\
Stone, clay, glass & 0.93 & 1.52 & 10.57 & 1.09 & 0.55 & 1.23 & 2.41 & 4.39 & 5.15 & 6.98 & 5.14 \\
Primary metals & 0.20 & 0.41 & 2.01 & 2.57 & 2.47 & 11.08 & 4.65 & 6.49 & 21.40 & 18.92 & 19.27 \\
Fabricated metals & 1.28 & 1.71 & 1.71 & 4.54 & 4.62 & 14.64 & 5.18 & 5.67 & 5.93 & 10.45 & 6.25 \\
Non-Electric machinety & 3.86 & 4.37 & 14.86 & 7.62 & 6.77 & 16.49 & 5.40 & 5.78 & 5.44 & 14.70 & 8.86 \\
Electrical machinery & - & 0.47 & - & 4.39 & 2.50 & 6.48 & 3.43 & 8.35 & 3.55 & 5.15 & 6.80 \\
Transport equipment & 3.54 & - & - & 2.28 & 0.24 & 4.18 & 3.88 & 6.05 & 3.75 & 5.91 & 11.28 \\
Jewelry & - & - & - & 0.73 & 11.46 & 3.88 & 1.24 & 0.61 & - & - & 0.27 \\
\hline
\end{tabular}

\begin{tabular}{|c|c|c|c|c|c|c|c|c|c|c|c|}
\hline & III. & Mich. & Wisc. & Minn. & Iowa & Mo. ' & Md. & Va. & W. Vs. & N. C. & S. C. \\
\hline Food & 14.82 & 5.53 & 13.89 & 34.77 & 41.23 & 15.93 & 14.64 & 7.61 & 4.39 & 2.34 & 2.59 \\
\hline Tobacco & 0.15 & 0.36 & - & - & - & 1.09 & 0.13 & 7.58 & 1.20 & 6.25 & - \\
\hline Textiles & 2.02 & 1.13 & 5.08 & 4.24 & 1.67 & 1.35 & 4.38 & 29.73 & 4.49 & 67.44 & 76.27 \\
\hline Apparel & 9.18 & 1.48 & 2.64 & 6.42 & 4.59 & 15.99 & 17.29 & 7.54 & 2.76 & 2.41 & 2.28 \\
\hline Lumber & 1.84 & 1.89 & 6.67 & 5.32 & 6.72 & 3.02 & 2.10 & 11.32 & 8.22 & 7.27 & 10.51 \\
\hline Furniture & 3.65 & 2.76 & 3.47 & 2.37 & 2.08 & 2.00 & 1.44 & 6.63 & 0.35 & 6.84 & 1.35 \\
\hline Paper & 3.02 & 3.71 & 9.11 & 6.20 & 1.17 & 2.95 & 2.58 & 4.84 & 1.84 & 1.23 & 1.96 \\
\hline Printing & 8.25 & 2.14 & 3.78 & 10.12 & 6.65 & 5.99 & 3.86 & 2.11 & 1.77 & 0.85 & 0.67 \\
\hline Chemicals & 3.05 & 2.56 & 1.15 & 1.90 & 2.13 & 3.58 & 8.81 & 4.27 & 11.93 & 2.32 & 2.06 \\
\hline Petroleum & 1.51 & 0.42 & 0.34 & 0.85 & - & 0.71 & 1.08 & 0.19 & 1.77 & - & - \\
\hline Rubber & 0.64 & 1.54 & 1.69 & 0.36 & 0.60 & 0.68 & 1.32 & 0.37 & - & - & - \\
\hline Leather & 4.59 & 0.87 & 8.53 & 1.55 & 0.85 & 18.44 & 2.44 & 3.71 & 2.15 & 0.39 & - \\
\hline Stone, clay, glass & 3.12 & 1.71 & 1.15 & 4.48 & 5.03 & 4.66 & 3.23 & 2.67 & 25.04 & 1.18 & 1.50 \\
\hline Primary metals & 10.18 & 7.05 & 5.48 & 3.48 & 2.18 & 4.46 & 14.63 & 1.53 & 21.99 & 0.49 & 0.15 \\
\hline Fabricated metals & 9.78 & 7.45 & 8.29 & 4.95 & 4.95 & 6.15 & 6.84 & 1.79 & 8.87 & 0.24 & - \\
\hline Non-Electric machinery & 14.38 & 8.63 & 17.38 & 10.02 & 17.99 & 3.42 & 2.47 & 0.59 & 1.58 & 0.51 & 0.49 \\
\hline Electric machinery & 6.98 & 1.08 & 3.30 & 1.15 & 1.41 & 4.55 & 1.46 & - & 0.76 & - & - \\
\hline Transport equipment & 2.57 & 49.66 & 8.07 & 1.83 & 0.75 & 5.03 & 10.99 & 7.49 & 0.88 & 0.25 & 0.15 \\
\hline Jewelty & 0.28 & - & - & - & - & - & 0.20 & - & - & - & - \\
\hline
\end{tabular}

\begin{tabular}{|c|c|c|c|c|c|c|c|c|c|c|c|}
\hline & Ga. & Fla. & Ky. & Tenn. & Als. & Miss. & La. & Tex. & Wash. & Ore. & Calif. \\
\hline Food & 7.50 & 19.23 & 15.43 & 8.34 & 4.10 & 9.62 & 27.05 & 20.36 & 16.99 & 17.50 & 26.84 \\
\hline Tobacco & - & 19.29 & 7.46 & 0.89 & - & - & 1.73 & - & - & - & - \\
\hline Textiles & 51.47 & 0.57 & 5.76 & 26.05 & 34.62 & 10.76 & 3.60 & 5.73 & 0.56 & 3.14 & 1.74 \\
\hline Apparel & 11.25 & 1.51 & 11.29 & 11.00 & 3.15 & 15.15 & 6.01 & 8.24 & 2.45 & 2.71 & 8.50 \\
\hline Lumber & 10.08 & 35.35 & 9.43 & 9.64 & 18.11 & 45.93 & 28.48 & 16.09 & 46.60 & 55.68 & 9.17 \\
\hline Furniture & 2.01 & 1.68 & 6.37 & 3.57 & 0.37 & 0.43 & 1.95 & 2.16 & 2.18 & 4.45 & 3.73 \\
\hline Paper & 2.08 & 4.92 & 0.73 & 1.93 & 2.71 & 5.64 & 10.49 & 1.26 & 10.02 & 5.39 & 2.07 \\
\hline Printing & 1.73 & 4.35 & 4.58 & 3.01 & 1.15 & 1.35 & 2.59 & 5.33 & 3.45 & 3.05 & 6.09 \\
\hline Chemicals & 4.80 & 5.18 & 1.76 & 11.70 & 3.52 & 7.66 & 5.55 & 5.54 & 1.03 & 0.52 & 3.74 \\
\hline Petroleum & 0.20 & - & 1.47 & - & 1.50 & - & 4.27 & 15.36 & - & - & 3.62 \\
\hline Rubber & - & - & - & 1.63 & 1.08 & - & - & $\rightarrow$ & - & - & 1.85 \\
\hline Leather & 1.54 & - & 3.52 & 4.27 & - & - & - & 0.52 & 0.27 & 0.36 & 0.92 \\
\hline Stone, clay, glass & 2.17 & .2 .74 & 4.61 & 3.86 & 2.72 & 2.05 & 2.33 & 4.13 & 1.87 & 0.94 & 4.21 \\
\hline Primary metals & 1.19 & 0.28 & 9.44 & 5.18 & 21.04 & - & 0.40 & 2.54 & 3.02 & 0.93 & 4.88 \\
\hline Fabricated metals & 1.30 & 1.02 & 8.18 & 6.54 & 3.09 & 0.18 & 2.19 & 3.39 & 2.55 & 2.38 & 7.21 \\
\hline Non-F.lectric machinery & 1.36 & 0.51 & 3.87 & 1.44 & 0.94 & 0.35 & 1.27 & 6.77 & 2.30 & 2.02 & 4.81 \\
\hline Flectric machinery & 0.17 & - & 3.48 & 0.13 & 0.15 & - & - & 0.36 & 0.20 & 0.18 & 1.48 \\
\hline Transport equipment & 0.15 & 3.36 & 2.62 & 0.83 & 1.74 & 0.85 & 2.10 & 2.24 & 6.52 & 0.77 & 8.90 \\
\hline Jewelry & - & - & - & - & - & - & - & - & - & - & 0.23 \\
\hline
\end{tabular}


TABLE 208. INDUSTRIAL COMPOSITION OF MANUFACTURING PRODUCTION WORKER EMPLOYMENT IN 33 STATES-1947"

\begin{tabular}{|c|c|c|c|c|c|c|c|c|c|c|c|}
\hline & Maine & N. H. & Vt. & Mass. & R. I. & Conn. & N. Y. & N. J. & Penn. & Ohio & Ind. \\
\hline Food & 8.21 & 1.82 & 6.01 & 5.56 & 2.44 & 1.75 & 7.36 & 6.21 & 6.54 & 5.02 & 7.72 \\
\hline Tobacco & - & 0.79 & - & - & - & 0.13 & 0.15 & 0.86 & 1.52 & 0.25 & 0.29 \\
\hline Textiles & 26.85 & 28.73 & 16.49 & 21.00 & 45.97 & 11.30 & 5.94 & 9.84 & 10.59 & 1.02 & 1.33 \\
\hline Apparel & 3.72 & 3.02 & 5.13 & 7.44 & 2.02 & 4.78 & 24.44 & 11.39 & 11.02 & 2.83 & 3.33 \\
\hline Lumber & 12.97 & 9.26 & 18.56 & 1.16 & 0.41 & 0.45 & 1.11 & 0.77 & 1.19 & 0.90 & 1.86 \\
\hline Furniture & 0.65 & 1.80 & 5.75 & 1.66 & 0.52 & 0.65 & 2.38 & 1.16 & 1.37 & 2.32 & 4.30 \\
\hline Paper & 16.62 & 7.73 & 8.59 & 5.14 & 1.38 & 2.10 & 4.09 & 3.14 & 2.58 & 2.84 & 1.70 \\
\hline Printing & 1.19 & 2.76 & 2.61 & 4.09 & 1.72 & 2.21 & 6.42 & 2.44 & 3.05 & 3.44 & 2.29 \\
\hline Chetnicals & 0.62 & 0.60 & 0.88 & 2.20 & 0.73 & 1.72 & 3.61 & 10.37 & 2.70 & 2.78 & 3.29 \\
\hline Petroleum & - & - & - & 0.30 & - & 0.09 & 0.47 & 2.31 & 1.95 & 0.95 & 2.94 \\
\hline Rubber. & 0.10 & 0.47 & - & 3.79 & 4.23 & 2.90 & 0.54 & 2.45 & 1.03 & 7.11 & 2.92 \\
\hline Leather & 16.37 & 28.38 & 1.45 & 11.08 & 0.30 & 0.42 & 4.62 & 1.59 & 2.39 & 1.69 & 0.54 \\
\hline Stone, clay, glass & 0.59 & 1.37 & 8.21 & 1.44 & 0.73 & 1.48 & 2.43 & 4.28 & 5.37 & 5.56 & 4.16 \\
\hline Primary metals & 0.39 & 0.90 & 2.11 & 2.94 & 3.58 & 9.63 & 4.88 & 5.73 & 19.30 & 16.33 & 15.91 \\
\hline Fabricated metals & 1.85 & 2.15 & 2.41 & 6.02 & 5.53 & 14.96 & 5.49 & 6.19 & 8.07 & 10.71 & 7.65 \\
\hline Non-Electric machinery & 6.24 & 7.87 & 20.25 & 12.01 & 10.93 & 20.87 & 8.06 & 8.88 & 9.07 & 19.41 & 14.51 \\
\hline Electrical machinery & - & 1.42 & 1.54 & 7.58 & 3.73 & 8.89 & 5.68 & 12.29 & 6.05 & 8.09 & 10.39 \\
\hline Transport equipment & 3.53 & - & - & 2.45 & 0.18 & 6.89 & 5.50 & 5. 98 & 4.48 & 8.13 & 14.21 \\
\hline lnstruments & - & 0.73 & - & 2.53 & 1.20 & 4.67 & 4.56 & 2.37 & 1.33 & 0.65 & 0.44 \\
\hline Jewelry & - & - & - & 1.55 & 14.43 & 4.12 & 2.28 & 1.65 & 0.40 & - & 0.23 \\
\hline
\end{tabular}

\begin{tabular}{|c|c|c|c|c|c|c|c|c|c|c|c|}
\hline & Ill. & Mich. & Wisc. & Minn. & Iowa & Mo. & Md. & Va. & w. Va. & N. C. & s. C. \\
\hline Food & 11.57 & 4.39 & 13.43 & 26.92 & 33.32 & 14.82 & 14.03 & 8.72 & 4.06 & 3.32 & 3.03 \\
\hline Tobacco & - & 0.10 & - & - & - & 0.64 & - & 8.21 & 0.94 & 8.43 & 1.06 \\
\hline Textiles & 1.00 & 0.67 & 3.07 & 3.08 & 0.67 & 0.97 & 2.94 & 16.69 & 3.30 & 57.78 & 68.23 \\
\hline Apparel & 5.72 & 0.99 & 2.60 & 5.69 & 3.64 & 12.73 & 11.55 & 7.50 & 3.37 & 4.51 & 5.77 \\
\hline Lumber & 1.22 & 1.81 & 4.38 & 4.12 & 3.75 & 2.49 & 2.14 & 11.88 & 7.03 & 8.52 & 11.86 \\
\hline Furniture & 2.80 & 2.40 & 3.18 & 2.00 & 1.70 & 2.39 & 1.27 & 6.77 & 0.75 & 7.43 & 1.31 \\
\hline Paper & 2.58 & 2.85 & 7.34 & 5.63 & 1.01 & 2.96 & 2.59 & 5.12 & 1.31 & 1.85 & 2.87 \\
\hline Printing & 6.54 & 1.68 & 3.35 & 8.67 & 5.05 & 5.12 & 3.59 & 1.87 & 1.56 & 0.98 & 0.64 \\
\hline Chemicals & 3.55 & 3.08 & 1.11 & 2.52 & 3.48 & 4.10 & 7.77 & 14.32 & 13.68 & 2.14 & 1.74 \\
\hline Petroleum & 1.48 & 0.35 & 0.27 & 0.90 & - & 0.77 & 1.06 & 0.14 & 1.93 & - & - \\
\hline Rubber & 0.48 & 1.54 & 1.42 & 0.44 & 1.81 & 0.37 & 2.60 & 0.25 & 0.12 & - & - \\
\hline Leather & 2.85 & 0.49 & 5.77 & 1.06 & 0.66 & 14.98 & 1.64 & 2.55 & 1.54 & 0.42 & - \\
\hline Stone, clay, glass & 2.86 & 1.66 & - & 2.37 & 3.73 & 4.95 & 3.25 & 2.20 & 26.68 & 1.45 & 1.74 \\
\hline Primary metals & 9.60 & 10.00 & 6.21 & 4.54 & 2.66 & 4.52 & 14.40 & 1.85 & 18.02 & 0.50 & 0.41 \\
\hline Fabricated metals & 10.69 & 9.66 & 9.31 & 6.71 & 3.92 & 7.27 & 7.97 & 2.53 & 8.77 & 0.65 & 0.19 \\
\hline Non-Electric machinery & 18.73 & 14.69 & 22.26 & 14.21 & 26.18 & 6.02 & 4.41 & 0.76 & 2.45 & 0.95 & 0.64 \\
\hline Electrical machinery & 11.23 & 2.20 & 6.87 & 8.47 & 3.77 & 5.70 & 3.32 & 0.15 & 3.82 & 0.96 & - \\
\hline Transport equipment & 4.12 & 40.88 & 7.80 & 1.99 & 2.22 & 8.63 & 14.94 & 7.79 & 1.58 & 0.31 & 0.50 \\
\hline Instruments & 2.63 & 0.48 & 1.55 & 0.66 & 0.69 & 0.58 & 0.36 & 0.58 & - & - & - \\
\hline Jewelry & 0.35 & 0.08 & - & - & 1.72 & - & 0.16 & - & - & - & - \\
\hline
\end{tabular}


TABLE 208 (Continued)

\begin{tabular}{|c|c|c|c|c|c|c|c|c|c|c|c|}
\hline & Ge. & Fla. & Ky. & Tenn. & Ala. & Miss. & La. & Tex. & Wash. & Ore. & Calif. \\
\hline Food & 8.94 & 22.30 & 17.90 & 8.86 & 4.54 & 8.63 & 20.52 & 17.88 & 17.51 & 15.97 & 18.68 \\
\hline Tobacco & - & 12.92 & 7.69 & 0.94 & - & - & 0.68 & 0.14 & - & - & - \\
\hline Textiles. & 44.14 & 0.15 & 3.08 & 17.85 & 27.09 & 7.47 & 2.04 & 3.23 & 0.42 & 2.89 & 0.92 \\
\hline Apparel & 10.49 & 2.84 & 10.90 & 9.30 & 4.18 & 15.59 & 5.03 & 8.42 & 2.00 & 1.80 & 7.60 \\
\hline Lumber & 14.75 & 23.00 & 9.98 & 9.53 & 19.61 & 40.39 & 24.97 & 12.26 & 32.81 & 52.83 & 6.97 \\
\hline Furniture & 2.30 & 2.83 & 5.77 & 3.82 & 0.75 & 1.96 & 1.11 & 2.14 & 2.36 & 3.53 & 3.20 \\
\hline Paper & 2.78 & 7.75 & 0.59 & 2.18 & 2.82 & 6.39 & 11.24 & 1.61 & 9.36 & 4.43 & 2.03 \\
\hline Printing & 1.73 & 5.54 & 3.97 & 3.25 & 1.15 & 1.37 & 2.06 & 4.32 & 3.12 & 2.64 & 4.77 \\
\hline Chemicals & 4.04 & 6.05 & 3.28 & 11.89 & 3.51 & 6.10 & 8.95 & 7.30 & 1.12 & 0.87 & 3.76 \\
\hline Petroleum & 0.18 & - & 0.93 & 0.26 & 1.35 & 0.14 & 8.25 & 12.39 & 0.11 & 0.21 & 3.39 \\
\hline Rubber & - & - & - & 2.91 & 2.27 & - & - & 0.41 & - & 0.11 & - \\
\hline Leather & 1.03 & 0.22 & 2.94 & 5.25 & - & - & - & 0.61 & 0.29 & 0.32 & 0.98 \\
\hline Stone, clay, glass & 2.81 & 3.71 & 3.52 & 3.98 & 3.06 & 2.65 & 2.68 & 3.88 & 2.38 & 1.14 & 4.69 \\
\hline Primary metals & 1.10 & 0.46 & 6.17 & 7.08 & 18.74 & 0.34 & 0.65 & 4.42 & 6.17 & 2.81 & 5.12 \\
\hline Fabricated metals & 1.36 & 2.80 & 8.87 & B. 82 & 3.38 & 0.58 & 2.80 & 4.58 & 3.17 & 3.62 & 8.95 \\
\hline Non-Electric machinery & 2.39 & 1.69 & 7.37 & 2.44 & 3.28 & 1.21 & 1.44 & 7.65 & 3.45 & 3.33 & 7.88 \\
\hline Electrical machinery & 0.55 & 0.28 & 3.46 & 0.55 & 0.19 & - & - & 0.72 & 0.59 & 0.85 & 2.79 \\
\hline Transport equipment & 1.38 & 7.45 & 2.53 & 2.40 & 4.08 & 7.18 & 7.59 & 7.64 & 15.15 & 2.56 & 16.98 \\
\hline Instruments & - & - & 1.05 & 0.73 & - & - & - & 0.31 & - & - & 1.04 \\
\hline Jewelry & - & - & - & - & - & - & - & 0.09 & - & - & 0.27 \\
\hline
\end{tabular}

Source: U. S. Bureau of Census, Census of Manufactures, 1947.

- Each entry is the per cent of total state manufacturing employment in that particular industry. Totals may not add to 100 because of rounding.

\section{APPENDIX C: SOURCES OF DATA AND STATISTICAL CONSTRUCTS}

The regional and national data on manufacturing employment have been derived from three principal sources: the Census of Manufactures of the Bureau of the Census, the publications of the Bureau of Labor Statistics, and Fabricant's Employment in Manufacturing. ${ }^{1}$ Data are shown in Appendix Table 194.

Average annual production-worker employment in manufacturing was derived from Census sources for the years 1904, 1909, 1914, 1919, 1921, 1923, $1929,1931,1933,1935,1937,1939$ and 1947, in each of which a census of manufactures was taken. For the years 1948 to 1953 , total monthly employment in manufacturing was derived from Bureau of Labor Statistics publications. In these, the monthly data permit a finer pinpointing of peak and trough dates.

The use of 1919 as a peak date requires some explanation. Burns and Mitchell ${ }^{2}$ indicate that economic activity was at a higher level in 1918 and 1920 than in 1919. Nevertheless, the rise between 1914 and 1919 far exceeded either the 1918-1919 contraction or the 1919-1920 expansion. ${ }^{3}$ In addition, the 1920 peak came in January. If one were to use a centered twelve-month moving total to measure employment at the 1920 peak, it would contain five monthly values from 1919.

The employment data from Census sources are annual averages. Therefore, no attempt can be made to identify monthly peak or trough dates for the

'Solomon Fabricant, Employment in Manufacturing, 1899-1999. op. cit.

* Arthur F. Burns and Wesley C. Mitchell. Measurino Business Cycles, op rit. p. 78.

A number of industrial sectors reached peaks in 1918 which were higher than levels reached in January. 1920. Chief among these was construction activity. Employment in the stone, clay, glass and in the lumber industries was lower in 1919 than in 1914. See Appendix Table 196. 
cycles before the second World War, and indeed identification of annual dates is somewhat precarious. The data from the Bureau of Labor Statistics are monthly data. Monthly peak and trough dates are determined by an examination of a twelve-month moving total of employment, used to avoid the need for seasonal adjustment. In one or two instances it was not possible to identify a state peak in 1948, the state moving total declining throughout the year. In those cases, a peak date, corresponding to the peak in the Census region containing the state, was assigned. The states for which a date was assigned are Connecticut, Illinois, and Vermont.

The Cyclical Amplitude. Cyclical severity is determined by the magnitude of the rise and the decline. A modified form of the technique described by Burns and Mitchell was used to measure cyclical severity. In the Burns-Mitchell technique, total cyclical amplitude is defined as follows: ${ }^{4}$

Peak Value minus Initial Trough Value

Cycle Base

$$
+\frac{\text { Peak Value minus Terminal Trough Value }}{\text { Cycle Base }}
$$

In addition, the average annual amplitude is defined as:

$$
\frac{1}{2} \frac{\frac{\text { Peak minus Initial Trough }}{\text { Number of Yrs. of Rise }}+\frac{\text { Peak minus Terminal Trough }}{\text { Number of Yrs. of Decline }}}{\text { Cycle Base }} .
$$

In both instances, the cycle base is an average of all observations over the cycle. A modified form of the average annual amplitude is used in this study.

The modifications of the amplitude measure are made necessary by the characteristics of the available data.

Census data do not permit continuous measurement of employment over the period of the cycle. The two- or five-year gaps in these figures mean that the cycle base must be estimated from the available observations. Accordingly, the cycle base for each of the three following cycles consists of the average of annual average employment at the following dates.
I. $1914 ; 1919 ; 1921$.
II. $1919 ; 1921 ; 1923$.
III. $1929 ; 1931 ; 1933 ; 1935 ; 1937$.

Monthly data are available for the postwar (1948-1953) cycle, with approximately 60 monthly observations to form the cycle base. However, the procedure described above was adhered to in the interests of comparability with earlier cycles. This did not introduce any serious error into the estimate of the

4 In those cases where an inverted cycle chronology is employed, there are two peaks, and but a single trough. The total amplitude measure then is:

(Initial Peak-Trough) + (Terminal Peak-Trough) 
base of the 1948-1953 cycle. The cycle base consists of the average of annual average employment at the following dates:

IV. 1948 peak; 1949 trough; 1951 intermediate peak; 1953 terminal peak. For the 1948-1953 cycle base, the maximum difference between the two procedures amounts to $-4.2 \%$ of the correct cycle base for California. Therefore, substitution of the correct cycle base for the one actually used would lower the computed amplitude by a factor of $\mathbf{0 4 2}$. Calculations made for other states indicate that the error is negative (correct cycle base is underestimated) for growing states and positive for declining states. The small size of the largest errors obtained indicates that the overall amplitude measures, and the relative amplitude standings of the states are hardly affected by the corrections implied in this footnote. Calculations which I have carried out indicate that at most, a state would move up or down in the amplitude rankings by one position.

The possibility that trend differences might bias the measurement of the bases of earlier cycles because of the small number of observations was explored. Cycles II and III provide observations which are symmetric about the mid-time point of the cycle; therefore, the bias is likely to be negligible. Since the observations of cycle I are asymmetric, calculations on the basis of assumed trends were made to ascertain the magnitude of possible bias. While errors are likely, their magnitudes indicate a change in the amplitude rankings of the states by at most, one position. 